\title{
Review Article \\ Recent Trends in Multifunctional Liposomal Nanocarriers for Enhanced Tumor Targeting
}

\author{
Federico Perche ${ }^{1}$ and Vladimir P. Torchilin ${ }^{2}$ \\ ${ }^{1}$ Center for Pharmaceutical Biotechnology and Nanomedicine, Northeastern University, 140 the Fenway, Room 236, \\ 360 Huntington Avenue, Boston, MA 02115, USA \\ ${ }^{2}$ Center for Pharmaceutical Biotechnology and Nanomedicine, Northeastern University, 140 the Fenway, Room 214, \\ 360 Huntington Avenue, Boston, MA 02115, USA \\ Correspondence should be addressed to Vladimir P. Torchilin; v.torchilin@neu.edu
}

Received 25 December 2012; Accepted 6 February 2013

Academic Editor: Tamer Elbayoumi

Copyright ( 2013 F. Perche and V. P. Torchilin. This is an open access article distributed under the Creative Commons Attribution License, which permits unrestricted use, distribution, and reproduction in any medium, provided the original work is properly cited.

Liposomes are delivery systems that have been used to formulate a vast variety of therapeutic and imaging agents for the past several decades. They have significant advantages over their free forms in terms of pharmacokinetics, sensitivity for cancer diagnosis and therapeutic efficacy. The multifactorial nature of cancer and the complex physiology of the tumor microenvironment require the development of multifunctional nanocarriers. Multifunctional liposomal nanocarriers should combine long blood circulation to improve pharmacokinetics of the loaded agent and selective distribution to the tumor lesion relative to healthy tissues, remotecontrolled or tumor stimuli-sensitive extravasation from blood at the tumor's vicinity, internalization motifs to move from tumor bounds and/or tumor intercellular space to the cytoplasm of cancer cells for effective tumor cell killing. This review will focus on current strategies used for cancer detection and therapy using liposomes with special attention to combination therapies.

\section{Introduction}

Liposomes, first described in 1965 [1, 2], are established drug and gene delivery carriers with clinical evidence of efficacy [3-5] and several commercially available approved clinical formulations [6]. Liposomes are lipid vesicles either unilamellar or multilamellar with an aqueous compartment. The structure of liposomes allows for delivery of a cargo loaded in the aqueous compartment or embedded in the lipid bilayer for cancer therapy, noninvasive cancer imaging, or therapy $[7,8]$. As recently reviewed [9], the most important property of liposomal nanocarriers is protection from the degradation and optimization of the pharmacokinetics of the encapsulated drug to improve tumor accumulation and therapeutic efficacy while reducing the adverse effects associated with bolus administration [7, 10, 11]. This paper will focus on the use of liposomal nanocarriers in cancer therapy and diagnosis. Cancer therapy targets the hallmark traits of cancer: deregulated cell growth, evasion from apoptosis, sustained angiogenesis, tissue, invasion and metastasis [12]. Liposomes remain one of the first drug delivery carrier tested for improvement of pharmacokinetics of new anticancer drugs with more than 2000 papers and 200 reviews published in 2011 and many liposomal drugs approved for cancer therapy notably Doxil for doxorubicin (Johnson \& Johnson, New Brunswick, USA), Lipusu for paclitaxel (Luye Pharma Group, Yantai, China), and Marqibo for vincristine (Talon Therapeutics, South San Francisco, USA) [7, 13-15]. The liposomal platform has undergone continuous optimization for improved stability in vivo, high drug and/or imaging agent loading, stimuli-targeted delivery of the cargo at the tumor site for efficient uptake by cancer cells, and intracellular payload release to engineer multifunctional liposomal nanocarriers (Table 1, Figures 1-3) [16]. We will describe the main axes of design of multifunctional liposomal nanocarriers.

\section{Stealth Targeted Liposomes}

2.1. Stealth Liposomes. Effective cancer treatment generally implies drug delivery to cancer cells after systemic administration by taking advantage of the leaky tumor vasculature 
to deposit at the tumor site [17]. Indeed, liposome uptake by tumors relies primarily on the enhanced permeability and retention (EPR) effect [13, 17-19]. EPR is dependent on large endothelial fenestrations in the tumor endothelial vasculature coupled with the incomplete pericyte coverage that permits extravasation of large molecules and liposomes of size below $200 \mathrm{~nm}$ into tumors with an impaired lymphatic drainage that is responsible for their retention $[17,18,20]$. However, after parenteral administration, most liposomes are captured by the mononuclear phagocyte system (MPS) in the liver and spleen [21]. This elimination is due to the recognition by serum proteins (opsonins) and complement components which prime liposomes for macrophage removal from the circulation $[21,22]$. The step, required to increase the probability of extravasation at the tumor site, involves extended stabilization, decreased blood clearance, and capture by the MPS to favor their accumulation in tumors (Figure 2) $[7,8,23]$.

To achieve this, two approaches are currently used in preclinical and clinical liposomal drug carriers [44]. Decrease of membrane fluidity through incorporation of cholesterol to impede lipid extraction by high density lipoproteins in the blood associated with to liposome breakdown (approved formulations DaunoXome, Myocet, Depocyt, Mariqibo, Doxil) $[44,45]$. The second approach is the incorporation of flexible hydrophilic moieties, mainly polyethylene glycol(PEG), since this component is approved for use by the United States Food and Drug Administration and is currently used in several approved formulations (Doxil, SPI-077, S-CDK602) $[7,10,44,46]$, but also polyvinyl pyrrolidones [8] or Poly[N(2-hydroxypropyl)methacrylamide] [47]. The inclusion of flexible hydrophobic inert and biocompatible polyethylene glycol, (PEG) with a lipid anchor in liposome allows the formation of an hydrated steric barrier decreasing liposome interaction with blood-borne component, increasing their blood circulation time, decreasing their spleen and liver capture $[48,49]$, and their resistance to serum degradation [50]. This lack of recognition by the MPS and decreased elimination of PEGylated liposomes led to the term "stealth" liposomes to qualify them [44].

Protection by PEG was shown to be dependent on both the PEG molecular weight and density on the liposome surface with $\sim 5 \%$ by weight, allowing the maximal decrease in protein adsorption and enhanced blood circulation time [51]. Longer blood circulation time, decreased spleen and liver capture, and increased tumor accumulation after intravenous injection have been reported for ${ }^{111}$ In-labeled liposomes containing 6\% PEG compared to 0.9\% PEG [52]. Lee et al. compared the liver and spleen accumulation of ${ }^{99 \mathrm{~m}} \mathrm{Tc}-$ labeled liposomes containing 0, 5, 9.6, or 13.7\% PEG (molar ratio) [53]. While 5 or 9.6\% PEG decreased spleen and liver accumulation compared to unPEGylated liposomes, spleen accumulation increased again with 13.7\% PEG, indicating an upper limit to the effect of PEGylation. When PEG chains of different lengths were appended to the surface of immunoliposomes, as short $(750 \mathrm{Da})$, intermediate $(2000 \mathrm{Da})$, or long PEG (5000 Da), DSPE-PEG2000 was the best compromise for extended blood circulation and target binding in vivo.
PEG750 did not improve blood circulation and PEG5000 decreased ligand binding [54].

Similarly, superior interaction of cell penetrating peptidemodified PEGylated liposomes with cells was evidenced in vitro after coupling of the peptide to PEG1000 over PEG750 or PEG3400 and was correlated with the architecture of ligand presentation [55]. The longer blood residency of PEGylated liposomes associated with their lower elimination by the MPS has been correlated with increased tumor accumulation and efficacy $[19,21,23,56]$. However, liver, spleen, and bone marrow remain the final destinations of empty or drugloaded PEGylated liposomes [23, 56]. Improvement of drug pharmacokinetics and therapeutic efficacy after encapsulation in PEGylated liposomes was well illustrated by Yang et al. [57]. Indeed, PEGylation of paclitaxel-loaded liposomes led to increased plasma and tumor levels of paclitaxel, in parallel decreased liver and spleen paclitaxel levels over Taxol or conventional paclitaxel liposomes and resulted in the best tumor growth inhibition [57].

Interestingly, albumin conjugation to drug-loaded PEGylated liposomes further enhanced their circulation time and resulting therapeutic activity $[58,59]$. Indeed the blood clearance of doxorubicin after intravenous administration in rats decreased from $131 \mathrm{~mL} / \mathrm{h}$ for free doxorubicin to $17.9 \mathrm{~mL} / \mathrm{h}$ for PEGylated liposomal doxorubicin and decreased further to $7 \mathrm{~mL} / \mathrm{h}$ for PEGylated and albumin-conjugated doxorubicinloaded liposomes. Albumin also decreased opsonin binding to PEGylated liposomes and improved the therapeutic activity of doxorubicin-loaded liposomes against sarcoma.

Inclusion of PEG in the liposome is achieved either by mixing a lipid-anchored PEG with the liposome forming lipids prior to liposome formation (preinsertion) or by insertion of PEG-lipid in already formed liposomes (postinsertion). These two approaches are currently used in clinically approved formulations [44]. Postinsertion of DSPE-PEG2000 compared to its preinsertion in irinotecanloaded liposomes revealed higher plasma concentration and slower drug release in rats [60]. Of note, this longer blood circulation time was correlated with better therapeutic efficacy of postinserted DSPE-PEG2000 drug-loaded liposomes. Although the lipid-PEG conjugates can be incorporated in liposomes before their formation (preinsertion) or inserted into preformed liposomes, the former strategy induces presentation of the PEG groups both at the liposomal surface and in reverse orientation at the inner side of the lipid bilayer. This results in decreased drug loading and stealth properties of the liposomes. Indeed, when both strategies of PEGylation were compared, higher blood circulation and higher therapeutic efficacy in vivo of postinsertion over preinsertion modification were demonstrated $[60,61]$.

A new alternative to increase the circulation time of drug-loaded liposomes is the use of superhydrophilic zwitterionic polymers to create a hydrated shell around the liposome [62]. Cao et al. compared the therapeutic activity of two doxorubicin formulations, Doxil where DSPE-PEG2000 imparts blood stability and doxorubicin-loaded liposomes containing the zwitterionic lipid DSPE-poly(carboxybetaine) for the same function. Similar doxorubicin accumulation in tumors after intravenous administration was detected 
TABLE 1: Examples of multifunctional liposomal nanocarriers.

\begin{tabular}{|c|c|c|c|}
\hline Encapsulated agent & Targeting ligand & Development stage & References \\
\hline Doxorubicin & None & Approved (Doxil/Caelyx) & [13] \\
\hline Vincristine & None & Approved (Marqibo) & {$[14]$} \\
\hline Paclitaxel & None & Approved (Lipusu) & {$[15]$} \\
\hline Cytarabine and daunorubicin & None & Phase I (CPX-351) & {$[24]$} \\
\hline Irinotecan and floxuridine & None & Phase I (CPX-1) & {$[25]$} \\
\hline PKN3 siRNA & None & Phase I (Atu-027) & {$[26]$} \\
\hline Irinotecan & None & Phase I (NL CPT-11) & {$[27]$} \\
\hline Doxorubicin & Stomach cancer-specific anti-GAH mAb & Phase I (MCC-465) & {$[28]$} \\
\hline Oxaliplatin & Transferrin & Phase II (MBP-426) & {$[29]$} \\
\hline Liposomal p53 DNA and docetaxel & Anti-Transferrin receptor $\mathrm{scFv}$ & Phase I (SGT53-01) & {$[30]$} \\
\hline Doxorubicin & Thermoresponsive liposomes & Phase III (ThermoDox) & {$[31]$} \\
\hline Doxorubicin & Cancer-specific 2C5 mAb & preclinical & {$[32]$} \\
\hline Doxorubicin & Anti-CD22 mAb & preclinical & {$[33]$} \\
\hline Paclitaxel & Anti-HER2 mAb & preclinical & {$[34]$} \\
\hline Vincristine & mBAFF & preclinical & {$[35]$} \\
\hline Oxaliplatin & Transferrin & preclinical & {$[36]$} \\
\hline Daunorubicin & Transferrin and mannose & preclinical & {$[37]$} \\
\hline Vinorelbine & NSCLC-specific peptide & preclinical & {$[38]$} \\
\hline Doxorubicin & Metastasis-specific peptide & preclinical & {$[39]$} \\
\hline Doxorubicin & MMP-2/9 detachable PEG & preclinical & {$[40]$} \\
\hline Irinotecan & Folic acid & preclinical & {$[41]$} \\
\hline Doxorubicin & Estrone & preclinical & {$[42]$} \\
\hline Etoposide & Chondroitin sulfate & preclinical & {$[43]$} \\
\hline
\end{tabular}

for both formulations, but poly(carboxybetaine) containing liposomes led to an earlier cure of tumor-bearing mice validating this chemistry.

2.1.1. Importance of Charge Neutralization for Passive Targeting. Although neutral non-PEGylated radiolabeled liposomes were shown to accumulate in human tumors [63], PEGylation is required for effective tumor localization. PEGylation protected against aggregation of assemblies made with cationic lipids, enhanced their tumor uptake, and decreased their accumulation in the liver [64]. Campbell et al. compared the biodistribution of negatively charged liposomes $(-20 \mathrm{mV})$ and positively charged liposomes $(+31 \mathrm{mV})$ after intravenous injection to tumor-bearing mice [65]. While liver was the major destination for both formulations with more than $50 \%$ of the injected dose, positively charged liposomes showed lower spleen accumulation and higher lung accumulation. Interestingly, in tumors, positively charged liposomes showed higher association with tumor blood vessels than negatively charged ones. Levchenko et al. proposed the modulation of positively and negatively charged liposomes biodistribution by different opsonins [66]. Moreover, neutral PEGylated liposomes encapsulating doxorubicin showed superior therapeutic activity compared to cationic ones the decreased antitumor efficacy was correlated with reduced blood circulation and tumor accumulation of cationic liposomes [67]. A critical correlation between negative liposome charge and uptake by liver and spleen has been reported [66]; charge shielding by PEG decreased liver uptake and prolonged blood circulation. Finally, Huang and coworkers reported abolishment of liver uptake of cationic liposomes after their neutralization by postinsertion of DSPE-PEG leading to an increased tumor accumulation [68].

2.1.2. Importance of Prior Administration/Accelerated Blood Clearance $(A B C)$. Cancer treatments usually imply repeated administration of the same therapeutic agent to previously treated (predosed) patients. Administration of radiolabeled PEGylated liposomes to animals pretreated with a first dose of PEGylated liposomes revealed a drastic decrease of their blood concentration $4 \mathrm{~h}$ after injection from $50 \%$ of the injected dose for naive animals to $0.6 \%$ of the injected dose for predosed animals [69]. Noteworthy, after the second administration, PEGylated liposomes were cleared from the circulation very rapidly (decrease in half-life from $2.4 \mathrm{~h}$ to $0.1 \mathrm{~h}$ ) and this decreased blood residency was mirrored by increased accumulation in liver and spleen, supporting the accelerated blood clearance of liposomes after their second administration. This phenomenon is termed accelerated blood clearance $(\mathrm{ABC}) . \mathrm{ABC}$ is dependent on the time after initial injection: no $\mathrm{ABC}$ was reported for PEGylated liposomes injected daily or with injection intervals less than 5 days in rats whereas a one week interval induced accelerated blood clearance in the same study [69]. This delay reflects the two phases of ABC $[70,71]$. First, anti-PEG IgM is secreted in the spleen during the effectuation phase $[72,73]$, an organ where both drugloaded PEGylated and non-PEGylated liposomes accumulate 
$[23,74]$. Second, during the effectuation phase, opsonisation of PEGylated liposomes by anti-PEG IgM primes them for elimination by liver macrophages [75]. Tagami et al. recently demonstrated that production of anti-PEG2000-DSPE IgM in mouse after administration of PEGylated lipoplexes was higher with PEGylated liposomes harboring siRNA on their surface over PEGylated liposome-wrapped siRNA lipoplexes [76]. Moreover, the same group reported higher anti-PEG IgM production after parenteral injection of PEGylated DNA lipoplexes prepared with adjuvant $\mathrm{CpG}$ motifs-containing pDNA over PEGylated lipoplexes prepared with pDNA devoid of CpG motifs [77]. This lower anti-PEG IgM production from $\mathrm{CpG}$-free lipoplexes was correlated with lower accelerated blood clearance. Both of these studies suggest an important effect of the liposome cargo in anti-PEG IgM production and the $\mathrm{ABC}$ phenomenon.

Anti-PEG IgM production is not limited to PEGylated liposomes; anti-PEG IgM was also detected in rats injected with PEGylated adenovirus, bovine serum albumin, or ovalbumin [78]. Interestingly, Laverman et al. reported no ABC induction of Doxil when rats were preinjected with Doxil one week before administration, whereas preinjection with empty PEGylated liposomes induced $\mathrm{ABC}$ of Doxil [70]. These data suggest prevention of $\mathrm{ABC}$ by doxorubicin entrapment in liposomes. This has been attributed to a decreased clearance capacity of Doxil-injected rats due to toxicity of doxorubicin for liver macrophages [79]. By contrast, Van Etten et al. reported no decrease in bacterial clearance after Doxil injection [80] suggesting a macrophage-independent mechanism. Kiwada and coworkers reported the induction of anti-PEG IgM production in the spleen after administration of PEGylated liposomes priming them for elimination by liver macrophages and also demonstrated decreased $A B C$ in splenectomized rats which was correlated with lower antiPEG IgM titers [72].

Longer blood circulation of doxorubicin-loaded PEGylated liposomes after a second administration has been observed in mice, dogs, rats, and patients [70, 81-83] and was proposed to be due to toxicity towards splenic B cells [70]. The importance of toxicity in resistance to $A B C$ by Doxil liposomes is supported by the suppression of IgM production after a second administration of oxaliplatinloaded PEGylated liposomes compared to empty PEGylated liposomes [84] and by the evidence of $\mathrm{ABC}$ induction with PEGylated topotecan-loaded liposomes that have a fast drug release rate [85]. Additionally, blood clearance of radiolabeled liposomes was inhibited by a preadministration of Doxil whereas preinjection of free doxorubicin or empty liposomes did not inhibit blood clearance [82] further supporting inhibition of the MPS as the mechanism of decreased blood clearance of drug-loaded liposomes.

However, as pointed out recently by Suzuki et al., there is no report yet of $\mathrm{ABC}$ in patients [86] although PEGylated liposomes such as Doxil have been in clinical use for more than 20 years suggesting caution in interpretation of the preclinical model data [86]. Indeed, Gabizon et al. recently reported decreased blood clearance of Doxil after repeated administration in cancer patients [81]. The high variability of pharmacokinetics of drug-loaded PEGylated liposomes in cancer patients [87] should also be considered as it may render an $\mathrm{ABC}$ phenomenon difficult to detect without a very large cohort. Although complement activation by PEGylated drug-loaded liposomes has been reported both in animal models and in patients (reviewed in [88]), its correlation with accelerated blood clearance is still controversial [89]. Finally, ABC could be decreased after methylation of the anionic charge on the phosphate group of PEG [90] further improving pharmacokinetics of PEGylated liposomes.

2.2. Targeted Stealth Liposomes. As recently reviewed, PEGylation fails to lead to more than $5 \%$ of the administered formulation accumulation in the tumor [23, 91]. Furthermore, although radiolabeled liposomes were shown to accumulate in solid tumors in patients, they also distributed to normal organs, revealing the need for tumor targeting [63]. Moreover, most macromolecules, free drugs, and liposomes without an internalization moiety have an accumulation limited to the periphery of a tumor due to the poor vascular density in tumors and the high tumor interstitial fluid pressure impeding transport of macromolecules [92-94]. In a direct comparison of doxorubicin-loaded PEGylated and non-PEGylated liposomes, PEGylation did not improve doxorubicin accumulation in tumors, with comparable therapeutic efficacy of PEGylated and non-PEGylated doxorubicinloaded liposomes [95]. On the contrary, conjugation of internalizing antibodies with the surface of doxorubicinloaded PEGylated liposomes dramatically improved their therapeutic efficacy $[96,97]$ demonstrating the need for improved internalization of antineoplastic agents for effective therapy [98]. Similarly, while Bartlett et al. reported identical tumor distribution of untargeted and transferrin-targeted siRNA nanoparticles, the latter achieved superior in vivo silencing [99].

To increase liposomal drug accumulation in the cancer cells, liposomes must combine small size and long circulation to reach the tumor (tumor site targeting), a targeting ligand to discriminate between cancer cells and supportive cells (cancer cell targeting), and an internalizing moiety for intracellular delivery (Figure 3, Table 2). For a combination of long blood circulation and targeting, the ligand must be accessible to the target for recognition while the liposomal surface should be coated with PEG for long blood circulation [117] (Figure 1). Thus, in addition to protection from steric hindrance of the liposome surface by the PEG chains, presentation of the ligand at the distal end of PEG allows better ligand recognition [117, 118] and multivalent binding thanks to the flexibility of PEG [119]. Such a combination allowed ultimately superior therapeutic activity compared to PEGylated drug-loaded liposomes without ligand [32$34,118,120,121]$. The rationale of targeting plus PEGylation for antitumor efficacy has been well demonstrated by Yamada et al. using folate-linked PEGylated liposomal doxorubicin [122]. They compared the in vitro cytotoxicity and in vivo antitumor efficacy of untargeted PEGylated doxorubicin-loaded liposomes, non-PEGylated liposomes harboring folate, and PEGylated liposomes with folate exposure at the liposomal surface. While the non-PEGylated folate-modified liposomes 
TABLE 2: Examples of ligands used for targeting of liposomal nanocarriers.

\begin{tabular}{|c|c|c|c|}
\hline Type of ligand & Ligand & Target & Reference(s) \\
\hline \multirow{3}{*}{ Antibody } & Anti-HER2 & HER2 receptor overexpressed by cancer cells & {$[34,98,100]$} \\
\hline & Anti-CD19 & CD19 overexpressed in B cell Lymphoma & [101] \\
\hline & Nucleosome-specific $2 \mathrm{C} 5 \mathrm{mAb}$ & Cancer cells surface-bound nucleosomes & {$[32,102]$} \\
\hline \multirow{2}{*}{ Protein } & Transferrin & Transferrin receptor overexpressed by cancer cells & {$[36,103]$} \\
\hline & Interleukin 13 (IL-13) & IL-13 receptor overexpressed in human gliomas & [104] \\
\hline \multirow{3}{*}{ Peptide } & Octreotide & Somatostatin receptor type 2 overexpressed by cancer cells & {$[105,106]$} \\
\hline & LHRH-derived peptide & LHRH receptors overabundant on cancer cells & {$[107]$} \\
\hline & Arg-Gly-Asp (RGD) & $\alpha \mathrm{V} \beta 3$ overexpressed by endothelial tumor cells & {$[108-110]$} \\
\hline \multirow{3}{*}{ Small molecule } & Folate & Folate receptor on cancer cells & {$[41,111]$} \\
\hline & Estrone & Estrogen receptors overexpressed in ovarian and breast cancers & {$[42,112]$} \\
\hline & Anisamide & Sigma receptors overexpressed by cancer cells & [113] \\
\hline \multirow{2}{*}{ Sugar } & Mannose & Dendritic cells and macrophages to induce an immune response & {$[114,115]$} \\
\hline & Lactose & Asialoglycoprotein receptors overexpressed by hepatocellular carcinomas & [116] \\
\hline
\end{tabular}

HER2: human epidermal growth factor receptor 2, mAb: monoclonal antibody, LHRH: luteinizing hormone releasing hormone.

showed the highest toxicity in vitro, the highest antitumor efficacy was reported with PEGylated, folate-modified doxorubicin-loaded liposomes. The need for targeted drug delivery for the best antitumor efficacy is not limited to liposomes. Indeed, when Saad et al. compared the therapeutic efficacy of targeted or untargeted paclitaxel delivery using a linear polymer, dendrimer or PEGylated liposomes, the best tumor accumulation and tumor suppression were obtained with targeted delivery systems over untargeted ones and free paclitaxel for the three types of carriers [107]. In agreement with this study, addition of a targeting moiety to PEGylated liposomes containing the near infrared probe NIR-797 or ${ }^{111}$ In improved tumor accumulation of the imaging agent, suggesting the benefit of targeting stealth liposomes for cancer therapy and monitoring [123]. Several ligands, including antibodies and peptides directed against molecular markers of tumor cells or their supportive endothelial cells present in the tumor microenvironment, have been employed for targeted drug delivery [124] (Table 2).

2.2.1. Antibody-Targeted PEGylated Liposomes. Targeted liposomes are obtained either by incorporation of ligand-lipid conjugates during liposome preparation, incorporation of lipids with reactive groups during liposome preparation and subsequent ligand coupling, and finally by insertion of ligand-lipid conjugates into preformed liposomes (postinsertion) $[125,126]$. For a comparison of techniques available for antibody conjugation to liposomes we refer the reader to recent reviews $[97,127]$.

Coupling of the humanized anti-CD22 antibody targeting the lymphocyte marker CD22 to PEGylated doxorubicinloaded liposomes increased doxorubicin accumulation in Non-Hodgkin's Lymphoma xenografts and increased survival over untargeted doxorubicin-loaded liposomes [33]. The p185HER2 (human epidermal growth factor receptor 2) receptor is upregulated in human cancers of several histology (breast, ovarian, and prostate) with a low basal expression in normal tissues allows cancer-specific delivery with HER2 monoclonal antibody conjugation [128, 129]. Conjugation of a single-chain fragment antibody against HER2 to doxorubicin-loaded liposomes led to higher doxorubicin accumulation in breast cancer xenografts and better tumor control than untargeted PEGylated doxorubicin-loaded liposomes [100]. Conjugation of the recombinant humanized anti-HER2 antibody Herceptin (Genentech, San Francisco, CA, USA) to paclitaxel-loaded PEGylated liposomes also increased drug accumulation in tumors and therapeutic efficacy over untargeted paclitaxel-loaded liposomes [34]. The potentiation of paclitaxel-loaded liposomes by HER2 antibody was due to enhanced drug uptake by receptormediated endocytosis since a similar tissue distribution and antitumor activity were reported against breast xenografts expressing low levels of HER2. Indeed, in a seminal study, Kirpotin et al. demonstrated that although HER2 antibodytargeted liposomes and untargeted liposomes had similar accumulation profiles in tumors after intravenous injection, they showed, by flow cytometry and histological analysis of disaggregated tumors, a 5.9-fold higher cancer cell accumulation of immunoliposomes versus untargeted liposomes [98]. Antinuclear autoantibodies are present in both healthy elderly individuals and cancer patients [32]. One of these antibodies, 2C5 monoclonal antibody recognizing cell surfacebound nucleosomes specifically recognizes multiple tumor cell lines [32]. Liposomes conjugated with 2C5 antibody at the distal end of PEG3400-DSPE were preferentially accumulated in tumors $[32,130]$ and increased the therapeutic activity of doxorubicin-loaded (Doxil) liposomes [102]. Tumor targeting of doxorubicin-loaded liposomes with the Fab' fragment of an anti-MT1-MMP (membrane type 1 matrix metalloproteinase, expressed by cancer cells and endothelial cells) led to increased liposome uptake in vitro and higher therapeutic activity in vivo [120]. It is noteworthy that, although the tumor accumulation of targeted and untargeted 
liposomes was similar, the MT1-MMP-targeted doxorubicinloaded liposomes showed superior tumor protection thanks to enhanced uptake of the drug by tumor cells, in agreement with the results of Kirpotin et al. with anti-HER2 targeted liposomes [98].

The conjugation of whole antibodies to the liposome surface can induce complement activation and decrease their blood circulation since the Fc fraction of immunoglobulins is recognized by macrophages $[45,131]$. Thus conjugation of Fab' fragments instead of the whole antibody was proposed. While doxorubicin-loaded PEGylated immunoliposomes harboring Fab' fragments of an anti-CD19 antibody had similar blood circulation and MPS accumulation than untargeted liposomes, immunoliposomes harboring the anti-CD19 IgG showed faster blood clearance and a threefold accumulation in liver and spleen over untargeted or Fab' liposomes [101]. Fab' immunoliposomes also resulted in superior therapeutic efficacy over untargeted or anti-CD19 antibody-decorated immunoliposomes [101]. Analogous with their results, the blood circulation of $\mathrm{pH}$-sensitive 1-D-arabinofuranosylcytosine-loaded liposomes harboring Fab' fragments against CD33 was superior to those decorated with the whole monoclonal antibody [121].

2.2.2. Protein-Targeted Liposomes. Qi et al. described a novel antineoplastic liposomal agent, liposomal saposin C [132]. Development of this agent is based on the observation that patients suffering from lysosomal storage diseases frequently have saposin $\mathrm{C}$ deficiencies leading to accumulation of toxic glycosylceramide sphingolipids [133] and that saposin $\mathrm{C}$ inserts into negatively charged membranes at acidic $\mathrm{pH}$ [134]. They prepared a saposin C-DOPS conjugate which assembled as $190 \mathrm{~nm}$ liposomes under sonication at acidic $\mathrm{pH}$. Tumor targeting is based on activation of membrane fusion domains of saposin $\mathrm{C}$ at the acidic $\mathrm{pH}$ in tumors leading to its internalization and glycosylceramideinduced apoptosis. Intravenous injection into neuroblastoma xenograft- bearing mice led to apoptosis induction in tumors and tumor growth inhibition without systemic toxicity. BAFF (B cell activating factor) is a cytokine whose receptor is overexpressed in $\mathrm{B}$-cell lymphomas, conjugation of a BAFF mutant to vincristine-loaded PEGylated liposomes increased the survival of lymphoma-bearing mice over untargeted vincristine-loaded liposomes or free drug [35]. Cancer cells overexpress transferrin receptors [135] making the glycoprotein, transferrin or antibodies to transferrin receptor, suitable ligands for tumor targeting [136]. Addition of transferrin to the surface of PEGylated oxaliplatinloaded liposomes increased tumor accumulation over free oxaliplatin or untargeted liposomes leading to the highest tumor growth inhibition against C26 colon carcinomabearing mice [36]. In parallel to these studies, conjugation of transferrin to doxorubicin-loaded liposomes resulted in higher doxorubicin delivery to tumors and tumor growth inhibition over untargeted doxorubicin-loaded liposomes [103].
2.2.3. Peptide-Targeted Liposomes. More and more tumorspecific ligands are being identified by combinatorial screening of bacteriophage-borne peptide libraries, phage display biopanning. This is a strategy whereby the recombinant virions able to bind cancer cells in vitro or tumors in vivo are purified before identification of the peptide and its use for targeted drug delivery, allowing identification of peptides specific for cancer cells, tumor vasculature or both (reviewed in [137]).

We previously described the selective exposure of nucleohistones by cancer cells effective cancer therapy of antinuclear-targeted doxorubicin-loaded liposomes [32]. In good agreement with these studies, Wang et al. reported tumor targeting of doxorubicin-loaded liposomes harboring the histone H1-specific peptide ApoPep-1 [138]. This peptide is selectively presented at the surface of tumor cells due to spontaneous apoptosis in avascular tumors. ApoPep-1 conjugation to doxorubicin-loaded liposomes led to superior doxorubicin distribution in lung xenografts and better tumor growth inhibition over untargeted liposomes. Somatostatin receptors, particularly somatostatin receptor type 2 , are overexpressed by cancer cells and endothelial cells of the tumor vasculature [139]. Coupling of the somatostatin receptor type 2 agonist to irinotecan-loaded liposomes improved their antitumor activity in a medullary thyroid carcinoma model [105]. Its coupling to PEGylated doxorubicin-loaded liposomes led to superior doxorubicin accumulation in tumors and enhanced anticancer efficacy against small cell lung cancer tumors compared to untargeted liposomes [106].

Han and coworkers selected a peptide (HVGGSSV) by phage display which selectively bound to the tumor vasculature of tumors that were regressing after radiotherapy, while no binding was detected before irradiation or in areas of tumor necrosis factor alpha-induced inflammation in mice [140]. They proposed the peptide that recognized a protein displayed only on tumor endothelial cells that were responding to therapy. Interestingly, they conjugated this peptide to the surface of doxorubicin-loaded liposomes for "radiation-guided tumor-targeted drug delivery" [141]. Higher tumor accumulation of doxorubicin was achieved with targeted liposomes after irradiation over untargeted doxorubicin-loaded liposomes with or without irradiation and resulted in higher therapeutic efficacy in both Lewis lung carcinoma and non-small cell lung carcinoma (HL460) tumors. Identification of a non-small cell lung cancer-specific peptide also identified by phage display to doxorubicin or vinorelbine-loaded PEGylated liposomes enhanced drug distribution to tumors and resulted in increased therapeutic efficacy over untargeted drug-loaded liposomes [38]. Another group reported higher therapeutic efficacy against lung cancer xenografts of PEGylated doxorubicin-loaded liposomes conjugated with a large-cell cancer-specific peptide over untargeted doxorubicin-loaded liposomes [142].

Breast cancer-specific peptide/phage fusion coat protein pVIII chimeras have been used for tumor-targeted drug delivery [143, 144]. Membranophilic major phage coat protein pVIII fused with a targeting peptide identified by phage display spontaneously inserts into liposomes. The insertion of a 
breast cancer-specific phage fusion protein into doxorubicinloaded liposomes (Doxil) led to an increased binding to breast tumor cells and enhanced cytotoxicity over untargeted Doxil liposomes in vitro $[143,144]$. This is noteworthy, since no chemical conjugation step is involved, this method allows fast and selective identification of tumor ligands.

PEGylated paclitaxel-loaded liposomes harboring a synthetic luteinizing hormone-releasing hormone (LHRH) peptide designed to interact with the LHRH receptors that are overabundant in the membrane of cancer cells [145] showed increased tumor accumulation and therapeutic efficacy over untargeted paclitaxel-loaded liposomes [107]. Matrix metalloproteinases (MMPs) are overabundant in tumor tissues where they act in angiogenesis, matrix degradation, and metastasis [146]. Moreover, MMP- $2 / \alpha_{V} \beta_{3}$ integrin complexes and MMP-9 are present at the surface of angiogenic blood vessels and cancer cells, respectively and their targeting by inhibitory peptides showed antitumor effects $[147,148]$. MMP-targeting of Caelyx doxorubicin-loaded liposomes by insertion of a DSPE-PEG3400-CTT2 conjugate, the CTT2 peptide binding to MMP 2 and 9, led to increased doxorubicin accumulation in tumors and extended the survival of ovarian carcinoma xenograft-bearing mice over unmodified Caelyx liposomes [40].

\subsubsection{Small Molecule-Mediated Tumor Targeting. Aberrant} tumor growth is correlated with a greater demand for nutrients relative to healthy organs and has been exploited for tumor targeting. To sustain their rapid growth, tumor cells overexpress folate receptor to capture the folate required for DNA synthesis [149]. The overexpression of folate receptor in cancers of several histology relative to normal tissues, the low cost of folic acid (FA), and the vast library of conjugation reactions available make it one of the most used ligands for tumor-targeted drug delivery and tumor imaging (reviewed in [150]). Inclusion of a FA-PEG-DSPE conjugate into irinotecan-loaded liposomes enhanced drug concentration in tumors after intravenous injection over untargeted liposomes or free irinotecan resulting in the highest anticancer activity without detected side toxicity [41]. Similarly, folate-targeting of doxorubicin-loaded liposomes increased the survival of tumor bearing mice by $50 \%$ over untargeted liposomes [111]. Lee et al. used tetraiodothyroacetic acid, a competitive inhibitor of thyroid hormone binding to the endothelial cell integrin $\alpha_{V} \beta_{3}$, as a new ligand for tumor-targeted drug delivery. This ligand increased liposomal accumulation in tumors after intravenous injection and enhanced anticancer activity of the encapsulated anticancer drug edelfosine [151].

Estrogen receptors are often overexpressed in breast and ovarian cancers and conjugation of the ovarian estrogenic hormone estrone to doxorubicin-loaded liposomes resulted in a dramatic increase in doxorubicin accumulation in breast tumors after intravenous injection over free drug or untargeted PEGylated doxorubicin-loaded liposomes (24.3 and 6.0-fold, resp.) resulting in the highest therapeutic activity $[42,112]$. Similarly, conjugation of a luteinizing hormone-releasing hormone (LHRH) analog to the surface of docetaxel-loaded liposomes increased docetaxel accumulation in ovarian xenografts by 2.86 -fold over untargeted docetaxel-loaded liposomes with decreased liver and spleen capture though binding to the LHRH receptors highly overexpressed in ovarian cancer [152]. The basic fibroblast growth factor (bFGF) receptor is also overexpressed in several cancers [153]. Electrostatic coating of cationic liposomes encapsulating doxorubicin or paclitaxel with a negatively charged bFGF-derived peptide resulted in increased survival of melanoma or prostate tumor-bearing mice over untargeted liposomal formulations, respectively [154]. The use of chondroitin sulfate which binds CD44 overexpressed by tumor cells has recently been introduced [43]. Coupling of chondroitin sulfate to the surface of etoposide-loaded liposomes increased etoposide accumulation in breast cancer xenografts after intravenous injection 40-fold compared to free drug and by 8 -fold compared to untargeted liposomes. Presentation of lactose at the surface of doxorubicin-loaded PEGylated liposomes using a lactose-DOPE conjugate to target the asialoglycoprotein receptors overexpressed in hepatocellular carcinomas increased doxorubicin accumulation in tumors and resulted in tumor growth inhibition over untargeted doxorubicin-loaded liposomes [116].

Tan and coworkers introduced ternary nucleic acid complexes, Liposome Polycation DNA (LPD) where nucleic acids are complexed by protamine before interaction with cationic liposomes to form a core nucleic acid complex surrounded by two lipid bilayers [155]. Sigma receptors are ion channel regulators overexpressed in several cancer types [156] Conjugation of the small molecular weight sigma receptor ligand anisamide, [157] to the distal end of PEG2000-DSPE allowed 70-80\% luciferase silencing in an experimental lung metastasis model [113]. Moreover, parenteral injection of anisamide-armed LPD prepared with a combination of siRNA against the inhibitor of p53, MDM2 (Murine Double Minute 2), against the Cmyc oncogene and the other against the angiogenesis regulator, VEGF (Vascular Endothelial Growth Factor) were localized in tumors and allowed a $70-80 \%$ decrease in tumor load [68]. However, while the common sigma receptor agonist haloperidol and anisamide recognize sigma receptor type 1 and 2, only sigma receptor type 2 overexpression has been reported to be a prognostic indicator [158]. The latter has low expression in healthy tissues, suggesting a higher therapeutic index of sigma receptor 2 targeted therapies [158]. Indeed, binding of the sigma 2 receptor agonist SV119 to its receptor induced cell death in vivo in a pancreatic cancer model, and conjugation of SV119 to the surface of liposomes increased their uptake in vitro in cell lines including lung, breast, and prostate cancer carcinoma whereas no increased uptake in normal cells was reported [158].

\section{Biological Targets}

3.1. Brain Tumor Targeting. Brain tumors are a major concern for both primary brain and brain metastases from primary lung, melanoma, breast, and kidney cancers [159]. Therapy against brain cancers is challenging since the brain is largely 
isolated from the rest of the body by the blood brain barrier (BBB), a dense barrier of endothelial cells, pericytes, astrocytes, and extracellular matrix which limits molecular transport into the brain [160]. Several strategies to overcome this barrier have been proposed for the treatment of brain tumors, either by targeted delivery of drug-loaded liposomes to the brain or by remote-controlled drug release within the brain.

Overexpression of IL-13 receptors has been reported in human gliomas [161], and conjugation of IL-13 to doxorubicin-loaded liposomes allowed a 5-fold reduction in tumor volume and extended survival of intracranial glioma tumor-bearing mice over untargeted doxorubicin-loaded liposomes [104]. In the same vein, the conjugation of IL13 to PEGylated doxorubicin-loaded liposomes for astrocytoma targeting dramatically improved brain delivery of doxorubicin compared to untargeted liposomes and resulted in increased survival of intracranial U87 glioma-bearing mice after intraperitoneal administration [104]. To reinforce brain drug delivery, Du et al. armed PEGylated topotecanloaded liposomes with both wheat germ agglutinin for brain capillary targeting and tamoxifen to decrease drug efflux [162]. These dual-targeted liposomes crossed a model BBB in vitro and increased the survival of brain tumor bearingrats over free topotecan or untargeted topotecan-loaded liposomes [162]. The need for dual-targeting for effective BBB crossing in vivo is also exemplified in a study by Ying et al. [163]. They took advantage of the expression of glucose transporter 1 and transferrin receptor by endothelial cells of the BBB for intracranial glioma therapy using mannose and transferrin dual-targeted daunorubicin-loaded liposomes. Dual-targeting led to superior tumor growth inhibition and increased life span over untargeted or single-targeted daunorubicin-loaded liposomes.

Gong et al. used thermosensitive doxorubicin-loaded PEGylated liposomes capable of releasing $90 \%$ of drug after $30 \mathrm{~min}$ at $42^{\circ} \mathrm{C}$ compared to less than $3 \%$ for unsensitive liposomes [164]. They reported improved doxorubicin delivery to the brain after intravenous injection (3.4-fold over nonsensitive liposomes) and increased survival of C6 glioma-bearing mice when heads of mice were heated in a water bath to $42^{\circ} \mathrm{C}$ after injection [164]. Another physically controlled content release strategy has been described by the group of Yang using focused ultrasounds for reversible disruption of the BBB as evidenced by higher brain accumulation of Evan's blue or gadolinium in ultrasound-treated animals over untreated ones [165]. Administration of brain tumor-targeted doxorubicin-loaded liposomes followed by ultrasound-mediated BBB disruption allowed higher levels of intracranial liposomes and doxorubicin accumulation over untargeted liposomes in an intracranial glioblastoma model [166].

3.2. Vasculature Targeting. The "angiogenic switch," when tumors establish their own blood supply by extensive neoangiogenesis, is critical for the progression of tumors from a dormant avascular nodule to an invasive carcinoma [167, 168]. This dependence on blood supply for tumor growth and the correlation between vascular permeability and accumulation of liposomal drug and therapeutic efficacy [169-171] supports research on liposomal tumor vasculature-targeting for cancer therapy (reviewed in [172]). After intravenous injection in mice, PEGylated liposomes were shown to accumulate in the perivascular space with limited tumor penetration $[94,173,174]$. Moreover, when the tumor accumulation and therapeutic efficacy of PEGylated liposomal oxaliplatin were compared in animals bearing C26 colon carcinoma, Lewis lung carcinoma and B16BL6 melanoma, a correlation among tumor blood vessel permeability, tumor drug accumulation and the resulting therapeutic efficacy have been reported [171]. In vitro results were not predictive of in vivo activity: the least tumor accumulation and tumor growth were detected in B16BL6 tumors, whereas this cell line was the most sensitive to liposomal oxaliplatin in vitro, [171]. Of note, the lower tumor vessel permeability of melanoma xenografts compared to colon or lung carcinoma is clinically relevant. When the microvessel density of biopsies from cancer patients was determined, melanoma was also the least vascularized ( 35 vessels/field) compared to colon $(\sim 70)$ or lung tumors $(\sim 127)$, stressing the point that extravasation of agents from the tumor vasculature is a major barrier for liposomal drug delivery [175].

Targeting of selectin on endothelial cells with P-selectin glycoprotein ligand 1 allowed a 3-fold higher luciferin delivery to B16F10 tumors after intravenous injection over untargeted liposomes [176]. The $\alpha_{V} \beta_{3}$ integrin is overexpressed by endothelial cells in the tumor vasculature [177]. The tripeptide Arg-Gly-Asp (RGD) and the cyclic RGD (ArgGly-Asp-D-Phe-Lys) are $\alpha_{V} \beta_{3}$ ligands used for tumortargeted drug delivery [108]. RGD-targeted paclitaxel or doxorubicin-loaded PEGylated liposomes showed superior therapeutic activity over free drug or untargeted liposomes $[109,110]$. Antitumor activity of RGD-targeted liposomes is consistent with tumor microvessel destruction after injection of RGD-targeted paclitaxel-loaded liposomes reported by another group [178]. Functionalization of doxorubicinloaded liposomes with a peptide targeted to bombesin receptors overexpressed in cancers improved therapeutic efficacy over untargeted liposomes [179]. $\alpha_{5} \beta_{1}$ is another integrin overexpressed in cancer in which the fibronectinderived peptide antagonist ATN-161 showed antineoplastic and antimetastatic properties [180]. Coupling of ATN161 to doxorubicin-loaded PEGylated liposomes increased their therapeutic activity in a melanoma model [181]. Doxorubicin-loaded PEGylated liposomes were functionalized with a NGR peptide at the distal end of PEG to target a CD13 isoform overexpressed in the tumor neovasculature [182-184]. In the study by Pastorino et al., vasculaturetargeted Caelyx showed superior apoptosis induction in tumor xenografts and decreased blood vessel density leading to increased survival of mice bearing lung, ovarian, or neuroblastoma xenografts compared to untargeted Caelyx [182].

To further improve the destruction of blood vessel support of tumors, Takara and coworkers recently developed a dual-ligand approach for antiangiogenic therapy using 
liposomes targeted to CD13 (NGR-PEG2000-DSPE) functionalized with the stearylated cell penetrating peptide tetraarginine at the liposome surface [183]. They first compared endothelial cell association in vivo in tumor-bearing mice after intravenous injection of PEGylated doxorubicin-loaded liposomes measuring either $100 \mathrm{~nm}$ (small liposomes) or $300 \mathrm{~nm}$ (large liposomes). Since a superior association with tumor blood vessels and lower extravasation was observed with large liposomes over small ones, they used the former for ligand conjugation. Dual-ligand labeled liposomes accumulated $\sim 3$-fold more in tumors than unmodified or single ligand-modified liposomes, revealing synergy of the two ligands. Consistent with the tumor accumulation and blood vessel association results, only the dual-ligand doxorubicinloaded liposomes allowed protection against tumor growth and induced tumor blood vessel destruction that revealed a synergy of endothelial cell targeting and enhanced uptake for antiangiogenic therapy.

Cationic liposomes selectively bound to endothelial cells in vivo with superior internalization over anionic or neutral liposomes due to the enrichment of tumor endothelial cell membranes with negatively charged lipids and heparan sulfate proteoglycan $[172,185,186]$. Superior accumulation of oxaliplatin in lung tumors was obtained after intravenous injection of PEG-coated cationic drug-loaded liposomes over neutral liposomes [187]. The same group used cationic liposomes for delivery of siRNA against the neoangiogenesis regulator, Argonaute 2 (Ago2) which resulted in Ago silencing in tumors together with apoptosis of tumor blood vessels and decreased tumor growth while no therapeutic effect was observed with cationic lipoplexes prepared with an irrelevant siRNA $[188,189]$. In support of the effect of the negative charge of angiogenic vessels, paclitaxel-loaded cationic liposomes (EndoTAG-1) induced endothelial cell apoptosis in vivo, retarded melanoma and pancreatic carcinoma tumor growth, and decreased the number of melanoma lung metastases in vivo [190-192]. Recently, targeting of tumor vasculature by an aptamer directed against the tumor vasculature marker E-selectin has been reported [193]. E-selectin aptamer conjugated liposomes accumulated in the tumor vasculature of breast cancer xenografts after intravenous injection, whereas no untargeted liposomes were detected in tumors, supporting use of this selective approach for vasculaturetargeted drug delivery. The vasculature-targeting group used may be relevant only to a particular histology. Indeed, while the p15-RGR peptide which recognizes platelet-derived growth factor receptor $\beta$ expressed by pericytes of the tumor vasculature identified by phage display against pancreatic cancer increased delivery of liposomes to pancreatic tumors in vivo, it did not direct liposomes to tumors in a melanoma model $[194,195]$. In the same study, liposomes harboring $\mathrm{p} 46-$ RGD $\alpha_{V}$-integrin-binding peptide targeting tumor endothelial cells allowed a significant tumor accumulation over controls with higher therapeutic efficacy [195]. Chang et al. also used phage display to identify neovasculature peptides which when conjugated to doxorubicin-loaded liposomes increased doxorubicin delivery to tumors and therapeutic efficacy over untargeted PEGylated doxorubicin-loaded liposomes [196].

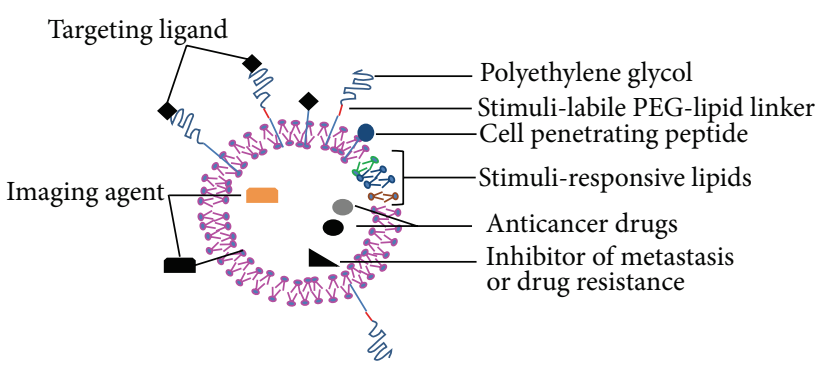

FIGURE 1: Schematic picture of a multifunctional liposomal nanocarrier.

Pericytes are a critical conjunctive component of vasculature; aminopeptidase A (APA) has been identified as a marker of pericytes from orthotopic primary and metastatic (ovary) neuroblastoma in mice [197]. Coupling of a peptide ligand of APA to doxorubicin-loaded liposomes increased doxorubicin accumulation in neuroblastoma tumors over untargeted doxorubicin with better therapeutic activity demonstrating that pericytes are another critical target within the vasculature [198]. Moreover, coadministration of APAtargeted doxorubicin-loaded liposomes and aminopeptidase $\mathrm{N}$ (APN, a marker of tumor endothelial cells) targeted doxorubicin-loaded liposomes led to superior doxorubicin accumulation in tumors over either targeted formulation alone [198]. The destruction of perivascular and endothelial cells in tumors resulted in a significant increase in survival of neuroblastoma-bearing mice over either endothelial celltargeted or pericyte-targeted liposomes alone [198].

Tumor lymphatics are also a therapeutic target since they support lymph node metastasis [199]. Indeed, lymph node invasion is frequent in melanoma and is an indicator of poor prognosis [200]. Laakkonen and coworkers identified a tumor lymphatics-binding peptide (LyP-1) which, after intravenous injection in breast carcinoma-bearing mice, was shown to accumulate in hypoxic areas of primary tumors, cofllocalize with lymphatic markers in primary tumors and lymph node metastases leading to tumor growth reduction and a decreased number of lymphatic vessels [201, 202]. Interestingly, presentation of this peptide on doxorubicinloaded liposomes increased tumor accumulation and therapeutic efficacy over untargeted liposomes and decreased lymph node metastasis rate and growth [201, 203-205].

A combination of targeting ligands may be needed for effective antiangiogenic therapy. Murase et al. demonstrated synergy in association with endothelial cells in vitro by liposomes modified with two angiogenic vessel-targeted peptides (APRPG and GNGRG) identified by phage display and revealed the more intense association with tumor blood vessels in vivo of dual-targeted liposomes over single-modified liposomes [206]. Similarly, Meng et al. demonstrated synergy in tumor growth inhibition of non-small cell lung cancer of PEGylated paclitaxel-loaded liposomes targeted to tumor vasculature by both RGD and a neuropilin 1-specific peptide over untargeted or single-targeted liposomes [207]. These results are in accordance with the increased detection of 


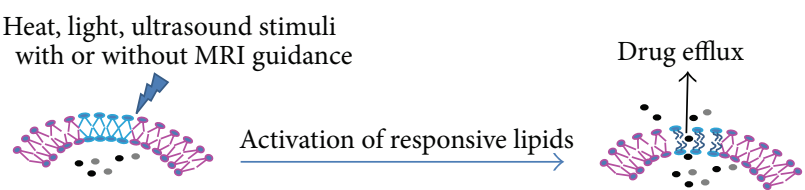

(a) External physical stimuli $\begin{array}{ll}\text { Low tumor } \mathrm{pH} \text {, tumor enzymes, } & \begin{array}{l}\text { Selective internalization by } \\ \text { cancer cells }\end{array}\end{array}$
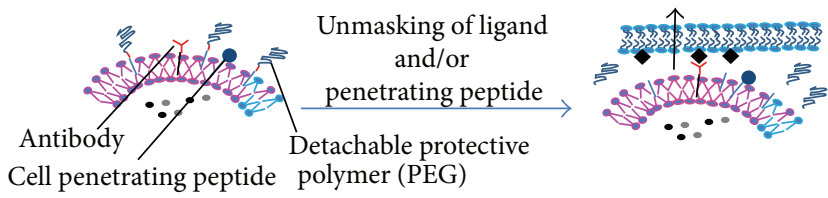

Cell penetrating peptide polymer (PEG)

(b) Physiological tumor-environment stimuli induced PEG release

FIgURE 2: Schemes for tumor-specific liposome destabilization or endocytosis.

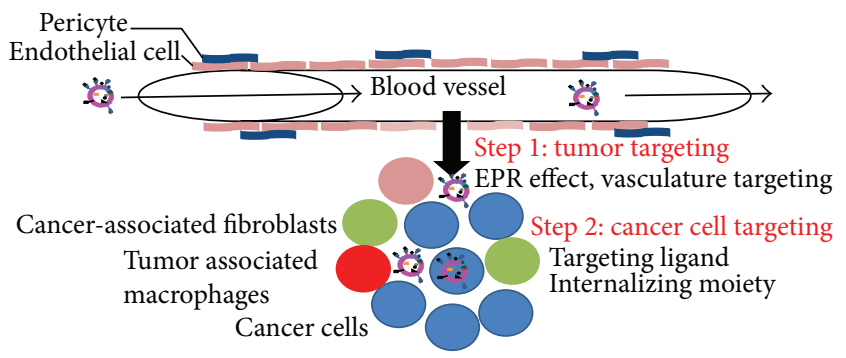

FIGURE 3: Targeting mechanisms in liposomal cancer therapy.

neoangiogenic blood vessels in surgical specimens from cancer patients when using two neovasculature-specific peptides simultaneously compared to individually used [196].

\subsection{Targeting and Inhibition of Metastasis. Metastasis is} the ultimate stage of clinical cancer and is the stage with the least survival. Treatment of metastasis is challenging because micrometastatic foci are hard to detect and more aggressive than the primary tumors [208]. Elimination of metastases is thus of utmost importance to prevent cancer recurrence after chemotherapy or surgical removal of the primary tumor. Platelets have been proposed as shuttles for tumor cell metastasis by formation of platelets-tumor cell aggregates $[209,210]$. This is consistent with the elevated platelet counts in patients with advanced cancer [210]. Therefore, Wenzel et al. used PEGylated liposomes to codeliver the haemostatic inhibitor dipyridamole (DIP) and the cytotoxic drug perifosine (OPP) to inhibit platelet-tumor cell aggregate formation and kill tumor cells, respectively [211]. OPP/DIP coloaded liposomes inhibited aggregation of platelets, decreased formation of platelet-tumor cell aggregates in vitro and decreased the number of experimental lung metastases when intravenously injected $6 \mathrm{~h}$ before parenteral injection of tumor cells. The metastasis-specific peptide TMPT1 [212] recognizes highly metastatic primary tumors and metastases of prostate, breast, and lung cancers relative to their nonmetastatic counterparts. Conjugation of this

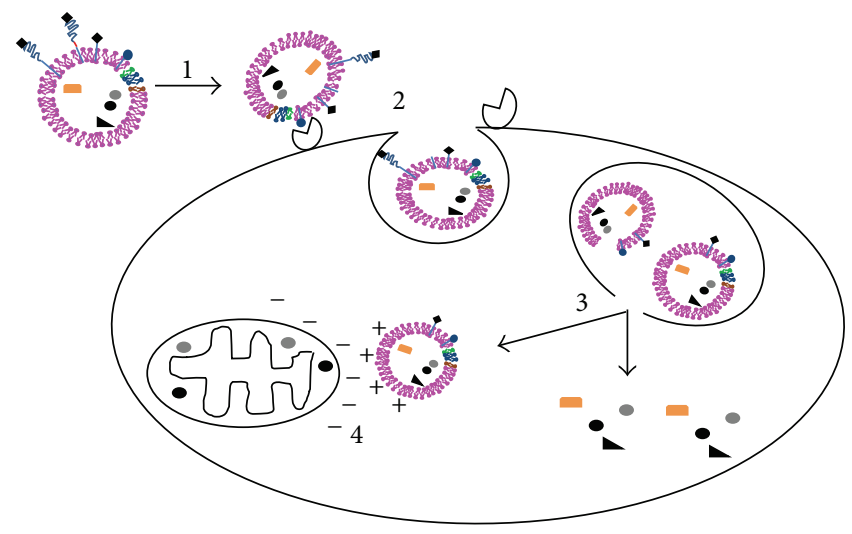

FIGURE 4: Strategies for intracellular delivery. Steps for intracellular delivery: (1) Stimuli-sensitive activation/unmasking of internalization moiety, (2) Cancer cell-specific endocytosis, (3) Endosomal escape and/or therapeutic agent release after activation of fusogenic peptides or lipids, (4) Binding to the highly negative mitochondrial outer membrane for mitochondria targeting. Legends are the same as in Figure 1.

peptide to doxorubicin-loaded liposomes led to deeper tumor penetration and greater induction of apoptosis with superior tumor growth inhibition against highly metastatic breast cancer xenografts [39]. PAR-1 (Protease Activated Receptor 1), a thrombin receptor, is a major regulator of metastasis in melanoma through its roles in matrix degradation and angiogenesis [213]. Villares et al. reported for the first time a dramatic antimelanoma therapeutic activity after systemic delivery of PAR-1 siRNA-loaded neutral DOPC liposomes with tumor weight reduction and a decrease in experimental lung metastatic colonies [214]. This was achieved via downregulation of promoters of angiogenesis (VEGF and IL-8) and invasion (MMP-2) together with decreased tumor blood vessel density (decreased CD31 staining).

3.4. Immune Cell Targeting. For therapeutic vaccination against cancer, patient's immune cells are stimulated by tumor cell antigens. Since the development of effective adaptive immune responses by $\mathrm{CD}^{+} \mathrm{T}$ cells or $\mathrm{CD}^{+}$ $\mathrm{T}$ cells with cytotoxic activity (Cytotoxic T Lymphocytes, $\mathrm{CTL}$ ) requires their activation by dendritic cells (DCs) that present tumor antigen peptides [215], their targeting is of therapeutic relevance [215-217]. Altin's group used a chelator lipid [Nickel/3(nitrilotriacetic acid)-ditetradecylamine], $\left(\mathrm{Ni}-\mathrm{NTA}_{3}\right.$-DTDA) for functionalization of liposomes with histidine-tagged peptides though polyhistidine binding to nitrilotriacetic acid in the presence of nickel [218, 219]. For antigen delivery, Ni-NTA ${ }_{3}$-DTDA functionalized liposomes were prepared by preinsertion before conjugation with histidine-tagged peptides derived from ICAM4 (Intercellular Cell Adhesion Molecule 4), a ligand of the murine dendritic cell (DC) integrin CD11c/CD18 [220]. Ovalbumin-loaded PEGylated liposomes decorated with DC-targeting peptides distributed to splenic DC in vivo, induced an adaptive immune response against, ovalbumin and exhibited dramatic therapeutic activity against established B16-OVA melanoma 
tumors with complete tumor regression in $80 \%$ of treated mice [218].

In other studies Altin's group reported on DC-targeted gene delivery in vivo and potent antitumor effects in the B16-OVA melanoma model after liposome functionalization with histidylated flagellin, the major constituent of the bacterial flagella, recognized by the Toll Like Receptor 5 that leads to their activation [221, 222]. LPR (Lipid-PolymerRNA) mannosylated and histidylated lipopolyplexes loaded with MART1 (Melanoma Antigen Recognized by T cells 1) mRNA delayed the progression of B16F10 melanoma more effectively than untargeted LPR [223]. This study also illustrated the importance of cytosolic delivery of nucleic acids for in vivo transfection of DC. The authors used a ternary formulation of mRNA or pDNA coding for the reporter gene EGFP (Enhanced Green Fluorescent Protein) complexed with PEGylated histidylated poly-L-Lysine and imidazole-rich liposomes, both of which promote endosomal escape [224, 225]. While no in vivo transfection of splenic DC was observed with pDNA, $12 \%$ were transfected with mRNA mannosylated LPR and 3\% with untargeted LPR demonstrating that nuclear delivery is a limiting step for DC transfection. Liposomes targeted to dendritic cells by mannosylated ligands have recently been used as a platform for effective cancer immunotherapy [114]. The liposomes used harbored mannosylated ligands at their surface for targeting of antigen presenting cells with a cytotoxic $\mathrm{T}$ lymphocyte peptide of the renal carcinoma antigen ErbB2 for induction of an adaptive immune response, Toll Like Receptors (TLRs) agonists as adjuvants and a $\mathrm{T}$ helper lymphocyte epitope peptide for improved immune activation. Of note, the authors developed new functionalized lipid anchors devoid of adjuvant activity for their study: dipalmitoylglycerol maleimide and dipalmitoylglycerol bromoacetate. These liposomes induced an adaptive immune response against the ErbB2 antigen with high therapeutic activity. Targeting of intraperitoneal macrophages by ovalbumin-loaded liposomes armed with dipalmitoylphosphatidylethanolamine conjugated mannotriose increased antigen-specific cell lysis induction by splenocytes over untargeted liposomes resulting in therapeutic efficacy both as a preventive and therapeutic cancer vaccine [115]. In addition to carrying tumor antigens, liposomal vaccines are armed with immunostimulatory lipids, usually derived from microorganisms, recognized by pathogen recognition receptors leading to immunostimulation (reviewed in [226]). Zhong et al. compared the antimetastatic efficacy of a basic Fibroblast Growth Factor (bFGF) vaccine in a mouse melanoma model when administered as a Freund's adjuvant mixture, in cationic liposomes, or cationic liposomes containing $0.25 \%$ of monophosphoryl lipid A as adjuvant [227]. They reported higher anti-bFGF IgG titers and higher pulmonary metastasis inhibition in mice treated with monophosphoryl lipid A bFGF-loaded liposomes over cationic liposomes or a bFGF/Freund's adjuvant mixture without the toxicity associated with administration of free adjuvants.

Selective depletion of tumor supporting cells represents another approach to cell-specific cancer therapy
[228]. The tumor environment is enriched in tumor supporting cells among the tumor-associated macrophages that constitute a predominant inflammatory population involved both in resistance to therapy and metastasis [228]. Dichloromethylenediphosphonate (DMDP) liposomes induced macrophage depletion after intravenous injection in mice [229]. Intradermal injection of DMDP liposomes into the tissues surrounding melanoma or squamous cell carcinoma tumors led to a decrease in tumor-associated macrophages content and tumor rejection [230].

Ligand density was shown to influence both drug retention and target recognition. Zhang et al. demonstrated increase in liposome uptake in vitro as the ligand density was increased from $0 \%$ to 1,3 , and $5 \%$ demonstrating enhanced ligand recognition [231]. However, increase of in vitro drug release as a function of DSPE-PEG-RGD ligand moiety has been reported by others [232]. Moreover, Saul et al. evidenced increase of nonspecific uptake in vitro with ligand density [233]. Consistent with their results, lower tumor accumulation of NGR (Asparagine-Glycine-Arginine) vasculature targeted liposomes has been evidenced in vivo with liposomes harboring $2.56 \%$ mole NGR-PEG-DSPE than 0.64\% mole NGR-PEG-DSPE [234]. Altogether, these data suggest the use of the lowest targeting ligand density allowing target binding for effective anticancer therapy.

\section{Liposomes for Combination Therapy}

The prevalence of drug resistance in cancer patients, both prior to treatment and de novo $[235,236]$, fueled the application of drug combinations to treat cancer as an alternative to increased doses of chemotherapeutics associated with life threatening sideeffects [237-239].

Codelivery was well illustrated in a study by Chen et al. [240]. Using LPH-NP (liposome-polycation-hyaluronic acid) nanoparticles targeted by postinsertion of DSPE-PEGGC4 (scFv selected by phage display against ovarian tumors [241]), they codelivered 3 different siRNA and one miRNA and obtained a $80 \%$ decrease in tumor load after treatment. They simultaneously targeted proliferation pathways with Cmyc siRNA and miR34a miRNA [242, 243], apoptosis with MDM2 siRNA [244], and angiogenesis using VEGF siRNA [245]. Liposomal codelivery of siRNA against the apoptosis regulator Mcl-1 (Myeloid cell leukemia sequence 1) and of the MEK (Mitogen-activated Extracellular Kinase) and apoptosis resistance inhibitor PD0325901 enhanced tumor growth inhibition compared to each treatment alone [246]. The same group also developed trilysinoyl oleyamide (trilysine peptide linked to oleyamine by a peptide bond) based PEGylated liposomes for codelivery of Mcl-1 siRNA and the histone deacytylase inhibitor suberoylanilide hydroxamic acid (SAHA) [247]. Intravenous administration increased the tumor growth delay compared to liposomes with SAHA and an irrelevant siRNA. Likewise, Xiao and coworkers used targeted liposomes to codeliver doxorubicin and DNA encoding a dominant mutant of survivin [248]. Liposomes were targeted by a truncated basic fibroblast growth factor (tbFGF) peptide recognizing the bFGF receptor upregulated 
in lung cancers and contained doxorubicin and pDNA encoding for a dominant negative mutant of survivin to counter survivin-mediated apoptosis resistance [249]. Their codelivery produced a higher therapeutic efficacy against Lewis lung carcinoma tumors than liposomes with either agent alone.

A further step in combination of an antineoplastic agent with modulation of drug resistance was achieved recently by Minko and coworkers [250] by formulation of peptide-targeted liposomes containing doxorubicin or cisplatin together with oligonucleotides against the two main drug resistance mechanisms $\mathrm{Bcl}-2$ and MDR1. The efficacy of this "combined targeted chemo and gene therapy" system was evaluated in xenografts established from human ovarian malignant ascites. While inclusion of either Bcl-2 or MDR1 antisense oligonucleotides in cisplatin or doxorubicin-loaded targeted liposomes decreased primary tumor volume and intraperitoneal metastases load, further inhibition of tumor growth inhibition was obtained with targeted liposomes containing doxorubicin or cisplatin, Bcl2 and MDR1 antisense oligonucleotides together with complete prevention of the development of detectable intraperitoneal metastases or ascites. Interestingly, Minko et al. proposed this system as a platform for personalized cancer therapy with liposomal formulations containing antisense oligonucleotides targeting individually relevant resistance mechanism. Sawant et al. coloaded PEGylated liposomes with a palmitoyl-ascorbate conjugate and paclitaxel [251]. The therapeutic benefit of the coloading against 4T1 mammary carcinoma was evident at $10 \mathrm{mg} / \mathrm{kg}$ compared to palmitoyl-ascorbate or paclitaxel-loaded liposomes. Atu027 (Silence Therapeutics, London, UK) is a liposomal formulation of siRNA against protein kinase N3, a downstream effector of the mitogenic PI3 K/PTEN pathway involved in prostate cancer metastasis [252, 253]. This formulation was composed of $2^{\prime}$-O-methyl-stabilized siRNA encapsulated in cationic liposomes $(50 \mathrm{~mol} \%$ cationic lipid -Larginyl-2,3-L-diaminopropionic acid-N-palmitoyl-N-oleylamide trihydrochloride (AtuFECT01), 49 mol\% co-lipid 1,2diphytanoyl-sn-glycero-3-phosphoethanolamine (DPhyPE), and $1 \mathrm{~mol} \%$ DSPE-PEG2000) [253]. This formulation showed very promising results in phase I clinical trial with tumor regressions in neuroendocrine and breast cancer patients [254].

Dai et al. combined targeted delivery with antineoplastic and antiangiogenic agent delivery in PEGylated liposomes [255]. Coloading of the antiangiogenic agent combretastin A-4 in the lipid bilayer and the anticancer drug doxorubicin in the aqueous core of PEGylated liposomes resulted in increased therapeutic activity. $\mathrm{Hu}$ et al. also combined liposomal delivery of the antineoplastic and antiangiogenic agent, honokiol with irradiation for maximal therapeutic efficacy [256]. They hypothesized that this protocol would combine the destruction of tumor cells by irradiation with inhibition of irradiation-induced neoangiogenesis by honokiol [257]. The combination of PEGylated honokiol-loaded and radiotherapy showed increased survival of Lewis lung carcinoma-bearing mice compared to radiotherapy or honokiol liposomes alone, resulting in decreased angiogenesis in vivo. Maitani et al. also combined an antineoplastic drug (irinotecan) and an antiangiogenic agent (sunitinib) [258]. The drug combination had more therapeutic efficacy against pheochromocytoma neuroendocrine tumors in vivo when they were administered as sunitinib liposomes plus irinotecan liposomes or as coloaded liposomes than the combination of the free drugs, with higher drug accumulation as liposomes than as free drug. In a similar fashion, folate-targeted doxorubicin-loaded liposomes coloaded with a bifunctional peptide capable of vascular disruption and antitumor activity were more effective against KB human nasopharyngeal carcinoma in vivo than untargeted coloaded liposomes than either monotherapy [259]. RGD-targeted liposomes coloaded with doxorubicin and the vascular disrupting drug combrestatin A-4 increased tumor regression of B16F10 melanoma compared to untargeted coloaded liposomes or targeted liposomes with either drug [260].

Zucker and coworkers have optimized the simultaneous loading of vincristine and topotecan into PEGylated liposomes (LipoViTo liposomes) and provided the reader with the methods needed to characterize a liposomal drug combination [261]. Use of LipoViTo increased 100-fold the drug distribution to tumors compared to free drug and led to superior therapeutic efficacy over a free drug combination or liposomes with a single drug. PEGylated liposomes containing both vincristine and quercetin allowed reduced blood clearance of both drugs in mice, increased the therapeutic activity over a combination of free drugs and decreased sidetoxicity [262].

Celator Pharmaceuticals Inc. (Princeton, NJ) developed a liposomal formulation of cytarabine: daunorubicin (CPX351, 5:1 molar ratio) [24, 263, 264]. These PEGylated liposomes coloaded with the weak acid drug, 5-fluoroorotic acid (FOA) and the amphiphatic drug, irinotecan (CPT-11) at a $5: 1$ ratio revealed a synergy between the two drugs with higher therapeutic efficacy than the free drug cocktails in animal models $[264,265]$. To encapsulate both drugs, they first prepared liposomes before active loading of CPT-11 by a $\mathrm{pH}$ gradient method, with the protonated CPT-11 retained in liposomes after complex formation with FOA. Mice treated with coloaded liposomes had increased survival compared to the combination with separate liposomes. However, the therapeutic efficacy was lower than with liposomes loaded with FOA only, probably because the FOA content had to be lowered for CPT-11 coloading, further demonstrating the difficulty of reproducing a synergy with liposomes relative to free drugs. When tested in phase I trial with acute leukemia patients, the 5:1 ratio was maintained in plasma for $24 \mathrm{~h}$, and CPX-351 induced complete responses in 9 out of 43 patients [24]. The same group developed irinotecan: floxuridine liposomes (CPX-1, 1:1 molar ratio). In phase I clinical trial they demonstrated that the drug ratio was maintained in plasma up to $12 \mathrm{~h}$ after infusion and showed positive clinical responses in patients with colorectal cancer [25]. It is noteworthy that the high therapeutic efficacy of liposomes encapsulating two anticancer drugs was always correlated with the maintenance of their synergistic molar ratio in plasma, in animal models [266] as well as in cancer patients $[24,25,264]$ indicating optimization of drug loading and 
liposomal stability as primary concerns for effective combination therapy. Ko et al. codelivered the proapoptotic peptide D$(\mathrm{KLAKKLAK})_{2}$ and the Bcl-2 antisense oligodeoxynucleotide G3139 [267]. The authors took the advantage of the electrostatic properties of these therapeutic molecules to codeliver them by formation of a negatively charged complex between the peptide and G3139 before mixing with positively charged liposomes. Intratumoral injection of coloaded liposomes led to an enhanced tumor growth suppression.

Finally, the combined liposomal delivery of magnetic fluid hyperthermia and photodynamic therapy using magnetic fluid and zinc phthalocyanine as the photosensitizer demonstrated superior toxicity in vitro of combined light and magnetic stimuli over their separate applications suggesting a new treatment modality for enhanced tumor therapy [268].

\section{Tumor Stimuli-Triggered PEG Release}

The addition of PEG to the liposome surface was reported to decrease the interaction of the ligand-targeted liposomes with their ligand, either when small molecules were conjugated to the liposome surface [269] or with antibody-targeted liposomes $[48,118]$ by steric hindrance of the surface ligand. Moreover, PEGylation decreases targeted liposomal accumulation and drug release [270]. Finally, for gene delivery, PEGylation has been shown to decrease intracellular trafficking of DNA [271]. These drawbacks and the extensive research in PEGylation chemistry (recently reviewed in $[272,273]$ ) have led to the preparation of new multifunctional carriers where PEG release is promoted at the tumor's vicinity after a stimulus either by physiological stimuli $(\mathrm{pH}$, altered redox potential, sensitivity to an enzyme overabundant in the tumor microenvironment) or by physical external stimuli (light, heat, and ultrasound) $[8,274]$ (Figure 2).

5.1. $p H$-Sensitive PEG Release. While normal tissues and blood have a physiological $\mathrm{pH}$ near 7.4, human tumors have lower $\mathrm{pH}$ values $(\sim 6.0 / 6.5)$ because of an elevated rate of glycolysis [275, 276]. pH-sensitive bonds have been developed for the coupling of PEG to liposomes [277] (Figure 1). $\mathrm{pH}$-sensitive liposomes achieved a higher concentration of cargo in the cytoplasm and nucleus than non-pH-sensitive PEGylated liposomes in vitro and allowed faster intratumoral content release in vivo $[278,279]$. In addition to tumor sensitivity, $\mathrm{pH}$ sensitive groups can potentiate the efficacy of targeted drug-loaded liposomes.

Folate-targeting of daunorubicin-loaded liposomes by incorporation of a $\mathrm{pH}$-sensitive folate-PEG-cholesterol hemisuccinate (CHEMS) conjugate combined tumor targeting and increased drug release at the tumor site with improved chemotherapeutic activity over untargeted liposomes [280]. Similarly, untargeted cisplatin-loaded liposomes or EGFR-targeted gemcitabine-loaded liposomes incorporating CHEMS had superior antitumor activity over untargeted drug-loaded liposomes or free drugs [281, 282]. Obata et al. used a glutamic acid-based zwitterionic lipid (1,5dihexadecyl N,N-diglutamyl-lysyl-L-glutamate) as titratable lipid for doxorubicin delivery [283]. These liposomes showed a charge inversion from negative to positive at acidic $\mathrm{pH}$ with endosomal escape leading to higher doxorubicin delivery in the cytoplasm and higher toxicity in vitro over conventional liposomes. This resulted in superior antitumor activity in vivo. Biswas et al. developed a new $\mathrm{pH}$-sensitive DSPE-PEG-hydrazone-PEG2000 conjugate for attachment of ligands to the liposome surface [284]. In their work, the cell penetrating peptide (TATp) was unmasked after PEG release at acidic $\mathrm{pH}$ allowing efficient cellular uptake.

Recently, three new approaches for generation of $\mathrm{pH}$ sensitivity have been reported. First, by electrostatic adsorption of negatively charged carboxyl-modified gold nanoparticles to the surface of cationic liposomes (egg dipalmitoylphosphatidylcholine/DOTAP 9:1 weight ratio) at $\mathrm{pH} 7$ (pKa of 5 for the carboxylic group) [285]. Authors reported detachment of gold nanoparticles at acidic $\mathrm{pH}$ due to protonation of the carboxyl groups and speculated that a similar strategy could be applied with negative charged liposomes and amine-modified gold nanoparticles. Second, a platform for finely tuned $\mathrm{pH}$-induced PEG release was introduced using phenyl-substituted-vinyl-ether-(PIVE)-PEG lipid conjugates [286]. Liposomes containing PIVE showed $\mathrm{pH}$-induced dePEGylation and content release at acidic $\mathrm{pH}$ whereas they were stable at physiological $\mathrm{pH}$. Third, ligand unmasking by acidic $\mathrm{pH}$-induced membrane reorganization has been introduced as a reversible ligand-masking strategy. Sofou and coworkers developed a new platform for $\mathrm{pH}$-triggered liposomal drug delivery $[287,288]$. The rationale for their design involves the increased permeability at the boundaries between lipid domains [289]. Using lipid pairs of phosphatidic acid as a titrable headgroup and phosphatidylcholine as the colipid headgroup with mismatched hydrophobic chain lengths (dipalmitoyl and distearoyl) they demonstrated that formation of heterogeneous domains in PEGylated liposomes containing $5 \%$ of cholesterol allowed faster $\mathrm{pH}$ dependent content release than liposomes with matched chains [288]. They showed a $\mathrm{pH}$-dependent membrane transition due to the protonation of phosphatidylserine at lower $\mathrm{pH}$ in cholesterol-rich membranes, with protonation favoring their homologous interaction, leading to the formation of DSPS (1,2-distearoyl-sn-glycero-3[phosphor-L-serine]) lipid domains. PEG-lipid conjugates of matching hydrophobic anchor (DSPE-PEG) also segregated to these domains at acidic $\mathrm{pH}$, whereas no redistribution of unmatched chain DPPE-PEG was in evidence [290]. The liposomes contained a ligand (biotin or an anti-HER2 peptide) harbored by an unmatched lipid (DPPE) which was masked by PEG at physiological $\mathrm{pH}$ but freed from PEG shielding at acidic $\mathrm{pH}$ after formation of the lipid heterogeneities. Application of this strategy to doxorubicin-loaded PEGylated (DSPEPEG2000) liposomes harboring an HER2-specific peptide led to $\mathrm{pH}$-dependent doxorubicin release in vitro and superior tumor growth inhibition than did untargeted vesicles or targeted vesicles devoid of $\mathrm{pH}$-responsiveness [291].

5.2. MMP-Sensitive PEG Release. Hatakeyama and coworkers introduced coupling of PEG to DOPE by an MMPcleavable linker, since MMPs are overexpressed in the tumor 
environment [292, 293]. Transfection efficiency in vitro was correlated with MMP levels and lipoplexes prepared with a MMP-responsive PEG-lipid conjugate showed tumorspecific transgene expression when compared to PEGylated lipoplexes with higher transgene expression for the same quantity of delivered lipoplexes. To enhance tumor targeting, Zhu et al. combined an MMP2-sensitive PEG-lipid conjugate with antibody targeting and an intracellular penetrating moiety (TaT peptide) [294] combining long circulation by PEGylation, tumor targeting via antinuclear antibody 2C5, and selective internalization by tumor cells through MMP-2 triggered exposure of TaT peptide.

5.3. Redox-Sensitive PEG Release. Tumor cells have a higher concentration of reductases than the extracellular environment or normal cells and this feature has promoted the use of disulfide linkers both for the design of reduction-sensitive PEG-lipid conjugates and crosslinked nanoparticles, since the linker is stable in the circulation and normal tissues but reduced in the tumor cells $[295,296]$. Goldenbogen et al. developed a versatile reduction-sensitive conjugate for targeted delivery [297]. Biotin was conjugated to a lipid anchor via a disulfide linker to prepare biotin-decorated liposomes; conjugation of streptavidin-HER2 monoclonal antibody allowed superior cellular uptake of doxorubicin in vitro over untargeted liposomes. Interestingly, less intracellular doxorubicin was detected after incubation with unsensitive HER2 targeted doxorubicin-loaded liposomes than reduction-sensitive targeted liposomes, further demonstrating the need for multifunctional liposomes. A combination of enhanced uptake and reduction-sensitivity was also done using reduction-detachable PEG and TAT [298]. Cleavage of DOPE-S-S-PEG5000 allowed unmasking of DOPEPEG1600-TAT and superior uptake of calcein in vitro over uncleavable TAT-modified liposomes together with stability in the presence of serum. Reduction-sensitive liposomes have also been used for gene delivery and a linear correlation between intracellular glutathione content and transfection efficiency has been recently demonstrated [299].

\section{Intracellular Delivery}

Internalization of anticancer drugs by cancer cells in tumors was shown to be a barrier to be overcome for cancer therapy $[98,101]$. The use of internalization modifications at the liposomal surface or exposed after release of a PEG corona in the tumor-environment for active transport into cells and even subcellular delivery increased therapeutic activity [7, 17, 96, 300]. The influence of lipid composition on drug release and internalization, endosomal escape strategies, and mitochondria targeting is discussed below (Figure 4).

6.1. Importance of Lipid Composition. The presence of cholesterol or rigid saturated lipids (DSPC, HSPC) stabilizes the liposomal membrane against liposomal dissociation by plasma proteins and limits drug leakage, and thus most drug-loaded liposomes include cholesterol in the lipid bilayer
[45, 288, 301]. These lipids have high gel-to-liquid crystalline phase transition temperatures $\left(55-58^{\circ} \mathrm{C}\right)$ compared to physiological temperature $\left(37^{\circ} \mathrm{C}\right)$ which prevents coexistence of the two phases and contributes to improved drug pharmacokinetics $[13,45,302]$. In some studies, the couple sphingomyelin/cholesterol is used to further rigidify the membrane through hydrogen bonding [303]. However, cholesterol inclusion can decrease drug loading. Indeed, paclitaxel loading decreased form $99.3 \%$ at a $5 \%$ molar content of cholesterol to $66.5 \%$ at $17 \%$ cholesterol content and $6.2 \%$ at a $37 \%$ molar content as a result of the hindered drug penetration in the increasingly rigid lipid bilayer [304]. The lipid composition is also important for the choice of the PEG-lipid conjugate used for PEGylation. Indeed, Kusumoto et al. reported a 10-fold higher transfection using liposomes armed with an endosomal-escape peptide (IFN7) harboring cholesteryl-PEG2000 over DSPE-PEG2000 [305]. The superior endosomal escape of liposomes prepared with the former was attributed to the higher fluidity of cholesterol over DSPE, a superior fluidity favoring interaction with endosomal membranes and the resulting endosomal escape and transfection efficiency. Hydrophobicity was also shown to be a determinant for the design of smart multifunctional nanocarriers. Hansen et al. compared UV-triggered TaT peptide-mediated liposome internalization with a 16 or 12 carbons lipid anchor [306]. In addition to better internalization, liposomes with a C16 anchor were less prone to aggregation than those with a $\mathrm{C} 12$ anchor. The authors suggested the more hydrophobic alkyl chain favored liposomal insertion and the burial of the TaT peptide in a PEG-loop for the best UV-responsiveness and stability in cell culture media with bovine serum albumin.

Insertion of negatively charged lipids such as cardiolipin has been used to increase the retention of positively charged drugs in liposomes [45]. This was recently well illustrated for the preparation of mitoxantrone liposomes (mitoxantrone-complexed liposomes) by electrostatic complexation between anionic cardiolipin-based liposomes and cationic mitoxantrone [307]. While loading efficiencies of 95\% were obtained with anionic liposomes using cardiolipin (CA), cholesteryl hemisuccinate (CHEMS), egg L- $\alpha$ phosphatidylglycerol (PG), or L- $\alpha$-phosphatidylserine (PS), only $3.8 \%$ loading was achieved with neutral liposomes. The therapeutic activity of the different anionic liposomal mitoxantrone preparations was in good agreement with release of mitoxantrone, that is, with the mitoxantrone release in vitro after heparin treatment. CHEMS liposomes had the lowest retention capacity and had virtually no impact on the survival of peritoneal carcinoma-bearing mice, and both PS and PG liposomes had intermediate mitoxantrone retention and exhibited higher therapeutic activity than free drug, albeit still inferior to that of CA liposomes capable of the highest mitoxantrone retention in vitro. Inclusion of anionic lipids should be coupled with PEGylation, since a negative charge directs liposomes to liver and spleen [308].

Lipid composition is also determinant for stimuliresponsive drug release. Goldenbogen et al. reported no calcein release from disulfide conjugated dipalmitoylphosphatidylcholine liposomes after treatment with a reducing agent, whereas reduction-induced release was observed 
from liposomes including 55\% of unsaturated dioleoylphosphatidylethanolamine [297]. Note that Candiani et al. also incorporated DOPE in the lipid composition for bioreducible gene delivery, stressing the importance of DOPE as a helper lipid for membrane destabilization [299]. Increased permeability for thermosensitive drug release has been addressed by inclusion of 1-palmitoyl-2-hydroxy-sn-glycero3-phosphocholine (P-lyso-PC) due to its tendency to form micelles and allow therapeutic efficacy in vivo of doxorubicinloaded thermosensitive liposomes [309]. Nevertheless, the pharmacokinetics after administration in dogs was more similar to free doxorubicin than Doxil, which demonstrates the need to further optimize the lipid composition. Although liposomal cisplatin with $80 \%$ hydrogenated soy phosphatidylcholine (HSPC) showed increased cisplatin accumulation in preclinical tumors over free drug [21], this did not translate into therapeutic activity in patients [310,311]. Absence of clinical activity was correlated with a lack of detectable released drug in the serum of treated patients, revealing the need for a balance between modifying the free drug pharmacokinetics for improved biodistribution to the diseased site and bioavilability [96]. PEGylation is required for enhanced blood residency and therapeutic efficacy, but postinsertion of DSPE-PEG6000 into preformulated siRNA lipoplexes was reported to induce siRNA release in vitro [312] and was nicely overcome by the use of cholesterol grafted siRNA for increased retention in liposomes. The combination of cellular uptake and targeting using a cholesterol-siRNA conjugate and cyclic RGD peptide allowed luciferase silencing in a B16F10-luc 2 experimental lung metastasis model, validating this new system [313].

6.2. Cell Penetrating Peptides. Cell penetrating peptides (CPPs) are amphiphatic peptides, usually cationic, either derived from viruses or synthetic that are able to improve the cellular internalization of the attached cargo [314] (Figure 4). The most frequently used CPPs are the TaT peptide derived from the transcription-transactivating protein of human immunodeficiency virus type 1 and synthetic polyarginine $[315,316]$. TaT peptide is a powerful internalization moiety. However its endocytosis lacks cell-specificity and TaT peptide exposure at the liposome surface can lead to MPS elimination after opsonin binding as well [317]. For Tatmediated internalization only in the tumor environment, masking strategies have been proposed. This concept was proved by Kale and Torchilin using masked TaT peptide surface-functionalized lipoplexes prepared with a plasmid coding for GFP (DSPE-PEG1000-TAT) by a $\mathrm{pH}$-sensitive PEG corona (DSPE-hydrazone-PEG2000), leading to higher transgene expression in tumor tissue after intratumoral injection of $\mathrm{pH}$-sensitive formulations [318]. Kuai et al. masked TaT peptide at the liposome surface (TAT-PEG2000-DSPE) by a reduction-sensitive PEG corona (PEG5000-S-S-DSPE) to take advantage of the higher concentration of reductive enzymes in tumors [319]. This allowed higher tumor accumulation and less liver uptake than unmasked Tat peptidemodified liposomes after intravenous administration.
More recently, UV-triggered CPPs have been proposed [306]. They added a CPP through incorporation of a TaT peptide-lipid conjugate with two lipid anchors, a TaT peptidePEG2000-DSPE conjugate linked to a less stable single chain hydrophobic group of 12 or 16 carbons via a UV-cleavable linker. They demonstrated a UV-dependent internalization of liposomes (a 15-fold increase in cellular adhesion and internalization only after irradiation), not observed with an uncleavable linker, that reached levels comparable to DSPE-PEG2000-TaT peptide liposomes. For the same purpose of cell-type selective CPP-mediated uptake, Kibria et al. functionalized liposomes with either RGD peptide or the tumor endothelial cell-specific peptide KYND and the octaarginine CPP and showed synergy of the combination of targeting peptide and cell penetrating peptide for liposome uptake in vitro with higher cell selectivity [320]. The same group later demonstrated superior antitumor activity of doxorubicin-loaded liposomes harboring both the tumor endothelial cell-specific peptide NGR and the cell penetrating peptide tetraarginine over untargeted liposomes or singlemodified doxorubicin-loaded liposomes [183]. Presentation of octaarginine at the surface of bleomycin-loaded liposomes increased apoptosis induction in tumors and tumor growth inhibition over bleomycin-loaded liposomes devoid of the CPP [321]. Superior tumor growth inhibition was evidenced over untargeted RTN (receptor-targeted nanocomplexes, RTN) using lipopolyplexes decorated with an integrintargeting peptide for delivery of pDNA encoding IL-2 and IL-12 to promote antitumor immunity $[322,323]$. In their study, the complexes were optimized for disassembly in the target cell $[323,324]$. The PEG-lipid conjugates used had an esterase-cleavable bond for endosomal escape and the integrin-targeting peptide was coupled to the polycation used for pDNA condensation by a linker cleavable by both cathepsin B and along with furin for intracellular release of the nucleic acid and high transfection efficiency.

In addition to enhancing cellular uptake, TaT peptide conjugation allowed crossing of the blood brain barrier in in vitro models and increased drug delivery of doxorubicinloaded liposomes, resulting in prolonged survival of orthotopic glioma-bearing animals after intravenous administration [325].

6.3. Endosomal Escape. After the endocytosis, the cargo is transferred from endosomes ( $\mathrm{pH}$ 6.5-6) to lysosomes $(\mathrm{pH}<$ 5) [326] in which enzymatic degradation occurs. Although PEGylation is required for extended blood circulation and tumor accumulation [7], this modification decreases cellular uptake and further increases endosomal degradation of the cargo, thereby reducing its activity [327, 328]. These conflicting properties of PEG have been referred to as the "PEG dilemma" [292]. The decreased endosomal $\mathrm{pH}$ has been exploited as a means to escape degradation using either fusogenic lipids or peptides which destabilize membranes after conformational activation at low $\mathrm{pH}$, amines protonable at acidic $\mathrm{pH}$ for endosome swelling and rupture by a buffer effect [329-338] (Figure 4). The peptides used are either 
derived from viruses such as TATp from Human Immunodeficiency Virus [339], IFN7 from the haemagglutinin of influenza virus [340], or artificial peptides like GALA [341]. Inclusion of these peptides leads to superior intracellular drug accumulation and resulting in higher cytotoxicity than liposomes devoid of endosomolysis properties. As a new approach, Kullberg et al. attached the pore-forming protein listeriolysin $\mathrm{O}$ to HER2-targeted bleomycin-loaded liposomes, resulting in a higher toxicity in vitro over targeted bleomycin-loaded liposomes without listeriolysin O [342].

6.4. Mitochondrial Targeting. Effective treatment of cancer faces problems due to limited drug penetration and drug resistance [343-345]. Since resistance to antineoplastic agents induced cell death is frequently associated with altered mitochondrial function and/or altered expression of mitochondrial regulators of apoptosis [300, 343], subcellular accumulation of anticancer drugs in mitochondria can give a therapeutic advantage and has been exploited [300, 346] (Figure 4).

Mitochondria targeting of epirubicin-loaded liposomes by inclusion of the positively charged electrolyte dequalinium increased their cytotoxicity in vitro and antitumor activity in vivo over untargeted liposomes [347]. Hatakeyama and coworkers developed a MitoPorter multifunctional envelope-type nanodevice (MEND) nanocarrier with sequential activation of essential functions necessary for mitochondria delivery [292, 346, 348]. These formulations have a "programmed packaging"; their surface is functionalized with a targeting moiety (transferrin or antibody), a PEG-lipid conjugate for long blood circulation; and a PEG-lipid bond that is cleaved in the tumor environment by matrix metalloproteinases leading to exposure of a CPP (octaarginine, tetraarginine) for tumor-selective endocytosis. Once inside the cell, a fusogenic peptide (KALA or GALA) allows endosomal escape of positively charged liposomes by membrane fusion, the positive charge favoring their interaction with the largely negative outer mitochondrial membrane, and finally the fusogenic lipid DOPE allows internalization of the cargo by the mitochondria [346]. Although complex, such nanocarriers are produced in GMP conditions warranting their clinical evaluation [348].

Instead of using one moiety for each step of intracellular targeting, Zhang and coworkers designed a smart, pH-responsive lipid (1,5-dioctadecyl-L-glutamyl-2-histidylhexahydroxybenzoic acid, $\mathrm{HHG}_{2} \mathrm{C}_{18}$ ) [349]. The liposomes generated are negatively charged at physiological $\mathrm{pH}$ and have a sharp charge inversion at acidic $\mathrm{pH}$ (from $-22.9 \mathrm{mV}$ at $\mathrm{pH} 7.4$ to $+6.3 \mathrm{mV}$ at $\mathrm{pH}$ 6.5) for tumor-selective uptake. After uptake, hexahydrobenzoic acid is released by cleavage of the $\beta$-carboxylic acid linker in the endosomes leading to exposure of histidine and the endosomal escape of positively charged liposomes electrostatically targeted to the outer mitochondrial membrane. Liposomes containing the $\mathrm{HHG}_{2} \mathrm{C}_{18}$ lipid and encapsulating the anticancer drug Temsirorimus showed higher renal cancer tumor growth inhibition than free drug or nonresponsive liposomes. Targeting of topotecan-loaded PEGylated liposomes to mitochondria by inclusion of dequalinium, a lipophilic cation with a delocalized charge center that is attracted by the mitochondrial transmembrane potential [350], showed higher therapeutic efficacy than untargeted drug-loaded liposomes or free drug in two animal tumor models.

In another study [351], postinsertion of the mitochondriotropic dye Rh123-PEG2000-DSPE conjugate into PEGylated liposomes permitted their mitochondrial accumulation and increased the toxicity of paclitaxel-loaded liposomes over untargeted liposomes or free drug. This result is in line with the activation of the intrinsic apoptosis pathway by paclitaxel [352]. Although these modifications lead to superior cytotoxicity, the lack of cancer cell specificity can decrease their therapeutic index. To address this challenge, the same authors modified paclitaxel-loaded liposomes with a mitochondriotropic lipid (triphenylphosphonium, TPP) TPP-PEG-PE conjugate [353]. While the PEGylation of liposomes leads to their extravasation into the tumor by the EPR effect, TPP modification allowed superior therapeutic activity of mitochondria-targeted liposomes since more drug was intracellularly available. Malhi et al. developed "mitocancerotropic" doxorubicin-loaded liposomes combining tumor targeting by folic acid and mitochondriotropism by TPP [354]. Dual-targeted liposomes led to higher doxorubicin accumulation in mitochondria and superior toxicity than single-targeted doxorubicin-loaded liposomes, thus warranting further evaluation of this strategy.

\section{Remote-Controlled Payload Release}

To achieve release of the therapeutic agent at the tumor site, several strategies have been explored including ultrasoundtriggered, photo-triggered, thermotriggered content release after controlled destabilization of the lipid bilayer (Figure 2).

7.1. Ultrasonication. Ultrasound-induced membrane permeabilization has been used for external stimuli-triggered drug release form liposomes by thermal or nonthermal effects (reviewed in [355]). Using PEGylated cisplatin-loaded liposomes, a $70 \%$ drug release after external ultrasound heating and a 2.7-fold increase in drug content occured in vivo whereas only $3 \%$ cisplatin was released without ultrasound exposure, leading to the superior therapeutic activity of the formulation in ultrasound-treated mice [356]. A correlation between DSPE content in liposome membranes and sonosensitivity has also been reported [357].

7.2. Photo-Sensitive Release and Photodynamic Therapy. Photo-sensitive liposomal drug delivery relies on photodestabilization of the liposomal bilayer to release the encapsulated drug [358]. The liposomes used should be able to route the drug to the tumor and protect it from photodynamic damage [359]. Photodynamic therapy (PDT) consists of the destruction of tumors by light-activation of a photosensitizer, resulting in liberation of singlet oxygen that destroys the tumor by apoptosis, necrosis, or autophagy-induced cell death mechanisms [360]. Although the limited light diffusion 
of this approach has been challenged by coupling of a light source to diffusing tips to treat deeper tumors [361], the area of cell death induction is still restrained due to the short lifetime of singlet oxygen (nanoseconds) [360]. Moreover, as these agents are mainly hydrophobic, their administration is limited by their aggregation, and the technique is limited to detectable tumors due to the nonspecific photosensitization $[360,362,363]$. Liposomal delivery of photosensitizers would allow treatment of both primary tumors and metastases by enhanced uptake of the photosensitizer by tumor cells. Yavlovich et al. reported for the first time light-triggered release of doxorubicin from PEGylated liposomes after laser irradiation including $10 \%$ of the photopolymerizable diacetylene phospholipid (1,2bis-(tricosa-10, 12-diynoyl)-snglycero-3-phosphocholine, $\mathrm{DC}_{89} \mathrm{PC}$ ) resulting in phototriggered cell killing in vitro [359]. The encapsulation of zinc tetraphenylporphyrin into PEGylated, folate-targeted liposomes improved its uptake and cytotoxicity after irradiation compared to untargeted liposomes in vitro [364]. Bovis et al. compared the pharmacokinetics of m-THPC $[5,10,15,20$ tetra-(m-hydroxyphenyl)chlorin] administered either in its clinically approved ethanol/propylene glycol formulation (Foscan) or in PEGylated liposomes [363]. Formulation of $\mathrm{m}$-THPC in liposomes decreased its blood clearance and decreased skin photosensitivity compared to Foscan. Furthermore, m-THPC showed superior tumor accumulation and higher tumor necrosis than Foscan supporting its preclinical evaluation. Using another m-THPC unPEGylated liposomal formulation (dipalmitoylphosphatidylcholine/dipalmitoylphosphatidylglycerol, 9:1 molar ratio) Lasalle et al. stressed the importance of optimization of the delay between photosensitizer administration and irradiation [365]. Indeed, while no increase in survival of mammary carcinoma-bearing mice was observed compared to control for $1 \mathrm{~h}$ and $3 \mathrm{~h}$ drug-light intervals, $6 \mathrm{~h}$ and $15 \mathrm{~h}$ intervals cured $79 \%$ and $63 \%$ of mice, respectively.

7.3. Thermoresponsive Preparations. While lipids with high transition temperatures (above $55^{\circ} \mathrm{C}$ ) are required for blood stability and to decrease blood leakage, inclusion of lipids with transition temperatures closer to physiological body temperature $\left(40-45^{\circ} \mathrm{C}\right)$ allows induction of drug release after external localized heating [45]. Inclusion of low transition temperature lipids is a strategy used in tumor therapy for more than 30 years since the pioneering study of Weinstein et al. who used dipalmitoylphosphatidylcholine [366]. Doxorubicin-loaded liposomes containing $2 \%$ of poly [2(2-ethoxy)ethoxyethyl vinyl ether (EOEOVE)], (transition temperature $40^{\circ} \mathrm{C}$ ) exhibited a rapid doxorubicin release after heating to $45^{\circ} \mathrm{C}$ with limited release at $37^{\circ} \mathrm{C}$, and allowed tumor growth suppression only after heating [367]. Interestingly, in their study thermoresponsiveness of poly (EOEOVE) liposomes was improved by coinclusion of DSPE-PEG5000 in the liposome formulation and revealed an advantage of multifunctional liposome PEGylation. Encapsulation of the doxorubicin analog, epirubicin into PEGylated thermoresponsive liposomes increased blood residency and tumor accumulation over unresponsive liposomes or free drug, resulting in a $20 \%$ higher tumor growth inhibition in animals treated with thermoresponsive liposomes over unresponsive epirubicin-loaded liposomes [368].

Paasonen et al. used gold-nanoparticles as "energy collectors" to lower the threshold energy required to induce photo-sensitive drug release [369]. After heat transfer from gold nanoparticles to lipids promoting liquid crystal-togel phase transition, a UV-induced liberation of the model compound calcein was evidenced with virtually no release without irradiation. Magnetic fluid hyperthermia involves heat transfer from magnetic particles after exposure to a magnetic field that results in localized elevation of temperature and induction of cell death [370]. To improve the selectivity, doxorubicin thermo-responsive liposomes coloaded with doxorubicin and magnetic nanoparticles were armed with folic acid and resulted in improved cytotoxicity in vitro over nonresponsive liposomes or untargeted thermo-responsive doxorubicin-loaded liposomes [371]. Intra-tumoral injection of anti-HER2 immunoliposomes containing magnetite followed by alternate magnetic field heating promoted iron retention in tumors in a HER2-specific manner $48 \mathrm{~h}$ after injection [372]. A 3-fold higher iron content was detected in HER2-overexpressing BT474 breast cancer xenografts over low HER2-expressing SKOV3 ovarian cancer xenografts, and magnetite retention in BT474 xenografts correlated with stable tumor regression [372]. In line with these studies, conjugation of HER2 antibody to thermo-sensitive doxorubicinloaded liposomes improved the doxorubicin-mediated toxicity over controls [373].

Boron capture neutron therapy relies on delivery of ${ }^{10} \mathrm{~B}$ boron followed by $\gamma$-irradiation and capture of neutrons by ${ }^{10} \mathrm{~B}$, leading to the production of toxic $\alpha$-particles, ${ }^{4} \mathrm{H}$ and ${ }^{7} \mathrm{Li}$ for cell death induction [374]. Maruyama encapsulated ${ }^{10} \mathrm{~B}$ into PEGylated transferrin-armed liposomes for targeted delivery to colon carcinoma xenografts, this led to higher ${ }^{10} \mathrm{~B}$ tumor accumulation compared to the free isotope or untargeted liposomes and resulted in superior therapeutic efficacy after irradiation over free isotope or untargeted ${ }^{10} \mathrm{~B}$ liposomes [36]. Lastly, the group led by Miyata reported a 3.6-fold higher ${ }^{10} \mathrm{~B}$ tumor concentration in orthotopic gliomas after intratumoral convection-enhanced delivery using PEGylated transferrin armed liposomes over untargeted liposomes with a lower retention in normal brains [375]. Superior therapeutic activity was observed against intracranial gliomas after intravenous injection of transferrin-targeted liposomes encapsulating sodium borocaptate over untargeted ones after neutron irradiation [376].

\section{Theranostic Liposomes}

Simultaneous therapy and diagnosis following codelivery of therapeutic and imaging agents, theranostic, are determinant for the development of personalized medicine since it would allow clinicians to detect and characterize lesions and rapidly evaluate tumor response and modify treatment accordingly (increase dose, stop treatment, or use an alternate drug) [377-379]. Indeed, liposomes are currently widely used for diagnosis (see recent reviews) [380-382]. 
Kenny et al. designed PEGylated liposome-entrapped siRNA nanoparticles (LEsiRNA) loaded with gadolinium (III) for magnetic resonance imaging, siRNA against the apoptosis inhibitor survivin for tumor therapy, and labeled with DOPE-rhodamine for fluorescence detection [383]. Accumulation of LEsiRNA in ovarian cancer xenografts after intravenous injection was demonstrated by MRI and confirmed post mortem in tumor biopsies by fluorescence with in vivo survivin silencing and tumor weight reduction. Gdlabeled, doxorubicin-loaded thermo-responsive liposomes allowed detection of both tumor imaging by MRI and tumor regression after localized heating [384]. Note that to retain thermoresponsiveness after Gd-labeling a new Gd-chelatedendron-based lipid was included in the lipid bilayer instead of a standard Gd-lipid conjugate to decrease Gd-lipid content to enhance thermosensitivity.

The use of magnetic resonance imaging (MRI) to allow both tumor visualization and temperature feedback for imaging-guided thermo-responsive drug delivery showed improved therapy of the image-guided, thermallyinduced drug release [385, 386]. Labeling of prednisolone-labeled liposomes did not decrease its therapeutic activity, allowed evaluation of in vivo drug biodistribution and response monitoring simultaneously, with MRI signal detection 1 week after injection [387]. To combine the advantages of three imaging modalities (optical imaging, CT imaging, and MRI), Li et al. and Mitchell et al. developed liposomes labeled with a fluorophore tracer, with ${ }^{99 \mathrm{~m}} \mathrm{Tc}$, ${ }^{111} \mathrm{In}$ or ${ }^{64} \mathrm{Cu}$, and Gd [388, 389]. Since most facilities do not possess all the imaging equipment, this system would allow a more flexible followup of therapeutic activity by optical imaging, while in depth studies would use CT or MRI without the need of administration of another imaging agent. Spatially controlled thermallyinduced drug release was achieved with MRI-guided high intensity focused ultrasound heating of the targeted tumor region resulting in deep tumor penetration of doxorubicin-loaded thermo-sensitive liposomes, coloading of liposomes with doxorubicin and gadolinium allowing tumor visualization and therapy $[385,386,390]$.

The contrast agent used for the preparation of theranostic siRNA liposomes must be chosen with care. Mikhaylova et al. reported nonspecific protein downregulation in vitro after incorporation of gadolinium of Magnevist into COX2 (cyclooxygenase 2) siRNA-loaded liposomes, while COX-2 silencing without nonspecific downregulation was detected with liposomes coloaded with COX-2 siRNA and Feridex [391]. Targeting drug-loaded liposomes, in addition to enhancing their therapeutic activity, enhances tumor detection and response monitoring when they are coloaded with an imaging agent. Addition of transferrin to ${ }^{10} \mathrm{~B}$ plus iodine contrast agent coloaded liposomes allowed a 3.6-fold higher

${ }^{10} \mathrm{~B}$ concentration in tumor tissues over untargeted coloaded liposomes [375]. The selective retention of transferrintargeted formulations led to better tumor detection $72 \mathrm{~h}$ after administration of liposomes, a period during which the signal from untargeted liposomes had washed out, thus combining monitoring of drug delivery and tumor response with boron neutron capture therapy [375]. Combined delivery of Gd and doxorubicin in liposomes targeted with a neural cell adhesion molecule-specific peptide allowed higher concentration of doxorubicin in tumor tissues correlated with increased tumor growth inhibition over untargeted coloaded liposomes together with better visualization of tumors by MRI [392]. Targeting of iron oxide and doxorubicin coloaded liposomes to pancreatic tumors by conjugation of an antimesothelin antibody improved the antitumor activity and tumor signal enhancement over untargeted liposomes [393]. Folate targeting of doxorubicin-loaded liposomes encapsulating iron oxide resulted in superior tumor growth inhibition of liver cancer tumors than the standard formulation Doxil and simultaneously allowed tumor imaging by MRI with higher sensitivity than the commercial contrast agent, Resovist [394].

\section{Conclusions}

In addition to the need for extended blood circulation and stimuli-controlled extravasation to the tumor's niche, multifunctional liposomal nanocarriers must target at least one hallmark of cancer (aberrant cell growth, drug resistance, sustained angiogenesis, and tissue invasion) for enhancement of tumor therapy and/or diagnosis. As described throughout the paper, this requires coordinated action of stealth, targeting, and internalizing moieties to achieve intracellular delivery to cancer cells in tumors. Moreover, combined targeting of tumor cells and related neoangiogenesis is becoming a focus of research that allows destruction of both primary and distant tumor nodules. However, targeted therapies rely on ligands presented by a few types of tumors and must face up to the fact of the heterogeneity of tumor cells and their surface markers $[175,395,396]$. A possible direction may be the coupling of ligands of different natures (antibody, protein, peptides and chimiokine, hormone analogs) to target at least two tumor cell populations for relapse-free cancer therapy and more sensitive malignant lesion detection.

\section{Conflict of Interests}

The authors declare that they have no conflict of interests.

\section{Acknowledgments}

This work was supported by the NIH Grant U54CA151881 to V. P. Torchilin. The authors are grateful to W. C. Hartner for critical review of the paper.

\section{References}

[1] A. D. Bangham, M. M. Standish, and J. C. Watkins, "Diffusion of univalent ions across the lamellae of swollen phospholipids," Journal of Molecular Biology, vol. 13, no. 1, pp. 238-252, 1965.

[2] G. Gregoriadis, "Liposome research in drug delivery: the early days," Journal of Drug Targeting, vol. 16, no. 7-8, pp. 520-524, 2008.

[3] D. J. Porteous, J. R. Dorin, G. McLachlan et al., "Evidence for safety and efficacy of DOTAP cationic liposome mediated 
CFTR gene transfer to the nasal epithelium of patients with cystic fibrosis," Gene Therapy, vol. 4, no. 3, pp. 210-218, 1997.

[4] G. J. Nabel, E. G. Nabel, Z. Y. Yang et al., "Direct gene transfer with DNA-liposome complexes in melanoma: expression, biologic activity, and lack of toxicity in humans," Proceedings of the National Academy of Sciences of the United States of America, vol. 90, no. 23, pp. 11307-11311, 1993.

[5] N. D. James, R. J. Coker, D. Tomlinson et al., "Liposomal doxorubicin (Doxil): an effective new treatment for Kaposi's sarcoma in AIDS," Clinical Oncology, vol. 6, no. 5, pp. 294-296, 1994.

[6] A. Z. Wang, R. Langer, and O. C. Farokhzad, "Nanoparticle delivery of cancer drugs," Annual Review of Medicine, vol. 63, pp. 185-198, 2012.

[7] T. M. Allen and P. R. Cullis, "Liposomal drug delivery systems: from concept to clinical applications," Advanced Drug Delivery Reviews, vol. 65, no. 1, pp. 36-48, 2012, 10.1016/j.addr.2012.09.037.

[8] V. P. Torchilin, "Recent advances with liposomes as pharmaceutical carriers," Nature Reviews Drug Discovery, vol. 4, no. 2, pp. 145-160, 2005.

[9] G. Song, H. Wu, K. Yoshino, and W. C. Zamboni, "Factors affecting the pharmacokinetics and pharmacodynamics of liposomal drugs," Journal of Liposome Research, vol. 22, pp. 177-192, 2012.

[10] A. A. Gabizon, O. Lyass, G. J. Berry, and M. Wildgust, "Cardiac safety of pegylated liposomal doxorubicin (Doxil/Caelyx) demonstrated by endomyocardial biopsy in patients with advanced malignancies," Cancer Investigation, vol. 22, no. 5, pp. 663-669, 2004.

[11] A. Gabizon, R. Catane, B. Uziely et al., "Prolonged circulation time and enhanced accumulation in malignant exudates of doxorubicin encapsulated in polyethylene-glycol coated liposomes," Cancer Research, vol. 54, no. 4, pp. 987-992, 1994.

[12] D. Hanahan and R. A. Weinberg, "Hallmarks of cancer: The next generation," Cell, vol. 144, no. 5, pp. 646-674, 2011.

[13] Y. Barenholz, "Doxil(R)—the first FDA-approved nano-drug: lessons learned," Journal of Controlled Release, vol. 160, pp. 117134, 2012.

[14] S. M. O’Brien, W. Aulitzky, D. Ben Yehuda et al., "Phase II study of marqibo in adult patients with refractory or relapsed philadelphia chromosome negative (Ph-) acute lymphoblastic leukemia (ALL)," Journal of Clinical Oncology, Abstract 6507, 2010, ASCO Annual Meeting 2010.

[15] Q. Zhang, X. E. Huang, and L. L. Gao, "A clinical study on the premedication of paclitaxel liposome in the treatment of solid tumors," Biomedicine and Pharmacotherapy, vol. 63, no. 8, pp. 603-607, 2009.

[16] V. P. Torchilin, "Multifunctional nanocarriers," Advanced Drug Delivery Reviews, vol. 58, no. 14, pp. 1532-1555, 2006.

[17] D. Peer, J. M. Karp, S. Hong, O. C. Farokhzad, R. Margalit, and R. Langer, "Nanocarriers as an emerging platform for cancer therapy," Nature Nanotechnology, vol. 2, no. 12, pp. 751-760, 2007.

[18] Y. Matsumura and H. Maeda, "A new concept for macromolecular therapeutics in cancer chemotherapy: mechanism of tumoritropic accumulation of proteins and the antitumor agent smancs," Cancer Research, vol. 46, no. 12 I, pp. 6387-6392, 1986.

[19] S. Zalipsky, M. Saad, R. Kiwan, E. Ber, N. Yu, and T. Minko, "Antitumor activity of new liposomal prodrug of mitomycin C in multidrug resistant solid tumor: insights of the mechanism of action," Journal of Drug Targeting, vol. 15, no. 7-8, pp. 518-530, 2007.
[20] J. Fang, H. Nakamura, and H. Maeda, “The EPR effect: unique features of tumor blood vessels for drug delivery, factors involved, and limitations and augmentation of the effect," Advanced Drug Delivery Reviews, vol. 63, no. 3, pp. 136-151, 2011.

[21] M. S. Newman, G. T. Colbern, P. K. Working, C. Engbers, and M. A. Amantea, "Comparative pharmacokinetics, tissue distribution, and therapeutic effectiveness of cisplatin encapsulated in long-circulating, pegylated liposomes (SPI-077) in tumorbearing mice," Cancer Chemotherapy and Pharmacology, vol. 43, pp. 1-7, 1999.

[22] H. M. Patel, "Serum opsonins and liposomes: their interaction and opsonophagocytosis," Critical Reviews in Therapeutic Drug Carrier Systems, vol. 9, no. 1, pp. 39-90, 1992.

[23] Y. H. Bae and K. Park, "Targeted drug delivery to tumors: myths, reality and possibility," Journal of Controlled Release, vol. 153, no. 3, pp. 198-205, 2011.

[24] E. J. Feldman, J. E. Lancet, J. E. Kolitz et al., "First-in-man study of CPX-351: a liposomal carrier containing cytarabine and daunorubicin in a fixed 5:1 molar ratio for the treatment of relapsed and refractory acute myeloid leukemia," Journal of Clinical Oncology, vol. 29, no. 8, pp. 979-985, 2011.

[25] G. Batist, K. A. Gelmon, K. N. Chi et al., "Safety, pharmacokinetics, and efficacy of CPX-1 liposome injection in patients with advanced solid tumors," Clinical Cancer Research, vol. 15, no. 2, pp. 692-700, 2009.

[26] A. Santel, M. Aleku, N. Röder et al., "Atu027 prevents pulmonary metastasis in experimental and spontaneous mouse metastasis models," Clinical Cancer Research, vol. 16, no. 22, pp. 5469-5480, 2010.

[27] M. Prados, "A Phase I trial of nanoliposomal CPT-11 (NL CPT-11) in patients with recurrent high-grade gliomas," ClinicalTrials.Gov (NCT00734682), University of California,, San Francisco, Calif, USA.

[28] T. Hamaguchi, Y. Matsumura, Y. Nakanishi et al., "Antitumor effect of MCC-465, pegylated liposomal doxorubicin tagged with newly developed monoclonal antibody $\mathrm{GAH}$, in colorectal cancer xenografts," Cancer Science, vol. 95, no. 7, pp. 608-613, 2004.

[29] K. K. Sankhala, A. C. Mita, R. Adinin et al., "A phase I pharmacokinetic (PK) study of MBP-426, a novel liposome encapsulated oxaliplatin," Journal of Clinical Oncology, vol. 27, Abstract 2535, no. 15s, 2009, ASCO Annual Meeting 2009.

[30] I. SynerGene Therapeutics, "Safety study of infusion of SGT-53 to treat solid tumors," ClinicalTrials.Gov, (NCT00470613).

[31] Celsion, "Phase 3 study of thermoDox with RadioFrequency Ablation (RFA) in treatment of Hepatocellular Carcinoma (HCC)," ClinicalTrials.Gov (NCT00617981).

[32] V. P. Torchilin, "Antinuclear antibodies with nucleosomerestricted specificity for targeted delivery of chemotherapeutic agents," Therapeutic Delivery, vol. 1, no. 2, pp. 257-272, 2010.

[33] J. M. Tuscano, S. M. Martin, Y. Ma, W. Zamboni, and R. T. O'Donnell, "Efficacy, biodistribution, and pharmacokinetics of CD22-targeted pegylated liposomal doxorubicin in a B-cell non-Hodgkin's lymphoma xenograft mouse model," Clinical Cancer Research, vol. 16, no. 10, pp. 2760-2768, 2010.

[34] T. Yang, M. K. Choi, F. D. Cui et al., "Antitumor effect of paclitaxel-loaded PEGylated immunoliposomes against human breast cancer cells," Pharmaceutical Research, vol. 24, no. 12, pp. 2402-2411, 2007.

[35] L. Zhang, H. Gao, L. Chen et al., "tumor targeting of vincristine by mBAFF-modified PEG liposomes in B lymphoma cells," Cancer Letters, vol. 269, no. 1, pp. 26-36, 2008. 
[36] K. Maruyama, "Intracellular targeting delivery of liposomal drugs to solid tumors based on EPR effects," Advanced Drug Delivery Reviews, vol. 63, no. 3, pp. 161-169, 2011.

[37] X. Ying, H. Wen, W. L. Lu et al., "Dual-targeting daunorubicin liposomes improve the therapeutic efficacy of brain glioma in animals," Journal of Controlled Release, vol. 141, no. 2, pp. 183192, 2010.

[38] D. K. Chang, C. T. Lin, C. H. Wu, and H. C. Wu, "A novel peptide enhances therapeutic efficacy of liposomal anti-cancer drugs in mice models of human lung cancer," PLoS ONE, vol. 4, no. 1, article e4171, 2009.

[39] Z. Wang, Y. Yu, W. Dai et al., "The use of a tumor metastasis targeting peptide to deliver doxorubicin-containing liposomes to highly metastatic cancer," Biomaterials, vol. 33, pp. 84518460, 2012.

[40] O. P. Medina, M. Haikola, M. Tahtinen et al., "Liposomal tumor targeting in drug delivery utilizing MMP-2- and MMP9-binding ligands," Journal of Drug Delivery, vol. 2011, Article ID 160515, 9 pages, 2011.

[41] Z. Zhang and J. Yao, "Preparation of irinotecan-loaded folatetargeted liposome for tumor targeting delivery and its antitumor activity," AAPS PharmSciTech, vol. 13, pp. 802-810, 2012.

[42] S. R. Paliwal, R. Paliwal, H. C. Pal et al., "Estrogen-anchored pHsensitive liposomes as nanomodule designed for site-specific delivery of doxorubicin in breast cancer therapy," Molecular Pharmaceutics, vol. 9, pp. 176-186, 2012.

[43] R. Bagari, D. Bansal, A. Gulbake, A. Jain, V. Soni, and S. K. Jain, "Chondroitin sulfate functionalized liposomes for solid tumor targeting," Journal of Drug Targeting, vol. 19, no. 4, pp. 251-257, 2011.

[44] M. L. Immordino, F. Dosio, and L. Cattel, "Stealth liposomes: review of the basic science, rationale, and clinical applications, existing and potential," International journal of nanomedicine, vol. 1, no. 3, pp. 297-315, 2006.

[45] D. C. Drummond, C. O. Noble, M. E. Hayes, J. W. Park, and D. B. Kirpotin, "Pharmacokinetics and in vivo drug release rates in liposomal nanocarrier development," Journal of Pharmaceutical Sciences, vol. 97, no. 11, pp. 4696-4740, 2008.

[46] E. H. Kraut, M. N. Fishman, P. M. Lorusso et al., "Final results of a phase I study of liposome encapsulated SN-38 (LE-SN38): safety, pharmacogenomics, pharmacokinetics, and tumor response," Journal of Clinical Oncology, vol. 23, no. 16S, 2005, ASCO Annual Meeting Proceedings.

[47] K. R. Whiteman, V. Subr, K. Ulbrich, and V. P. Torchilin, "Poly(HPMA)-coated liposomes demonstrate prolonged circulation in mice," Journal of Liposome Research, vol. 11, no. 2-3, pp. 153-164, 2001.

[48] A. L. Klibanov, K. Maruyama, A. M. Beckerleg, V. P. Torchilin, and L. Huang, "Activity of amphipathic poly(ethylene glycol) 5000 to prolong the circulation time of liposomes depends on the liposome size and is unfavorable for immunoliposome binding to target," Biochimica et Biophysica Acta, vol. 1062, no. 2, pp. 142-148, 1991.

[49] Y. Maitani, A. Nakamura, T. Tanaka, and Y. Aso, "Hydration of surfactant-modified and PEGylated cationic cholesterol-based liposomes and corresponding lipoplexes by monitoring a fluorescent probe and the dielectric relaxation time," International Journal of Pharmaceutics, vol. 427, pp. 372-378, 2012.

[50] V. Reshetov, V. Zorin, A. Siupa, M. A. D’Hallewin, F. Guillemin, and L. Bezdetnaya, "Interaction of liposomal formulations of meta-tetra(hydroxyphenyl)chlorin (Temoporfin) with serum proteins: protein binding and liposome destruction," Photochemistry and Photobiology, vol. 88, pp. 1256-1264, 2012.

[51] R. Gref, M. Lück, P. Quellec et al., "'Stealth' corona-core nanoparticles surface modified by polyethylene glycol (PEG): influences of the corona (PEG chain length and surface density) and of the core composition on phagocytic uptake and plasma protein adsorption," Colloids and Surfaces B, vol. 18, no. 3-4, pp. 301-313, 2000.

[52] T. H. Chow, Y. Y. Lin, J. J. Hwang et al., "Improvement of biodistribution and therapeutic index via increase of polyethylene glycol on drug-carrying liposomes in an HT-29/luc xenografted mouse model," Anticancer Research, vol. 29, no. 6, pp. 2111-2120, 2009.

[53] C. M. Lee, Y. Choi, E. J. Huh et al., "Polyethylene glycol (PEG) modified 99mTc-HMPAO-liposome for improving blood circulation and biodistribution: the effect of the extent of PEGylation," Cancer Biotherapy and Radiopharmaceuticals, vol. 20, no. 6, pp. 620-628, 2005.

[54] A. Mori, A. L. Klibanov, V. P. Torchilin, and L. Huang, "Influence of the steric barrier activity of amphipathic poly(ethyleneglycol) and ganglioside GM1 on the circulation time of liposomes and on the target binding of immunoliposomes in vivo," FEBS Letters, vol. 284, no. 2, pp. 263-266, 1991.

[55] R. R. Sawant, R. M. Sawant, A. A. Kale, and V. P. Torchilin, "The architecture of ligand attachment to nanocarriers controls their specific interaction with target cells," Journal of Drug Targeting, vol. 16, no. 7-8, pp. 596-600, 2008.

[56] W. C. Zamboni, S. Strychor, E. Joseph et al., "Plasma, tumor, and tissue disposition of STEALTH liposomal CKD-602 (SCKD602) and nonliposomal CKD-602 in mice bearing A375 human melanoma xenografts," Clinical Cancer Research, vol. 13, no. 23, pp. 7217-7223, 2007.

[57] T. Yang, F. D. Cui, M. K. Choi et al., "Enhanced solubility and stability of PEGylated liposomal paclitaxel: in vitro and in vivo evaluation," International Journal of Pharmaceutics, vol. 338, no. 1-2, pp. 317-326, 2007.

[58] J. I. Yokoe, S. Sakuragi, K. Yamamoto et al., "Albuminconjugated PEG liposome enhances tumor distribution of liposomal doxorubicin in rats," International Journal of Pharmaceutics, vol. 353, no. 1-2, pp. 28-34, 2008.

[59] K. Furumoto, J. I. Yokoe, K. I. Ogawara et al., "Effect of coupling of albumin onto surface of PEG liposome on its in vivo disposition," International Journal of Pharmaceutics, vol. 329, no. 1-2, pp. 110-116, 2007.

[60] K. Yoshino, K. Nakamura, Y. Terajima et al., "Comparative studies of irinotecan-loaded polyethylene glycol-modified liposomes prepared using different PEG-modification methods," Biochimica et Biophysica Acta, vol. 1818, pp. 2901-2907, 2012.

[61] K. Nakamura, K. Yamashita, Y. Itoh, K. Yoshino, S. Nozawa, and H. Kasukawa, "Comparative studies of polyethylene glycolmodified liposomes prepared using different PEG-modification methods," Biochimica et Biophysica Acta, vol. 1818, pp. 28012807, 2012.

[62] Z. Cao, L. Zhang, and S. Jiang, "Superhydrophilic zwitterionic polymers stabilize liposomes," Langmuir, vol. 28, pp. 1162511632, 2012.

[63] K. J. Harrington, S. Mohammadtaghi, P. S. Uster et al., "Effective targeting of solid tumors in patients with locally advanced cancers by radiolabeled pegylated liposomes," Clinical Cancer Research, vol. 7, no. 2, pp. 243-254, 2001. 
[64] S. D. Li and L. Huang, "Pharmacokinetics and biodistribution of nanoparticles," Molecular Pharmaceutics, vol. 5, no. 4, pp. 496504, 2008.

[65] R. B. Campbell, D. Fukumura, E. B. Brown et al., "Cationic charge determines the distribution of liposomes between the vascular and extravascular compartments of tumors," Cancer Research, vol. 62, no. 23, pp. 6831-6836, 2002.

[66] T. S. Levchenko, R. Rammohan, A. N. Lukyanov, K. R. Whiteman, and V. P. Torchilin, "Liposome clearance in mice: the effect of a separate and combined presence of surface charge and polymer coating," International Journal of Pharmaceutics, vol. 240, no. 1-2, pp. 95-102, 2002.

[67] W. Zhao, S. Zhuang, and X. R. Qi, "Comparative study of the in vitro and in vivo characteristics of cationic and neutral liposomes," International Journal of Nanomedicine, vol. 6, pp. 3087-3098, 2011.

[68] S. D. Li, S. Chono, and L. Huang, "Efficient oncogene silencing and metastasis inhibition via systemic delivery of siRNA," Molecular Therapy, vol. 16, no. 5, pp. 942-946, 2008.

[69] E. T. M. Dams, P. Laverman, W. J. G. Oyen et al., "Accelerated blood clearance and altered biodistribution of repeated injections of sterically stabilized liposomes," Journal of Pharmacology and Experimental Therapeutics, vol. 292, no. 3, pp. 1071-1079, 2000.

[70] P. Laverman, M. G. Carstens, O. C. Boerman et al., "Factors affecting the accelerated blood clearance of polyethylene glycolliposomes upon repeated injection," Journal of Pharmacology and Experimental Therapeutics, vol. 298, no. 2, pp. 607-612, 2001.

[71] T. Ishida and H. Kiwada, "Accelerated blood clearance (ABC) phenomenon upon repeated injection of PEGylated liposomes," International Journal of Pharmaceutics, vol. 354, no. 1-2, pp. 5662, 2008.

[72] T. Ishida, M. Ichihara, X. Wang, and H. Kiwada, "Spleen plays an important role in the induction of accelerated blood clearance of PEGylated liposomes," Journal of Controlled Release, vol. 115, no. 3, pp. 243-250, 2006.

[73] X. Wang, T. Ishida, and H. Kiwada, "Anti-PEG IgM elicited by injection of liposomes is involved in the enhanced blood clearance of a subsequent dose of PEGylated liposomes," Journal of Controlled Release, vol. 119, no. 2, pp. 236-244, 2007.

[74] A. Gabizon, R. Chisin, S. Amselem et al., "Pharmacokinetic and imaging studies in patients receiving a formulation of liposomeassociated adriamycin," British Journal of Cancer, vol. 64, no. 6, pp. 1125-1132, 1991.

[75] T. Ishida, S. Kashima, and H. Kiwada, "The contribution of phagocytic activity of liver macrophages to the accelerated blood clearance (ABC) phenomenon of PEGylated liposomes in rats," Journal of Controlled Release, vol. 126, no. 2, pp. 162$165,2008$.

[76] T. Tagami, Y. Uehara, N. Moriyoshi, T. Ishida, and H. Kiwada, "Anti-PEG IgM production by siRNA encapsulated in a PEGylated lipid nanocarrier is dependent on the sequence of the siRNA," Journal of Controlled Release, vol. 151, no. 2, pp. 149-154, 2011.

[77] T. Tagami, K. Nakamura, T. Shimizu, N. Yamazaki, T. Ishida, and H. Kiwada, "CpG motifs in pDNA-sequences increase anti-PEG IgM production induced by PEG-coated pDNAlipoplexes," Journal of Controlled Release, vol. 142, no. 2, pp. 160166,2010

[78] T. Shimizu, M. Ichihara, Y. Yoshioka, T. Ishida, S. Nakagawa, and $\mathrm{H}$. Kiwada, "Intravenous administration of polyethylene glycol-coated (PEGylated) proteins and PEGylated adenovirus elicits an anti-PEG immunoglobulin M response," Biological \& Pharmaceutical Bulletin, vol. 35, pp. 1336-1342, 2012.

[79] T. Daemen, G. Hofstede, M. T. T. Kate, I. A. J. M. BakkerWoudenberg, and G. L. Scherphof, "Liposomal doxorubicininduced toxicity: depletion and impairment of phagocytic activity of liver macrophages," International Journal of Cancer, vol. 61, no. 5, pp. 716-721, 1995.

[80] E. W. M. Van Etten, M. T. T. Kate, S. V. Snijders, and I. A. J. M. Bakker-Woudenberg, "Administration of liposomal agents and blood clearance capacity of the mononuclear phagocyte system," Antimicrobial Agents and Chemotherapy, vol. 42, no. 7, pp. 1677-1681, 1998.

[81] A. Gabizon, R. Isacson, O. Rosengarten, D. Tzemach, H. Shmeeda, and R. Sapir, "An open-label study to evaluate dose and cycle dependence of the pharmacokinetics of pegylated liposomal doxorubicin," Cancer Chemotherapy and Pharmacology, vol. 61, no. 4, pp. 695-702, 2008.

[82] A. Gabizon, D. Tzemach, L. Mak, M. Bronstein, and A. T. Horowitz, "Dose dependency of pharmacokinetics and therapeutic efficacy of pegylated liposomal doxorubicin (DOXIL) in murine models," Journal of Drug Targeting, vol. 10, no. 7, pp. 539548, 2002.

[83] M. Amantea, M. S. Newman, T. M. Sullivan, A. Forrest, and P. K. Working, "Relationship of dose intensity to the induction of palmar-plantar erythrodysesthia by pegylated liposomal doxorubicin in dogs," Human and Experimental Toxicology, vol. 18, no. 1, pp. 17-26, 1999.

[84] A. S. Abu-Lila, N. E. Eldin, M. Ichihara, T. Ishida, and H. Kiwada, "Multiple administration of PEG-coated liposomal oxaliplatin enhances its therapeutic efficacy: a possible mechanism and the potential for clinical application," International Journal of Pharmaceutics, vol. 438, no. 1-2, pp. 176-183, 2012.

[85] C. Li, J. Cao, Y. Wang et al., "Accelerated blood clearance of pegylated liposomal topotecan: influence of polyethylene glycol grafting density and animal species," Journal of Pharmaceutical Sciences, vol. 101, pp. 3864-3876, 2012.

[86] T. Suzuki, M. Ichihara, K. Hyodo et al., "Accelerated blood clearance of PEGylated liposomes containing doxorubicin upon repeated administration to dogs," International Journal of Pharmaceutics, vol. 436, pp. 636-643, 2012.

[87] N. M. La-Beck, B. A. Zamboni, A. Gabizon et al., "Factors affecting the pharmacokinetics of pegylated liposomal doxorubicin in patients," Cancer Chemother Pharmacol, vol. 69, pp. 43-50, 2012.

[88] J. Szebeni, F. Muggia, A. Gabizon, and Y. Barenholz, "Activation of complement by therapeutic liposomes and other lipid excipient-based therapeutic products: prediction and prevention," Advanced Drug Delivery Reviews, vol. 63, pp. 1020-1030, 2011.

[89] J. Szebeni and S. M. Moghimi, "Liposome triggering of innate immune responses: a perspective on benefits and adverse reactions," Journal of Liposome Research, vol. 19, no. 2, pp. 85-90, 2009.

[90] S. M. Moghimi, I. Hamad, T. L. Andresen, K. Jørgensen, and J. Szebeni, "Methylation of the phosphate oxygen moiety of phospholipid- methoxy(polyethylene glycol) conjugate prevents PEGylated liposome-mediated complement activation and anaphylatoxin production," FASEB Journal, vol. 20, no. 14, pp. 2591-2593, 2006. 
[91] I. K. Kwon, S. C. Lee, B. Han, and K. Park, "Analysis on the current status of targeted drug delivery to tumors," Journal of Controlled Release, vol. 164, no. 2, pp. 108-114, 2012.

[92] C. H. Heldin, K. Rubin, K. Pietras, and A. Östman, "High interstitial fluid pressure-an obstacle in cancer therapy," Nature Reviews Cancer, vol. 4, no. 10, pp. 806-813, 2004.

[93] A. J. Primeau, A. Rendon, D. Hedley, L. Lilge, and I. F. Tannock, "The distribution of the anticancer drug doxorubicin in relation to blood vessels in solid tumors," Clinical Cancer Research, vol. 11, no. 24, pp. 8782-8788, 2005.

[94] F. Yuan, M. Leunig, S. K. Huang, D. A. Berk, D. Papahadjopoulos, and R. K. Jain, "Microvascular permeability and interstitial penetration of sterically stabilized (stealth) liposomes in a human tumor xenograft," Cancer Research, vol. 54, no. 13, pp. 3352-3356, 1994.

[95] M. J. Parr, D. Masin, P. R. Cullis, and M. B. Bally, "Accumulation of liposomal lipid and encapsulated doxorubicin in murine Lewis Lung carcinoma: the lack of beneficial effects by coating liposomes with poly(ethylene glycol)," Journal of Pharmacology and Experimental Therapeutics, vol. 280, no. 3, pp. 1319-1327, 1997.

[96] T. M. Allen, D. R. Mumbengegwi, and G. J. R. Charrois, "AntiCD19-targeted liposomal doxorubicin improves the therapeutic efficacy in murine B-cell lymphoma and ameliorates the toxicity of liposomes with varying drug release rates," Clinical Cancer Research, vol. 11, no. 9, pp. 3567-3573, 2005.

[97] R. Wang, R. Xiao, Z. Zeng, L. Xu, and J. Wang, "Application of poly(ethylene glycol)-distearoylphosphatidylethanolamine (PEG-DSPE) block copolymers and their derivatives as nanomaterials in drug delivery," International Journal of Nanomedicine, vol. 7, pp. 4185-4198, 2012.

[98] D. B. Kirpotin, D. C. Drummond, Y. Shao et al., "Antibody targeting of long-circulating lipidic nanoparticles does not increase tumor localization but does increase internalization in animal models," Cancer Research, vol. 66, no. 13, pp. 6732-6740, 2006.

[99] D. W. Bartlett, H. Su, I. J. Hildebrandt, W. A. Weber, and M. E. Davis, "Impact of tumor-specific targeting on the biodistribution and efficacy of siRNA nanoparticles measured by multimodality in vivo imaging," Proceedings of the National Academy of Sciences of the United States of America, vol. 104, no. 39, pp. 15549-15554, 2007.

[100] K. M. Laginha, E. H. Moase, N. Yu, A. Huang, and T. M. Allen, "Bioavailability and therapeutic efficacy of HER2 scFvtargeted liposomal doxorubicin in a murine model of HER2overexpressing breast cancer," Journal of Drug Targeting, vol. 16, no. 7-8, pp. 605-610, 2008.

[101] P. Sapra, E. H. Moase, J. Ma, and T. M. Allen, "Improved therapeutic responses in a xenograft model of human B lymphoma (Namalwa) for liposomal vincristine versus liposomal doxorubicin targeted via anti-CD19 IgG2a or Fab/ fragments," Clinical Cancer Research, vol. 10, no. 3, pp. 1100-1111, 2004.

[102] T. A. Elbayoumi and V. P. Torchilin, "tumor-targeted nanomedicines: enhanced antitumor efficacy in vivo of doxorubicin-loaded, long-circulating liposomes modified with cancer-specific monoclonal antibody," Clinical Cancer Research, vol. 15, no. 6, pp. 1973-1980, 2009.

[103] X. Li, L. Ding, Y. Xu, Y. Wang, and Q. Ping, "Targeted delivery of doxorubicin using stealth liposomes modified with transferrin," International Journal of Pharmaceutics, vol. 373, no. 1-2, pp. 116123, 2009.
[104] A. B. Madhankumar, B. Slagle-Webb, X. Wang et al., "Efficacy of interleukin-13 receptor-targeted liposomal doxorubicin in the intracranial brain tumor model," Molecular Cancer Therapeutics, vol. 8, no. 3, pp. 648-654, 2009.

[105] Y. Iwase and Y. Maitani, “Octreotide-targeted liposomes loaded with CPT-11 enhanced cytotoxicity for the treatment of medullary thyroid carcinoma," Molecular Pharmaceutics, vol. 8, no. 2, pp. 330-337, 2011.

[106] J. Zhang, W. Jin, X. Wang, J. Wang, X. Zhang, and Q. Zhang, "A novel octreotide modified lipid vesicle improved the anticancer efficacy of doxorubicin in somatostatin receptor 2 positive tumor models," Molecular Pharmaceutics, vol. 7, no. 4, pp. 1159$1168,2010$.

[107] M. Saad, O. B. Garbuzenko, E. Ber et al., "Receptor targeted polymers, dendrimers, liposomes: which nanocarrier is the most efficient for tumor-specific treatment and imaging?" Journal of Controlled Release, vol. 130, no. 2, pp. 107-114, 2008.

[108] F. Danhier, A. L. Breton, and V. Preat, "RGD-based strategies to target alpha(v) beta(3) integrin in cancer therapy and diagnosis," Molecular Pharmaceutics, vol. 9, no. 11, pp. 29612973, 2012.

[109] H. Zhao, J. C. Wang, Q. S. Sun, C. L. Luo, and Q. Zhang, "RGD-based strategies for improving antitumor activity of paclitaxel-loaded liposomes in nude mice xenografted with human ovarian cancer," Journal of Drug Targeting, vol. 17, no. 1, pp. 10-18, 2009.

[110] X. B. Xiong, Y. Huang, W. L. Lu et al., "Intracellular delivery of doxorubicin with RGD-modified sterically stabilized liposomes for an improved antitumor efficacy: in vitro and in vivo," Journal of Pharmaceutical Sciences, vol. 94, no. 8, pp. 1782-1793, 2005.

[111] K. Riviere, Z. Huang, K. Jerger, N. MacAraeg, and F. C. Szoka, "Antitumor effect of folate-targeted liposomal doxorubicin in KB tumor-bearing mice after intravenous administration," Journal of Drug Targeting, vol. 19, no. 1, pp. 14-24, 2011.

[112] S. R. Paliwal, R. Paliwal, N. Mishra, A. Mehta, and S. P. Vyas, "A novel cancer targeting approach based on estrone anchored stealth liposome for site-specific breast cancer therapy," Current Cancer Drug Targets, vol. 10, no. 3, pp. 343-353, 2010.

[113] S. D. Li, S. Chono, and L. Huang, "Efficient gene silencing in metastatic tumor by siRNA formulated in surface-modified nanoparticles," Journal of Controlled Release, vol. 126, no. 1, pp. 77-84, 2008.

[114] J. S. Thomann, B. Heurtault, S. Weidner et al., "Antitumor activity of liposomal ErbB2/HER2 epitope peptide-based vaccine constructs incorporating TLR agonists and mannose receptor targeting," Biomaterials, vol. 32, no. 20, pp. 4574-4583, 2011.

[115] Y. Ikehara, N. Shiuchi, S. Kabata-Ikehara et al., "Effective induction of anti-tumor immune responses with oligomannosecoated liposome targeting to intraperitoneal phagocytic cells," Cancer Letters, vol. 260, no. 1-2, pp. 137-145, 2008.

[116] X. Zhou, M. Zhang, B. Yung et al., "Lactosylated liposomes for targeted delivery of doxorubicin to hepatocellular carcinoma," International Journal of Nanomedicine, vol. 7, pp. 5465-5474, 2012.

[117] G. Blume, G. Cevc, M. D. J. A. Crommelin, I. A. J. M. Bakker-Woudenberg, C. Kluft, and G. Storm, "Specific targeting with poly(ethylene glycol)-modified liposomes: coupling of homing devices to the ends of the polymeric chains combines effective target binding with long circulation times," Biochimica et Biophysica Acta, vol. 1149, no. 1, pp. 180-184, 1993.

[118] A. Gabizon, A. T. Horowitz, D. Goren et al., "Targeting folate receptor with folate linked to extremities of poly(ethylene 
glycol)-grafted liposomes: in vitro studies," Bioconjugate Chemistry, vol. 10, no. 2, pp. 289-298, 1999.

[119] K. Loomis, B. Smith, Y. Feng et al., "Specific targeting to B cells by lipid-based nanoparticles conjugated with a novel CD22ScFv," Experimental and Molecular Pathology, vol. 88, no. 2, pp. 238-249, 2010.

[120] H. Hatakeyama, H. Akita, E. Ishida et al., "tumor targeting of doxorubicin by anti-MT1-MMP antibody-modified PEG liposomes," International Journal of Pharmaceutics, vol. 342, no. 1-2, pp. 194-200, 2007.

[121] P. Simard and J. C. Leroux, "In vivo evaluation of $\mathrm{pH}$-sensitive polymer-based immunoliposomes targeting the CD33 antigen," Molecular Pharmaceutics, vol. 7, no. 4, pp. 1098-1107, 2010.

[122] A. Yamada, Y. Taniguchi, K. Kawano, T. Honda, Y. Hattori, and Y. Maitani, "Design of folate-linked liposomal doxorubicin to its antitumor effect in mice," Clinical Cancer Research, vol. 14, no. 24, pp. 8161-8168, 2008.

[123] K. H. Chuang, H. E. Wang, F. M. Chen et al., "Endocytosis of PEGylated agents enhances cancer imaging and anticancer efficacy," Molecular Cancer Therapeutics, vol. 9, pp. 1903-1912, 2010.

[124] N. Kamaly, Z. Xiao, P. M. Valencia, A. F. Radovic-Moreno, and O. C. Farokhzad, "Targeted polymeric therapeutic nanoparticles: design, development and clinical translation," Chemical Society Reviews, vol. 41, pp. 2971-3010, 2012.

[125] B. Frisch, F. S. Hassane, and F. Schuber, "Conjugation of ligands to the surface of preformed liposomes by click chemistry," Methods in Molecular Biology, vol. 605, pp. 267-277, 2010.

[126] F. Schuber, F. S. Hassane, and B. Frisch, "Coupling of peptides to the surface of liposomes-Application to liposome-based synthetic vaccines," in Liposome Technology, G. Gregoriadis, Ed., pp. 111-130, Informa Healthcare, New York, NY, USA, 3rd edition, 2007.

[127] A. S. Manjappa, K. R. Chaudhari, M. P. Venkataraju et al., "Antibody derivatization and conjugation strategies: application in preparation of stealth immunoliposome to target chemotherapeutics to tumor," Journal of Controlled Release, vol. 150, no. 1, pp. 2-22, 2011.

[128] W. Tai, R. Mahato, and K. Cheng, "The role of HER2 in cancer therapy and targeted drug delivery," Journal of Controlled Release, vol. 146, no. 3, pp. 264-275, 2010.

[129] M. F. Press, C. Cordon-Cardo, and D. J. Slamon, "Expression of the HER-2/neu proto-oncogene in normal human adult and fetal tissues," Oncogene, vol. 5, no. 7, pp. 953-962, 1990.

[130] S. Erdogan, Z. O. Medarova, A. Roby, A. Moore, and V. P. Torchilin, "Enhanced tumor MR imaging with gadoliniumloaded polychelating polymer-containing tumor-targeted liposomes," Journal of Magnetic Resonance Imaging, vol. 27, no. 3, pp. 574-580, 2008.

[131] P. Sapra and T. M. Allen, "Ligand-targeted liposomal anticancer drugs," Progress in Lipid Research, vol. 42, no. 5, pp. 439-462, 2003.

[132] X. Qi, Z. Chu, Y. Y. Mahller, K. F. Stringer, D. P. Witte, and T. P. Cripe, "Cancer-selective targeting and cytotoxicity by liposomal-coupled lysosomal saposin C protein," Clinical Cancer Research, vol. 15, no. 18, pp. 5840-5851, 2009.

[133] A. M. Vaccaro, M. Motta, M. Tatti et al., "Saposin C mutations in Gaucher disease patients resulting in lysosomal lipid accumulation, saposin $\mathrm{C}$ deficiency, but normal prosaposin processing and sorting," Human molecular genetics, vol. 19, no. 15, pp. 29872997, 2010.
[134] X. Qi and G. A. Grabowski, "Differential membrane interactions of saposins A and C: implications for the functional specificity," Journal of Biological Chemistry, vol. 276, no. 29, pp. 27010-27017, 2001.

[135] T. R. Daniels, T. Delgado, J. A. Rodriguez, G. Helguera, and M. L. Penichet, "The transferrin receptor part I: biology and targeting with cytotoxic antibodies for the treatment of cancer," Clinical Immunology, vol. 121, no. 2, pp. 144-158, 2006.

[136] T. R. Daniels, T. Delgado, G. Helguera, and M. L. Penichet, "The transferrin receptor part II: targeted delivery of therapeutic agents into cancer cells," Clinical Immunology, vol. 121, no. 2, pp. 159-176, 2006.

[137] T. R. Pearce, K. Shroff, and E. Kokkoli, "Peptide targeted lipid nanoparticles for anticancer drug delivery," Advanced Materials, vol. 24, pp. 3803-3822, 2012.

[138] K. Wang, M. H. Na, A. S. Hoffman et al., "In situ dose amplification by apoptosis-targeted drug delivery," Journal of Controlled Release, vol. 154, pp. 214-217, 2011.

[139] L. C. Sun and D. H. Coy, "Somatostatin receptor-targeted anticancer therapy," Current Drug Delivery, vol. 8, no. 1, pp. 2-10, 2011.

[140] Z. Han, A. Fu, H. Wang et al., "Noninvasive assessment of cancer response to therapy," Nature Medicine, vol. 14, no. 3, pp. 343-349, 2008.

[141] A. Lowery, H. Onishko, D. E. Hallahan, and Z. Han, "tumortargeted delivery of liposome-encapsulated doxorubicin by use of a peptide that selectively binds to irradiated tumors," Journal of Controlled Release, vol. 150, no. 1, pp. 117-124, 2011.

[142] X. He, M. H. Na, J. S. Kim et al., "A novel peptide probe for imaging and targeted delivery of liposomal doxorubicin to lung tumor," Molecular Pharmaceutics, vol. 8, no. 2, pp. 430-438, 2011.

[143] T. Wang, G. G. D’souza, D. Bedi et al., "Enhanced binding and killing of target tumor cells by drug-loaded liposomes modified with tumor-specific phage fusion coat protein," Nanomedicine, vol. 5, no. 4, pp. 563-574, 2010.

[144] T. Wang, N. Kulkarni, D. Bedi et al., "In vitro optimization of liposomal nanocarriers prepared from breast tumor cell specific phage fusion protein," Journal of Drug Targeting, vol. 19, pp. 597605, 2011.

[145] S. S. Dharap, Y. Wang, P. Chandna et al., "tumor-specific targeting of an anticancer drug delivery system by LHRH peptide," Proceedings of the National Academy of Sciences of the United States of America, vol. 102, no. 36, pp. 12962-12967, 2005.

[146] K. Kessenbrock, V. Plaks, and Z. Werb, "Matrix metalloproteinases: regulators of the tumor microenvironment," Cell, vol. 141, no. 1, pp. 52-67, 2010.

[147] P. C. Brooks, S. Silletti, T. L. Von Schalscha, M. Friedlander, and D. A. Cheresh, "Disruption of angiogenesis by PEX, a noncatalytic metalloproteinase fragment with integrin binding activity," Cell, vol. 92, no. 3, pp. 391-400, 1998.

[148] E. Koivunen, W. Arap, H. Valtanen et al., "tumor targeting with a selective gelatinase inhibitor," Nature Biotechnology, vol. 17, no. 8, pp. 768-774, 1999.

[149] L. E. Kelemen, "The role of folate receptor $\alpha$ in cancer development, progression and treatment: cause, consequence or innocent bystander?" International Journal of Cancer, vol. 119, no. 2, pp. 243-250, 2006.

[150] P. S. Low, W. A. Henne, and D. D. Doorneweerd, "Discovery and development of folic-acid-based receptor targeting for imaging and therapy of cancer and inflammatory diseases," Accounts of Chemical Research, vol. 41, no. 1, pp. 120-129, 2008. 
[151] S. Lee, J. Kim, G. Shim et al., “Tetraiodothyroacetic acid-tagged liposomes for enhanced delivery of anticancer drug to tumor tissue via integrin receptor," Journal of Controlled Release, vol. 164, no. 2, pp. 213-220, 2012.

[152] Y. Qin, Q. G. Song, Z. R. Zhang et al., "Ovarian tumor targeting of docetaxel-loaded liposomes mediated by luteinizing hormone-releasing hormone analogues: in vivo distribution in nude mice," Arzneimittel-Forschung/Drug Research, vol. 58, no. 10, pp. 529-534, 2008.

[153] T. Terada, M. Mizobata, S. Kawakami, Y. Yabe, F. Yamashita, and M. Hashida, "Basic fibroblast growth factor-binding peptide as a novel targeting ligand of drug carrier to tumor cells," Journal of Drug Targeting, vol. 14, no. 8, pp. 536-545, 2006.

[154] X. Chen, X. Wang, Y. Wang et al., "Improved tumor-targeting drug delivery and therapeutic efficacy by cationic liposome modified with truncated bFGF peptide," Journal of Controlled Release, vol. 145, no. 1, pp. 17-25, 2010.

[155] Y. Tan, M. Whitmore, S. Li, P. Frederik, and L. Huang, "LPD nanoparticles-novel nonviral vector for efficient gene delivery," Methods in molecular medicine, vol. 69, pp. 73-81, 2002.

[156] B. J. Vilner, C. S. John, and W. D. Bowen, "Sigma-1 and sigma-2 receptors are expressed in a wide variety of human and rodent tumor cell lines," Cancer Research, vol. 55, no. 2, pp. 408-413, 1995.

[157] R. Banerjee, P. Tyagi, S. Li, and L. Huang, "Anisamide-targeted stealth liposomes: a potent carrier for targeting doxorubicin to human prostate cancer cells," International Journal of Cancer, vol. 112, no. 4, pp. 693-700, 2004.

[158] D. Spitzer, P. O. Simon Jr., H. Kashiwagi et al., "Use of multifunctional sigma-2 receptor ligand conjugates to trigger cancer-selective cell death signaling," Cancer Research, vol. 72, pp. 201-209, 2012.

[159] P. Boyle and B. Levin, Eds., World Cancer Report, International Agency for Research on Cancer, Lyon, France, 2008.

[160] R. Paolinelli, M. Corada, F. Orsenigo, and E. Dejana, "The molecular basis of the blood brain barrier differentiation and maintenance. Is it still a mystery?” Pharmacological Research, vol. 63, no. 3, pp. 165-171, 2011.

[161] W. Debinski, B. Slagle, D. M. Gibo, S. K. Powers, and G. Y. Gillespie, "Expression of a restrictive receptor for interleukin 13 is associated with glial transformation," Journal of NeuroOncology, vol. 48, no. 2, pp. 103-111, 2000.

[162] J. Du, W. L. Lu, X. Ying et al., "Dual-targeting topotecan liposomes modified with tamoxifen and wheat germ agglutinin significantly improve drug transport across the blood-brain barrier and survival of brain tumor-bearing animals," Molecular Pharmaceutics, vol. 6, no. 3, pp. 905-917, 2009.

[163] X. Ying, H. Wen, H. J. Yao et al., "Pharmacokinetics and tissue distribution of dual-targeting daunorubicin liposomes in mice," Pharmacology, vol. 87, no. 1-2, pp. 105-114, 2011.

[164] W. Gong, Z. Wang, N. Liu et al., "Improving efficiency of adriamycin crossing blood brain barrier by combination of thermosensitive liposomes and hyperthermia," Biological and Pharmaceutical Bulletin, vol. 34, no. 7, pp. 1058-1064, 2011.

[165] F. Y. Yang and P. Y. Lee, "Efficiency of drug delivery enhanced by acoustic pressure during blood-brain barrier disruption induced by focused ultrasound," International Journal of Nanomedicine, vol. 7, pp. 2573-2582, 2012.

[166] F. Y. Yang, H. E. Wang, R. S. Liu et al., "Pharmacokinetic analysis of (111)in-labeled liposomal Doxorubicin in murine glioblastoma after blood-brain barrier disruption by focused ultrasound," PLoS One, vol. 7, article e45468, 2012.
[167] G. Bergers and L. E. Benjamin, "tumorigenesis and the angiogenic switch," Nature Reviews Cancer, vol. 3, no. 6, pp. 401-410, 2003.

[168] S. M. Weis and D. A. Cheresh, "tumor angiogenesis: molecular pathways and therapeutic targets," Nature Medicine, vol. 17, pp. 1359-1370, 2011.

[169] Q. Chen, A. Krol, A. Wright, D. Needham, M. W. Dewhirst, and F. Yuan, "tumor microvascular permeability is a key determinant for antivascular effects of doxorubicin encapsulated in a temperature sensitive liposome," International Journal of Hyperthermia, vol. 24, no. 6, pp. 475-482, 2008.

[170] K. I. Ogawara, K. Un, K. Minato, K. I. Tanaka, K. Higaki, and T. Kimura, "Determinants for in vivo anti-tumor effects of PEG liposomal doxorubicin: importance of vascular permeability within tumors," International Journal of Pharmaceutics, vol. 359, no. 1-2, pp. 234-240, 2008.

[171] A. S. Abu Lila, H. Matsumoto, Y. Doi, H. Nakamura, T. Ishida, and H. Kiwada, "tumor-type-dependent vascular permeability constitutes a potential impediment to the therapeutic efficacy of liposomal oxaliplatin," European Journal of Pharmaceutics and Biopharmaceutics, vol. 81, pp. 524-531, 2012.

[172] R. B. Campbell, B. Ying, G. M. Kuesters, and R. Hemphill, "Fighting cancer: from the bench to bedside using second generation cationic liposomal therapeutics," Journal of Pharmaceutical Sciences, vol. 98, no. 2, pp. 411-429, 2009.

[173] D. C. Litzinger, A. M. J. Buiting, N. Van Rooijen, and L. Huang, "Effect of liposome size on the circulation time and intraorgan distribution of amphipathic poly(ethylene glycol)-containing liposomes," Biochimica et Biophysica Acta, vol. 1190, no. 1, pp. 99-107, 1994.

[174] D. C. Drummond, C. O. Noble, Z. Guo, K. Hong, J. W. Park, and D. B. Kirpotin, "Development of a highly active nanoliposomal irinotecan using a novel intraliposomal stabilization strategy," Cancer Research, vol. 66, no. 6, pp. 3271-3277, 2006.

[175] S. Taurin, H. Nehoff, and K. Greish, "Anticancer nanomedicine and tumor vascular permeability, where is the missing link?" Journal of Controlled Release, vol. 164, no. 3, pp. 265-275, 2012.

[176] R. Carlisle, L. W. Seymour, and C. C. Coussios, "Targeting of liposomes via PSGL1 for enhanced tumor accumulation," Pharmaceutical Research, vol. 30, no. 2, pp. 352-361, 2012.

[177] L. Vellon, J. A. Menendez, and R. Lupu, “ $\alpha \mathrm{v} \beta 3$ integrin regulates heregulin (HRG)-induced cell proliferation and survival in breast cancer," Oncogene, vol. 24, no. 23, pp. 3759-3773, 2005.

[178] S. Meng, B. Su, W. Li et al., "Integrin-targeted paclitaxel nanoliposomes for tumor therapy," Medical Oncology, vol. 28, pp. 1180-1187, 2011.

[179] A. Accardo, G. Salsano, A. Morisco et al., "Peptide-modified liposomes for selective targeting of bombesin receptors overexpressed by cancer cells: a potential theranostic agent," International Journal of Nanomedicine, vol. 7, pp. 2007-2017, 2012.

[180] F. Doñate, G. C. Parry, Y. Shaked et al., "Pharmacology of the novel antiangiogenic peptide ATN-161 (Ac-PHSCN-NH 2): observation of a U-shaped dose-response curve in several preclinical models of angiogenesis and tumor growth," Clinical Cancer Research, vol. 14, no. 7, pp. 2137-2144, 2008.

[181] W. Dai, T. Yang, Y. Wang et al., "Peptide PHSCNK as an integrin alpha(5)beta(1) antagonist targets stealth liposomes to integrinoverexpressing melanoma," Nanomedicine, vol. 8, pp. 1152-1161, 2012. 
[182] F. Pastorino, D. Di Paolo, F. Piccardi et al., "Enhanced antitumor efficacy of clinical-grade vasculature-targeted liposomal doxorubicin," Clinical Cancer Research, vol. 14, no. 22, pp. 73207329, 2008.

[183] K. Takara, H. Hatakeyama, G. Kibria, N. Ohga, K. Hida, and H. Harashima, "Size-controlled, dual-ligand modified liposomes that target the tumor vasculature show promise for use in drugresistant cancer therapy," Journal of Controlled Release, vol. 162, pp. 225-232, 2012.

[184] G. Colombo, F. Curnis, G. M. S. De Mori et al., "Structureactivity relationships of linear and cyclic peptides containing the NGR tumor-homing motif," Journal of Biological Chemistry, vol. 277, no. 49, pp. 47891-47897, 2002.

[185] G. Thurston, J. W. McLean, M. Rizen et al., "Cationic liposomes target angiogenic endothelial cells in tumors and chronic inflammation in mice," Journal of Clinical Investigation, vol. 101, pp. 1401-1413, 1998.

[186] S. Ran and P. E. Thorpe, "Phosphatidylserine is a marker of tumor vasculature and a potential target for cancer imaging and therapy," International Journal of Radiation Oncology Biology Physics, vol. 54, no. 5, pp. 1479-1484, 2002.

[187] A. S. Abu Lila, S. Kizuki, Y. Doi, T. Suzuki, T. Ishida, and H. Kiwada, "Oxaliplatin encapsulated in PEG-coated cationic liposomes induces significant tumor growth suppression via a dual-targeting approach in a murine solid tumor model," Journal of Controlled Release, vol. 137, no. 1, pp. 8-14, 2009.

[188] T. Tagami, T. Suzuki, M. Matsunaga et al., "Anti-angiogenic therapy via cationic liposome-mediated systemic siRNA delivery," International Journal of Pharmaceutics, vol. 422, pp. 280289, 2012.

[189] T. Asai, Y. Suzuki, S. Matsushita et al., "Disappearance of the angiogenic potential of endothelial cells caused by Argonaute2 knockdown," Biochemical and Biophysical Research Communications, vol. 368, no. 2, pp. 243-248, 2008.

[190] M. E. Eichhorn, S. Becker, S. Strieth et al., "Paclitaxel encapsulated in cationic lipid complexes (MBT-0206) impairs functional tumor vascular properties as detected by dynamic contrast enhanced magnetic resonance imaging," Cancer Biology and Therapy, vol. 5, no. 1, pp. 89-96, 2006.

[191] M. Schmitt-Sody, S. Strieth, S. Krasnici et al., "Neovascular targeting therapy: paclitaxel encapsulated in cationic liposomes improves antitumoral efficacy," Clinical Cancer Research, vol. 9, no. 6, pp. 2335-2341, 2003.

[192] C. Bode, L. Trojan, C. Weiss et al., "Paclitaxel encapsulated in cationic liposomes: a new option for neovascular targeting for the treatment of prostate cancer," Oncology Reports, vol. 22, no. 2, pp. 321-326, 2009.

[193] A. P. Mann, R. C. Bhavane, A. Somasunderam et al., "Thioaptamer conjugated liposomes for tumor vasculature targeting," Oncotarget, vol. 2, pp. 298-304, 2011.

[194] J. Hamzah, J. G. Altin, T. Herringson et al., "Targeted liposomal delivery of TLR9 ligands activates spontaneous antitumor immunity in an autochthonous cancer model," Journal of Immunology, vol. 183, no. 2, pp. 1091-1098, 2009.

[195] T. P. Herringson and J. G. Altin, "Increasing the antitumor efficacy of doxorubicin-loaded liposomes with peptides anchored via a chelator lipid," Journal of Drug Targeting, vol. 19, pp. 681689, 2011.

[196] D. K. Chang, C. Y. Chiu, S. Y. Kuo et al., "Antiangiogenic targeting liposomes increase therapeutic efficacy for solid tumors," Journal of Biological Chemistry, vol. 284, no. 19, pp. 12905-12916, 2009.
[197] S. Marchiò, J. Lahdenranta, R. O. Schlingemann et al., "Aminopeptidase A is a functional target in angiogenic blood vessels," Cancer Cell, vol. 5, no. 2, pp. 151-162, 2004.

[198] M. Loi, S. Marchiò, P. Becherini et al., "Combined targeting of perivascular and endothelial tumor cells enhances anti-tumor efficacy of liposomal chemotherapy in neuroblastoma," Journal of Controlled Release, vol. 145, no. 1, pp. 66-73, 2010.

[199] J. E. Gershenwald and I. J. Fidler, "Cancer: targeting lymphatic metastasis," Science, vol. 296, no. 5574, pp. 1811-1812, 2002.

[200] A. J. Cochran, R. R. Huang, J. Lee, E. Itakura, S. P. L. Leong, and R. Essner, "Tumour-induced immune modulation of sentinel lymph nodes," Nature Reviews Immunology, vol. 6, no. 11, pp. 659-670, 2006.

[201] P. Laakkonen, M. E. Åkerman, H. Biliran et al., "Antitumor activity of a homing peptide that targets tumor lymphatics and tumor cells," Proceedings of the National Academy of Sciences of the United States of America, vol. 101, no. 25, pp. 9381-9386, 2004.

[202] P. Laakkonen, K. Porkka, J. A. Hoffman, and E. Ruoslahti, “A tumor-homing peptide with a targeting specificity related to lymphatic vessels," Nature Medicine, vol. 8, no. 7, pp. 751-755, 2002.

[203] Z. Yan, C. Zhan, Z. Wen et al., "LyP-1-conjugated doxorubicinloaded liposomes suppress lymphatic metastasis by inhibiting lymph node metastases and destroying tumor lymphatics2011," Nanotechnology, vol. 22, no. 41, article 415103.

[204] Z. Yan, F. Wang, Z. Wen et al., "LyP-1-conjugated PEGylated liposomes: a carrier system for targeted therapy of lymphatic metastatic tumor," Journal of Controlled Release, vol. 157, pp. 118125,2012

[205] T. P. Herringson and J. G. Altin, "Effective tumor targeting and enhanced anti-tumor effect of liposomes engrafted with peptides specific for tumor lymphatics and vasculature," International Journal of Pharmaceutics, vol. 411, no. 1-2, pp. 206-214, 2011.

[206] Y. Murase, T. Asai, Y. Katanasaka et al., "A novel DDS strategy, "dual-targeting", and its application for antineovascular therapy," Cancer Letters, vol. 287, no. 2, pp. 165-171, 2010.

[207] S. Meng, B. Su, W. Li et al., "Enhanced antitumor effect of novel dual-targeted paclitaxel liposomes," Nanotechnology, vol. 21, no. 41, Article ID 415103, 2010.

[208] S. Valastyan and R. A. Weinberg, "tumor metastasis: molecular insights and evolving paradigms," Cell, vol. 147, pp. 275-292, 2011.

[209] L. Borsig, R. Wong, J. Feramisco, D. R. Nadeau, N. M. Varki, and A. Varki, "Heparin and cancer revisited: mechanistic connections involving platelets, P-selectin, carcinoma mucins, and tumor metastasis," Proceedings of the National Academy of Sciences of the United States of America, vol. 98, no. 6, pp. 33523357, 2001.

[210] D. Buergy, F. Wenz, C. Groden, and M. A. Brockmann, "tumorplatelet interaction in solid tumors," International Journal of Cancer, vol. 130, pp. 2747-2760, 2012.

[211] J. Wenzel, R. Zeisig, and I. Fichtner, "Inhibition of breast cancer metastasis by dual liposomes to disturb complex formation," International Journal of Pharmaceutics, vol. 370, no. 1-2, pp. 121$128,2009$.

[212] W. Yang, D. Luo, S. Wang et al., "TMTP1, a novel tumorhoming peptide specifically argeting metastasis," Clinical Cancer Research, vol. 14, no. 17, pp. 5494-5502, 2008. 
[213] M. Zigler, T. Kamiya, E. C. Brantley, G. J. Villares, and M. BarEli, "PAR-1 and thrombin: the ties that bind the microenvironment to melanoma metastasis," Cancer Research, vol. 71, pp. 6561-6566, 2011.

[214] G. J. Villares, M. Zigler, H. Wang et al., "Targeting melanoma growth and metastasis with systemic delivery of liposomeincorporated protease-activated receptor-1 small interfering RNA," Cancer Research, vol. 68, no. 21, pp. 9078-9086, 2008.

[215] T. R. Petersen, N. Dickgreber, and I. F. Hermans, "tumor antigen presentation by dendritic cells," Critical Reviews in Immunology, vol. 30, no. 4, pp. 345-386, 2010.

[216] H. Ueno, E. Klechevsky, N. Schmitt et al., "Targeting human dendritic cell subsets for improved vaccines," Seminars in Immunology, vol. 23, pp. 21-27, 2011.

[217] L. C. Bonifaz, D. P. Bonnyay, A. Charalambous et al., "In vivo targeting of antigens to maturing dendritic cells via the DEC-205 receptor improves T cell vaccination," Journal of Experimental Medicine, vol. 199, no. 6, pp. 815-824, 2004.

[218] A. Faham and J. G. Altin, "Ag-bearing liposomes engrafted with peptides that interact with CD1lc/CD18 induce potent Ag-specific and antitumor immunity," International Journal of Cancer, vol. 129, no. 6, pp. 1391-1403, 2011.

[219] A. Faham, D. Bennett, and J. G. Altin, "Liposomal Ag engrafted with peptides of sequence derived from HMGB1 induce potent Ag-specific and anti-tumour immunity," Vaccine, vol. 27, no. 42, pp. 5846-5854, 2009.

[220] E. Ihanus, L. M. Uotila, A. Toivanen, M. Varis, and C. G. Gahmberg, "Red-cell ICAM-4 is a ligand for the monocyte/macrophage integrin CD11c/CD18: characterization of the binding sites on ICAM-4," Blood, vol. 109, no. 2, pp. 802-810, 2007.

[221] A. Faham, T. Herringson, C. Parish, A. Suhrbier, A. A. Khromykh, and J. G. Altin, "pDNA-lipoplexes engrafted with flagellin-related peptide induce potent immunity and antitumour effects," Vaccine, vol. 29, pp. 6911-6919, 2011.

[222] A. Faham and J. G. Altin, "Antigen-containing liposomes engrafted with flagellin-related peptides are effective vaccines that can induce potent antitumor immunity and immunotherapeutic effect," Journal of Immunology, vol. 185, no. 3, pp. 1744$1754,2010$.

[223] F. Perche, T. Benvegnu, M. Berchel et al., "Enhancement of dendritic cells transfection in vivo and of vaccination against B16F10 melanoma with mannosylated histidylated lipopolyplexes loaded with tumor antigen messenger RNA," Nanomedicine, vol. 7, no. 4, pp. 445-453, 2011.

[224] P. Midoux and M. Monsigny, "Efficient gene transfer by histidylated polylysine/pDNA complexes," Bioconjugate Chemistry, vol. 10, no. 3, pp. 406-411, 1999.

[225] M. Mével, G. Breuzard, J. J. Yaouanc et al., "Synthesis and transfection activity of new cationic phosphoramidate lipids: high efficiency of an imidazolium derivative," ChemBioChem, vol. 9, no. 9, pp. 1462-1471, 2008.

[226] D. S. Watson, A. N. Endsley, and L. Huang, "Design considerations for liposomal vaccines: influence of formulation parameters on antibody and cell-mediated immune responses to liposome associated antigens," Vaccine, vol. 30, pp. 22562272, 2012.

[227] Z. Zhong, X. Wei, B. Qi et al., "A novel liposomal vaccine improves humoral immunity and prevents tumor pulmonary metastasis in mice," International Journal of Pharmaceutics, vol. 399, no. 1-2, pp. 156-162, 2010.
[228] X. Tang, C. Mo, Y. Wang, D. Wei, and H. Xiao, "Antitumour strategies aiming to target Tumour-associated Macrophages2012," Immunology, vol. 138, no. 2, pp. 93-104.

[229] N. Van Rooijen, N. Kors, M. V. D. Ende, and C. D. Dijkstra, "Depletion and repopulation of macrophages in spleen and liver of rat after intravenous treatment with liposome-encapsulated dichloromethylene diphosphonate," Cell and Tissue Research, vol. 260, no. 2, pp. 215-222, 1990.

[230] T. Takahashi, M. Ibata, Z. Yu et al., "Rejection of intradermally injected syngeneic tumor cells from mice by specific elimination of tumor-associated macrophages with liposome-encapsulated dichloromethylene diphosphonate, followed by induction of CD11b(+)/CCR3(-)/Gr-1(-) cells cytotoxic against the tumor cells," Cancer Immunology and Immunotherapy, vol. 58, no. 12, pp. 2011-2023, 2009.

[231] Y. Zhang, Y. Huang, P. Zhang, X. Gao, R. B. Gibbs, and S. Li, "Incorporation of a selective sigma-2 receptor ligand enhances uptake of liposomes by multiple cancer cells," International Journal of Nanomedicine, vol. 7, pp. 4473-4485, 2012.

[232] R. Nallamothu, G. C. Wood, M. F. Kiani, B. M. Moore, F. P. Horton, and L. A. Thoma, "A targeted liposome delivery system for combretastatin A4: formulation optimization through drug loading and in vitro release studies," PDA Journal of Pharmaceutical Science and Technology, vol. 60, no. 3, pp. 144-155, 2006.

[233] J. M. Saul, A. Annapragada, J. V. Natarajan, and R. V. Bellamkonda, "Controlled targeting of liposomal doxorubicin via the folate receptor in vitro," Journal of Controlled Release, vol. 92, no. 1-2, pp. 49-67, 2003.

[234] M. Dunne, J. Zheng, J. Rosenblat, D. A. Jaffray, and C. Allen, "APN/CD13-targeting as a strategy to alter the tumor accumulation of liposomes," Journal of Controlled Release, vol. 154, pp. 298-305, 2011.

[235] T. Aas, A. L. Børresen, S. Geisler et al., "Specific P53 mutations are associated with de novo resistance to doxorubicin in breast cancer patients," Nature Medicine, vol. 2, no. 7, pp. 811-814, 1996.

[236] A. Persidis, "Cancer multidrug resistance," Nature Biotechnology, vol. 17, no. 1, pp. 94-95, 1999.

[237] G. Cavaletti, G. Bogliun, L. Marzorati et al., "Peripheral neurotoxicity of taxol in patients previously treated with cisplatin," Cancer, vol. 75, pp. 1141-1150, 1995.

[238] P. Parhi, C. Mohanty, and S. K. Sahoo, "Nanotechnology-based combinational drug delivery: an emerging approach for cancer therapy," Drug Discovery Today, vol. 17, pp. 1044-1052, 2012.

[239] S. Wu and R. K. Singh, "Resistance to chemotherapy and molecularly targeted therapies: rationale for combination therapy in malignant melanoma," Current Molecular Medicine, vol. 11, pp. 553-563, 2011.

[240] Y. Chen, X. Zhu, X. Zhang, B. Liu, and L. Huang, "Nanoparticles modified with tumor-targeting scFv deliver siRNA and miRNA for cancer therapy," Molecular Therapy, vol. 18, no. 9, pp. 16501656, 2010.

[241] J. Xia, H. Bi, Q. Yao, S. Qu, and Y. Zong, "Construction of human $\mathrm{ScFv}$ phage display library against ovarian tumor," Journal of Huazhong University of Science and Technology [Medical Sciences], vol. 26, pp. 497-499, 2006.

[242] N. Li, H. Fu, Y. Tie et al., "miR-34a inhibits migration and invasion by down-regulation of c-Met expression in human hepatocellular carcinoma cells," Cancer Letters, vol. 275, no. 1, pp. 44-53, 2009.

[243] F. De Nigris, M. L. Balestrieri, and C. Napoli, "Targeting c-Myc, Ras and IGF cascade to treat cancer and vascular disorders," Cell Cycle, vol. 5, no. 15, pp. 1621-1628, 2006. 
[244] M. J. Halaby and D. Q. Yang, "p53 translational control: a new facet of $\mathrm{p} 53$ regulation and its implication for tumorigenesis and cancer therapeutics," Gene, vol. 395, no. 1-2, pp. 1-7, 2007.

[245] A. Grothey, "Future directions in vascular endothelial growth factor-targeted therapy for metastatic colorectal cancer," Seminars in Oncology, vol. 33, no. 10, pp. S41-S49, 2006.

[246] S. H. Kang, H. J. Cho, G. Shim et al., "Cationic liposomal codelivery of small interfering RNA and a MEK inhibitor for enhanced anticancer efficacy," Pharmaceutical Research, vol. 28, pp. 3069-3078, 2011.

[247] G. Shim, S. E. Han, Y. H. Yu et al., “Trilysinoyl oleylamide-based cationic liposomes for systemic co-delivery of siRNA and an anticancer drug," Journal of Controlled Release, vol. 155, pp. 6066, 2011.

[248] W. Xiao, X. Chen, L. Yang, Y. Mao, Y. Wei, and L. Chen, "Codelivery of doxorubicin and plasmid by a novel FGFR-mediated cationic liposome," International Journal of Pharmaceutics, vol. 393, no. 1-2, pp. 119-126, 2010.

[249] D. Grossman, P. J. Kim, J. S. Schechner, and D. C. Altieri, "Inhibition of melanoma tumor growth in vivo by survivin targeting," Proceedings of the National Academy of Sciences of the United States of America, vol. 98, no. 2, pp. 635-640, 2001.

[250] M. Zhang, O. B. Garbuzenko, K. R. Reuhl, L. RodriguezRodriguez, and T. Minko, "Two-in-one: combined targeted chemo and gene therapy for tumor suppression and prevention of metastases," Nanomedicine, vol. 7, pp. 185-197, 2012.

[251] R. R. Sawant, O. S. Vaze, K. Rockwell, and V. P. Torchilin, "Palmitoyl ascorbate-modified liposomes as nanoparticle platform for ascorbate-mediated cytotoxicity and paclitaxel codelivery," European Journal of Pharmaceutics and Biopharmaceutics, vol. 75, no. 3, pp. 321-326, 2010.

[252] K. Unsal-Kacmaz, S. Ragunathan, E. Rosfjord et al., "The interaction of PKN3 with RhoC promotes malignant growth," Molecular Oncology, vol. 6, pp. 284-298, 2012.

[253] M. Aleku, P. Schulz, O. Keil et al., "Atu027, a liposomal small interfering RNA formulation targeting protein kinase N3, inhibits cancer progression," Cancer Research, vol. 68, no. 23, pp. 9788-9798, 2008.

[254] D. Strumberg, B. Schultheis, U. Traugott et al., "First-in-human phase I study of Atu027, a liposomal small interfering RNA formulation, targeting protein kinase N3 (PKN3) in patients with advanced solid tumors," Journal of Clinical Oncology, vol. 29, Abstract 3057, 2011, ASCO Annual Meeting 2011.

[255] W. Dai, W. Jin, J. Zhang et al., "Spatiotemporally controlled co-delivery of anti-vasculature agent and cytotoxic drug by octreotide-modified stealth liposomes," Pharmaceutical Research, vol. 29, pp. 2902-2911, 2012.

[256] J. Hu, L. J. Chen, L. Liu et al., "Liposomal honokiol, a potent antiangiogenesis agent, in combination with radiotherapy produces a synergistic antitumor efficacy without increasing toxicity," Experimental and Molecular Medicine, vol. 40, no. 6, pp. 617$628,2008$.

[257] P. E. Huber, M. Bischof, J. Jenne et al., "Trimodal cancer treatment: beneficial effects of combined antiangiogenesis, radiation, and chemotherapy," Cancer Research, vol. 65, no. 9, pp. 3643-3655, 2005.

[258] Y. Maitani, H. Saito, Y. Seishi et al., "A combination of liposomal sunitinib plus liposomal irinotecan and liposome co-loaded with two drugs enhanced antitumor activity in PC12-bearing mouse," Journal of Drug Targeting, vol. 20, no. 10, pp. 873-882, 2012.
[259] A. Sochanik, I. Mitrus, R. Smolarczyk et al., "Experimental anticancer therapy with vascular-disruptive peptide and liposomeentrapped chemotherapeutic agent," Archivum Immunologiae et Therapiae Experimentalis, vol. 58, no. 3, pp. 235-245, 2010.

[260] Y. F. Zhang, J. C. Wang, D. Y. Bian, X. Zhang, and Q. Zhang, "Targeted delivery of RGD-modified liposomes encapsulating both combretastatin A-4 and doxorubicin for tumor therapy: in vitro and in vivo studies," European Journal of Pharmaceutics and Biopharmaceutics, vol. 74, no. 3, pp. 467-473, 2010.

[261] D. Zucker, A. V. Andriyanov, A. Steiner, U. Raviv, and Y. Barenholz, "Characterization of PEGylated nanoliposomes coremotely loaded with topotecan and vincristine: relating structure and pharmacokinetics to therapeutic efficacy," Journal of Controlled Release, vol. 160, pp. 281-289, 2012.

[262] M. Y. Wong and G. N. Chiu, "Liposome formulation of coencapsulated vincristine and quercetin enhanced antitumor activity in a trastuzumab-insensitive breast tumor xenograft model," Nanomedicine, vol. 7, pp. 834-840, 2011.

[263] E. J. Feldman, J. E. Kolitz, J. M. Trang et al., "Pharmacokinetics of CPX-351, a nano-scale liposomal fixed molar ratio formulation of cytarabine: daunorubicin, in patients with advanced leukemia," Leukemia Research, vol. 36, pp. 1283-1289, 2012.

[264] W. S. Lim, P. G. Tardi, N. Dos Santos et al., "Leukemiaselective uptake and cytotoxicity of CPX-351, a synergistic fixedratio cytarabine: daunorubicin formulation, in bone marrow xenografts," Leukemia Research, vol. 34, no. 9, pp. 1214-1223, 2010.

[265] K. Riviere, H. M. Kieler-Ferguson, K. Jerger, and F. C. Szoka, "Anti-tumor activity of liposome encapsulated fluoroorotic acid as a single agent and in combination with liposome irinotecan," Journal of Controlled Release, vol. 153, no. 3, pp. 288-296, 2011.

[266] P. Tardi, S. Johnstone, N. Harasym et al., "In vivo maintenance of synergistic cytarabine:daunorubicin ratios greatly enhances therapeutic efficacy," Leukemia Research, vol. 33, no. 1, pp. 129139, 2009.

[267] Y. T. Ko, C. Falcao, and V. P. Torchilin, "Cationic liposomes loaded with proapoptotic peptide D-(KLAKLAK)2 and Bcl-2 antisense oligodeoxynucleotide G3139 for enhanced anticancer therapy," Molecular Pharmaceutics, vol. 6, no. 3, pp. 971-977, 2009.

[268] G. C. Bolfarini, M. P. Siqueira-Moura, G. J. Demets, P. C. Morais, and A. C. Tedesco, "In vitro evaluation of combined hyperthermia and photodynamic effects using magnetoliposomes loaded with cucurbituril zinc phthalocyanine complex on melanoma," Journal of Photochemistry and Photobiology B, vol. 115, pp. 1-4, 2012.

[269] E. P. Botosoa, M. Maillasson, M. Mougin-Degraef et al., "Antibody-hapten recognition at the surface of functionalized liposomes studied by SPR: steric hindrance of pegylated phospholipids in stealth liposomes prepared for targeted radionuclide delivery," Journal of Drug Delivery, vol. 2011, Article ID 368535, 9 pages, 2011.

[270] V. P. Torchilin, A. L. Klibanov, L. Huang, S. O’Donnell, N. D. Nossiff, and B. A. Khaw, "Targeted accumulation of polyethylene glycol-coated immunoliposomes in infarcted rabbit myocardium," FASEB Journal, vol. 6, no. 9, pp. 2716-2719, 1992.

[271] M. Keller, R. P. Harbottle, E. Perouzel et al., "Nuclear localisation sequence templated nonviral gene delivery vectors: Investigation of intracellular trafficking events of $L M D$ and $L D$ vector systems," ChemBioChem, vol. 4, no. 4, pp. 286-298, 2003. 
[272] G. Pasut and F. M. Veronese, "State of the art in PEGylation: the great versatility achieved after forty years of research," Journal of Controlled Release, vol. 161, pp. 461-472, 2012.

[273] M. J. Roberts, M. D. Bentley, and J. M. Harris, "Chemistry for peptide and protein PEGylation," Advanced Drug Delivery Reviews, vol. 54, no. 4, pp. 459-476, 2002.

[274] L. Zhu and V. P. Torchilin, "Stimulus-responsive nanopreparations for tumor targeting," Integrative Biology, vol. 5, pp. 96-107, 2013.

[275] R. van Sluis, Z. M. Bhujwalla, N. Raghunand et al., "In vivo imaging of extracellular $\mathrm{pH}$ using $1 \mathrm{H}$ MRSI," Magnetic Resonance in Medicine, vol. 41, pp. 743-750, 1999.

[276] I. F. Tannock and D. Rotin, "Acid pH in tumors and its potential for therpeutic exploitation," Cancer Research, vol. 49, no. 16, pp. 4373-4384, 1989.

[277] D. C. Drummond, M. Zignani, and J. C. Leroux, "Current status of pH-sensitive liposomes in drug delivery," Progress in Lipid Research, vol. 39, no. 5, pp. 409-460, 2000.

[278] D. D. Castelli, W. Dastrù, E. Terreno et al., "In vivo MRI multicontrast kinetic analysis of the uptake and intracellular trafficking of paramagnetically labeled liposomes," Journal of Controlled Release, vol. 144, no. 3, pp. 271-279, 2010.

[279] E. Ducat, J. Deprez, A. Gillet et al., "Nuclear delivery of a therapeutic peptide by long circulating $\mathrm{pH}$-sensitive liposomes: benefits over classical vesicles," International Journal of Pharmaceutics, vol. 420, pp. 319-332, 2011.

[280] S. Xiong, B. Yu, J. Wu, H. Li, and R. J. Lee, "Preparation, therapeutic efficacy and intratumoral localization of targeted daunorubicin liposomes conjugating folate-PEGCHEMS," Biomedicine and Pharmacotherapy, vol. 65, no. 1, pp. 2-8, 2011.

[281] I. Y. Kim, Y. S. Kang, D. S. Lee et al., "Antitumor activity of EGFR targeted $\mathrm{pH}$-sensitive immunoliposomes encapsulating gemcitabine in A549 xenograft nude mice," Journal of Controlled Release, vol. 140, no. 1, pp. 55-60, 2009.

[282] E. A. Leite, C. M. Souza, A. D. Carvalho-Junior et al., "Encapsulation of cisplatin in long-circulating and $\mathrm{pH}$-sensitive liposomes improves its antitumor effect and reduces acute toxicity," International Journal of Nanomedicine, vol. 7, pp. 5259-5269, 2012.

[283] Y. Obata, S. Tajima, and S. Takeoka, "Evaluation of $\mathrm{pH}-$ responsive liposomes containing amino acid-based zwitterionic lipids for improving intracellular drug delivery in vitro and in vivo," Journal of Controlled Release, vol. 142, no. 2, pp. 267-276, 2010.

[284] S. Biswas, N. S. Dodwadkar, R. R. Sawant, and V. P. Torchilin, "Development of the novel PEG-PE-based polymer for the reversible attachment of specific ligands to liposomes: synthesis and in vitro characterization," Bioconjugate Chemistry, vol. 22, pp. 2005-2013, 2011.

[285] D. Pornpattananangkul, S. Olson, S. Aryal et al., "Stimuliresponsive liposome fusion mediated by gold nanoparticles," ACS Nano, vol. 4, no. 4, pp. 1935-1942, 2010.

[286] H. K. Kim, J. Van den Bossche, S. H. Hyun, and D. H. Thompson, "Acid-triggered release via dePEGylation of fusogenic liposomes mediated by heterobifunctional phenyl-substituted vinyl ethers with tunable $\mathrm{pH}$-sensitivity," Bioconjugate Chemistry, vol. 23, pp. 2071-2077, 2012.

[287] A. Bandekar, S. Karve, M. Y. Chang, Q. Mu, J. Rotolo, and S. Sofou, "Antitumor efficacy following the intracellular and interstitial release of liposomal doxorubicin," Biomaterials, vol. 33, pp. 4345-4352, 2012.
[288] S. Karve, G. B. Kempegowda, and S. Sofou, "Heterogeneous domains and membrane permeability in phosphatidylcholinephosphatidic acid rigid vesicles as a function of $\mathrm{pH}$ and lipid chain mismatch," Langmuir, vol. 24, no. 11, pp. 5679-5688, 2008.

[289] A. Carruthers and D. L. Melchior, "Studies of the relationship between bilayer water permeability and bilayer physical state," Biochemistry, vol. 22, no. 25, pp. 5797-5807, 1983.

[290] G. B. Kempegowda, S. Karve, A. Bandekar, A. Adhikari, T. Khaimchayev, and S. Sofou, "pH-Dependent formation of lipid heterogeneities controls surface topography and binding reactivity in functionalized bilayers," Langmuir, vol. 25, no. 14, pp. 8144-8151, 2009.

[291] A. Bandekar, C. Zhu, A. Gomez, M. Z. Menzenski, M. Sempkowski, and S. Sofou, "Masking and triggered unmasking of targeting ligands on liposomal chemotherapy selectively suppress tumor growth in vivo," Molecular Pharmaceutics, vol. 10, no. 1, pp. 152-160.

[292] H. Hatakeyama, H. Akita, and H. Harashima, "A multifunctional envelope type nano device (MEND) for gene delivery to tumours based on the EPR effect: a strategy for overcoming the PEG dilemma," Advanced Drug Delivery Reviews, vol. 63, no. 3, pp. 152-160, 2011.

[293] H. Hatakeyama, H. Akita, K. Kogure et al., "Development of a novel systemic gene delivery system for cancer therapy with a tumor-specific cleavable PEG-lipid," Gene Therapy, vol. 14, no. 1, pp. 68-77, 2007.

[294] L. Zhu, P. Kate, and V. P. Torchilin, "Matrix metalloprotease 2responsive multifunctional liposomal nanocarrier for enhanced tumor targeting," ACS Nano, vol. 6, pp. 3491-3498, 2012.

[295] N. Ballatori, S. M. Krance, S. Notenboom, S. Shi, K. Tieu, and C. L. Hammond, "Glutathione dysregulation and the etiology and progression of human diseases," Biological Chemistry, vol. 390, no. 3, pp. 191-214, 2009.

[296] F. Meng, W. E. Hennink, and Z. Zhong, "Reduction-sensitive polymers and bioconjugates for biomedical applications," Biomaterials, vol. 30, no. 12, pp. 2180-2198, 2009.

[297] B. Goldenbogen, N. Brodersen, A. Gramatica et al., "Reductionsensitive liposomes from a multifunctional lipid conjugate and natural phospholipids: reduction and release kinetics and cellular uptake," Langmuir, vol. 27, pp. 10820-10829, 2011.

[298] R. Kuai, W. Yuan, Y. Qin et al., "Efficient delivery of payload into tumor cells in a controlled manner by TAT and thiolytic cleavable PEG Co-modified liposomes," Molecular Pharmaceutics, vol. 7, no. 5, pp. 1816-1826, 2010.

[299] G. Candiani, D. Pezzoli, L. Ciani, R. Chiesa, and S. Ristori, "Bioreducible liposomes for gene delivery: from the formulation to the mechanism of action," PLoS ONE, vol. 5, no. 10, article e13430, 2010.

[300] S. Fulda, L. Galluzzi, and G. Kroemer, "Targeting mitochondria for cancer therapy," Nature Reviews Drug Discovery, vol. 9, no. 6, pp. 447-464, 2010.

[301] J. Damen, J. Regts, and G. Scherphof, “Transfer and exchange of phospholipid between small unilamellar liposomes and rat plasma high density lipoproteins. Dependence on cholesterol content and phospholipid composition," Biochimica et Biophysica Acta, vol. 665, no. 3, pp. 538-545, 1981.

[302] F. Tokumasu, A. J. Jin, and J. A. Dvorak, "Lipid membrane phase behaviour elucidated in real time by controlled environment atomic force microscopy," Journal of Electron Microscopy, vol. 51, no. 1, pp. 1-9, 2002.

[303] M. P. Veiga, J. L. R. Arrondo, F. M. Goñi, A. Alonso, and D. Marsh, "Interaction of cholesterol with sphingomyelin in mixed 
membranes containing phosphatidylcholine, studied by spinlabel ESR and IR spectroscopies. A possible stabilization of gelphase sphingolipid domains by cholesterol," Biochemistry, vol. 40, no. 8, pp. 2614-2622, 2001.

[304] J. A. Zhang, G. Anyarambhatla, L. Ma et al., "Development and characterization of a novel Cremophor EL free liposomebased paclitaxel (LEP-ETU) formulation," European Journal of Pharmaceutics and Biopharmaceutics, vol. 59, no. 1, pp. 177-187, 2005.

[305] K. Kusumoto, H. Akita, A. El-Sayed, and H. Harashima, "Effect of the anchor in polyethylene glycol-lipids on the transfection activity of PEGylated cationic liposomes encapsulating DNA," Biological \& Pharmaceutical Bulletin, vol. 35, pp. 445-448, 2012.

[306] M. B. Hansen, E. van Gaal, I. Minten, G. Storm, J. C. van Hest, and D. W. Lowik, "Constrained and UV-activatable cellpenetrating peptides for intracellular delivery of liposomes," Journal of Controlled Release, vol. 164, no. 1, pp. 87-94, 2012.

[307] R. S. Chang, J. Kim, H. Y. Lee et al., "Reduced dose-limiting toxicity of intraperitoneal mitoxantrone chemotherapy using cardiolipin-based anionic liposomes," Nanomedicine, vol. 6, no. 6, pp. 769-776, 2010.

[308] D. C. Drummond, O. Meyer, K. Hong, D. B. Kirpotin, and D. Papahadjopoulos, "Optimizing liposomes for delivery of chemotherapeutic agents to solid tumors," Pharmacological Reviews, vol. 51, no. 4, pp. 691-743, 1999.

[309] M. L. Hauck, S. M. La Rue, W. P. Petros et al., "Phase I trial of doxorubicin-containing low temperature sensitive liposomes in spontaneous canine tumors," Clinical Cancer Research, vol. 12, no. 13, pp. 4004-4010, 2006.

[310] K. J. Harrington, C. R. Lewanski, A. D. Northcote et al., "Phase III study of pegylated liposomal cisplatin (SPI-077Ü) in patients with inoperable head and neck cancer," Annals of Oncology, vol. 12, no. 4, pp. 493-496, 2001.

[311] W. C. Zamboni, A. C. Gervais, M. J. Egorin et al., "Systemic and tumor disposition of platinum after administration of cisplatin or STEALTH liposomal-cisplatin formulations (SPI-077 and SPI-077 B103) in a preclinical tumor model of melanoma," Cancer Chemotherapy and Pharmacology, vol. 53, no. 4, pp. 329336, 2004.

[312] T. Asai, S. Matsushita, E. Kenjo et al., "Dicetyl phosphatetetraethylenepentamine-based liposomes for systemic siRNA delivery," Bioconjugate Chemistry, vol. 22, no. 3, pp. 429-435, 2011.

[313] N. Yonenaga, E. Kenjo, T. Asai et al., "RGD-based active targeting of novel polycation liposomes bearing siRNA for cancer treatment," Journal of Controlled Release, vol. 160, pp. 177-181, 2012.

[314] I. Nakase, H. Akita, K. Kogure et al., "Efficient intracellular delivery of nucleic acid pharmaceuticals using cell-penetrating peptides," Accounts of Chemical Research, vol. 45, pp. 1132-1139, 2012.

[315] S. Futaki, W. Ohashi, T. Suzuki et al., "Stearylated argininerich peptides: a new class of transfection systems," Bioconjugate Chemistry, vol. 12, no. 6, pp. 1005-1011, 2001.

[316] E. Koren and V. P. Torchilin, "Cell-penetrating peptides: breaking through to the other side," Trends in Molecular Medicine, vol. 18, pp. 385-393, 2012.

[317] E. Vivès, J. Schmidt, and A. Pèlegrin, "Cell-penetrating and celltargeting peptides in drug delivery," Biochimica et Biophysica Acta, vol. 1786, no. 2, pp. 126-138, 2008.

[318] A. A. Kale and V. P. Torchilin, "Enhanced transfection of tumor cells in vivo using "Smart" $\mathrm{pH}$-sensitive TAT-modified pegylated liposomes," Journal of Drug Targeting, vol. 15, no. 7-8, pp. 538-545, 2007.

[319] R. Kuai, W. Yuan, W. Li et al., “Targeted delivery of cargoes into a murine solid tumor by a cell-penetrating peptide and cleavable poly(ethylene glycol) comodified liposomal delivery system via systemic administration," Molecular Pharmacology, vol. 8, pp. 2151-2161, 2011.

[320] G. Kibria, H. Hatakeyama, and H. Harashima, "A new peptide motif present in the protective antigen of anthrax toxin exerts its efficiency on the cellular uptake of liposomes and applications for a dual-ligand system," International Journal of Pharmaceutics, vol. 412, no. 1-2, pp. 106-114, 2011.

[321] A. Koshkaryev, A. Piroyan, and V. P. Torchilin, "Bleomycin in octaarginine-modified fusogenic liposomes results in improved tumor growth inhibition," Cancer Letters, 2012.

[322] S. E. Barker, S. M. Grosse, E. K. Siapati et al., "Immunotherapy for neuroblastoma using syngeneic fibroblasts transfected with IL-2 and IL-12," British Journal of Cancer, vol. 97, no. 2, pp. 210217, 2007.

[323] A. D. Tagalakis, S. M. Grosse, Q. H. Meng et al., "Integrintargeted nanocomplexes for tumour specific delivery and therapy by systemic administration," Biomaterials, vol. 32 , no. 5, pp. 1370-1376, 2011.

[324] S. M. Grosse, A. D. Tagalakis, M. F. M. Mustapa et al., "tumorspecific gene transfer with receptor-mediated nanocomplexes modified by polyethylene glycol shielding and endosomally cleavable lipid and peptide linkers," FASEB Journal, vol. 24, no. 7, pp. 2301-2313, 2010.

[325] Y. Qin, H. Chen, Q. Zhang et al., "Liposome formulated with TAT-modified cholesterol for improving brain delivery and therapeutic efficacy on brain glioma in animals," International Journal of Pharmaceutics, vol. 420, pp. 304-312, 2011.

[326] N. Demaurex, "pH homeostasis of cellular organelles," News in Physiological Sciences, vol. 17, no. 1, pp. 1-5, 2002.

[327] S. Mishra, P. Webster, and M. E. Davis, "PEGylation significantly affects cellular uptake and intracellular trafficking of non-viral gene delivery particles," European Journal of Cell Biology, vol. 83, no. 3, pp. 97-111, 2004.

[328] K. Remaut, B. Lucas, K. Braeckmans, J. Demeester, and S. C. De Smedt, "Pegylation of liposomes favours the endosomal degradation of the delivered phosphodiester oligonucleotides," Journal of Controlled Release, vol. 117, no. 2, pp. 256-266, 2007.

[329] A. Makovitzki, A. Fink, and Y. Shai, "Suppression of human solid tumor growth in mice by intratumor and systemic inoculation of histidine-rich and $\mathrm{pH}$-dependent host defense-like lytic peptides," Cancer Research, vol. 69, no. 8, pp. 3458-3463, 2009.

[330] P. Midoux, C. Pichon, J. J. Yaouanc, and P. A. Jaffrès, "Chemical vectors for gene delivery: a current review on polymers, peptides and lipids containing histidine or imidazole as nucleic acids carriers," British Journal of Pharmacology, vol. 157, no. 2, pp. 166-178, 2009.

[331] N. D. Sonawane, F. C. Szoka, and A. S. Verkman, "Chloride accumulation and swelling in endosomes enhances DNA transfer by polyamine-DNA polyplexes," Journal of Biological Chemistry, vol. 278, no. 45, pp. 44826-44831, 2003.

[332] M. Thomas and A. M. Klibanov, "Enhancing polyethylenimine's delivery of plasmid DNA into mammalian cells," Proceedings of the National Academy of Sciences of the United States of America, vol. 99, no. 23, pp. 14640-14645, 2002. 
[333] Y. Xu and F. C. Szoka Jr., "Mechanism of DNA release from cationic liposome/DNA complexes used in cell transfection," Biochemistry, vol. 35, no. 18, pp. 5616-5623, 1996.

[334] J. P. Behr, "Synthetic gene transfer vectors II: back to the future," Journal of Drug Targeting, vol. 45, pp. 980-984, 2012.

[335] W. Zhang, J. Song, B. Zhang, L. Liu, K. Wang, and R. Wang, "Design of acid-activated cell penetrating peptide for delivery of active molecules into cancer cells," Bioconjugate Chemistry, vol. 22, no. 7, pp. 1410-1415, 2011.

[336] T. Jiang, Z. Zhang, Y. Zhang et al., "Dual-functional liposomes based on $\mathrm{pH}$-responsive cell-penetrating peptide and hyaluronic acid for tumor-targeted anticancer drug delivery," Biomaterials, vol. 33, no. 36, pp. 9246-9258, 2012.

[337] V. V. Kumar, C. Pichon, M. Refregiers, B. Guerin, P. Midoux, and A. Chaudhuri, "Single histidine residue in head-group region is sufficient to impart remarkable gene transfection properties to cationic lipids: evidence for histidine-mediated membrane fusion at acidic pH," Gene Therapy, vol. 10, no. 15, pp. 1206-1215, 2003.

[338] A. K. Varkouhi, M. Scholte, G. Storm, and H. J. Haisma, "Endosomal escape pathways for delivery of biologicals," Journal of Controlled Release, vol. 151, no. 3, pp. 220-228, 2011.

[339] V. P. Torchilin, T. S. Levchenko, R. Rammohan, N. Volodina, B. Papahadjopoulos-Sternberg, and G. G. M. D’Souza, "Cell transfection in vitro and in vivo with nontoxic TAT peptide-liposome-DNA complexes," Proceedings of the National Academy of Sciences of the United States of America, vol. 100, no. 4, pp. 1972-1977, 2003.

[340] X. Zhang, L. Collins, and J. W. Fabre, "A powerful cooperative interaction between a fusogenic peptide and lipofectamine for the enhancement of receptor-targeted, non-viral gene delivery via integrin receptors," Journal of Gene Medicine, vol. 3, no. 6, pp. 560-568, 2001.

[341] K. Sasaki, K. Kogure, S. Chaki et al., "An artificial virus-like nano carrier system: enhanced endosomal escape of nanoparticles via synergistic action of $\mathrm{pH}$-sensitive fusogenic peptide derivatives," Analytical and Bioanalytical Chemistry, vol. 391, no. 8, pp. 2717-2727, 2008.

[342] M. Kullberg, K. Mann, and T. J. Anchordoquy, “Targeting Her$2+$ breast cancer cells with bleomycin immunoliposomes linked to LLO," Molecular Pharmaceutics, vol. 9, no. 7, pp. 2000-2008, 2012.

[343] I. R. Indran, G. Tufo, S. Pervaiz, and C. Brenner, "Recent advances in apoptosis, mitochondria and drug resistance in cancer cells," Biochimica et Biophysica Acta, vol. 1807, no. 6, pp. 735-745, 2011.

[344] J. Lankelma, H. Dekker, R. F. Luque et al., "Doxorubicin gradients in human breast cancer," Clinical Cancer Research, vol. 5, no. 7, pp. 1703-1707, 1999.

[345] I. F. Tannock, C. M. Lee, J. K. Tunggal, D. S. M. Cowan, and M. J. Egorin, "Limited penetration of anticancer drugs through tumor tissue: a potential cause of resistance of solid tumors to chemotherapy," Clinical Cancer Research, vol. 8, no. 3, pp. 878884, 2002.

[346] Y. Yamada and H. Harashima, "Mitochondrial drug delivery systems for macromolecule and their therapeutic application to mitochondrial diseases," Advanced Drug Delivery Reviews, vol. 60, no. 13-14, pp. 1439-1462, 2008.

[347] Y. Men, X. X. Wang, R. J. Li et al., "The efficacy of mitochondrial targeting antiresistant epirubicin liposomes in treating resistant leukemia in animals," International Journal of Nanomedicine, vol. 6, pp. 3125-3137, 2011.
[348] T. Nakamura, H. Akita, Y. Yamada, H. Hatakeyama, and H. Harashima, "A multifunctional envelope-type nanodevice for use in nanomedicine: concept and applications," Accounts of Chemical Research, vol. 45, pp. 1113-1121, 2012.

[349] R. Mo, Q. Sun, J. Xue et al., "Multistage pH-responsive liposomes for mitochondrial-targeted anticancer drug delivery," Advanced Materials, vol. 24, pp. 3659-3665, 2012.

[350] M. J. Weiss, J. R. Wong, and C. S. Ha, "Dequalinium, a topical antimicrobial agent, displays anticarcinoma activity based on selective mitochondrial accumulation," Proceedings of the National Academy of Sciences of the United States of America, vol. 84, no. 15, pp. 5444-5448, 1987.

[351] S. Biswas, N. S. Dodwadkar, R. R. Sawant, A. Koshkaryev, and V. P. Torchilin, "Surface modification of liposomes with rhodamine-123-conjugated polymer results in enhanced mitochondrial targeting," Journal of Drug Targeting, vol. 19, no. 7, pp. 552-561, 2011.

[352] C. Ferlini, L. Cicchillitti, G. Raspaglio et al., "Paclitaxel directly binds to Bcl-2 and functionally mimics activity of Nur77," Cancer Research, vol. 69, no. 17, pp. 6906-6914, 2009.

[353] S. Biswas, N. S. Dodwadkar, P. P. Deshpande, and V. P. Torchilin, "Liposomes loaded with paclitaxel and modified with novel triphenylphosphonium-PEG-PE conjugate possess low toxicitytarget mitochondria and demonstrate enhanced antitumor effects in vitro and in vivo," Journal of Controlled Release, vol. 159, pp. 393-402, 2012.

[354] S. S. Malhi, A. Budhiraja, S. Arora et al., "Intracellular delivery of redox cycler-doxorubicin to the mitochondria of cancer cell by folate receptor targeted mitocancerotropic liposomes," International Journal of Pharmaceutics, vol. 432, pp. 63-74, 2012.

[355] A. Schroeder, J. Kost, and Y. Barenholz, "Ultrasound, liposomes, and drug delivery: principles for using ultrasound to control the release of drugs from liposomes," Chemistry and Physics of Lipids, vol. 162, no. 1-2, pp. 1-16, 2009.

[356] A. Schroeder, R. Honen, K. Turjeman, A. Gabizon, J. Kost, and Y. Barenholz, "Ultrasound triggered release of cisplatin from liposomes in murine tumors," Journal of Controlled Release, vol. 137, no. 1, pp. 63-68, 2009.

[357] T. J. Evjen, E. A. Nilssen, S. Rognvaldsson, M. Brandl, and S. L. Fossheim, "Distearoylphosphatidylethanolamine-based liposomes for ultrasound-mediated drug delivery," European Journal of Pharmaceutics and Biopharmaceutics, vol. 75, pp. 327333, 2010.

[358] P. Shum, J. M. Kim, and D. H. Thompson, "Phototriggering of liposomal drug delivery systems," Advanced Drug Delivery Reviews, vol. 53, no. 3, pp. 273-284, 2001.

[359] A. Yavlovich, A. Singh, R. Blumenthal, and A. Puri, "A novel class of photo-triggerable liposomes containing DPPC:DC $8,9 \mathrm{PC}$ as vehicles for delivery of doxorubcin to cells," Biochimica et Biophysica Acta, vol. 1808, no. 1, pp. 117-126, 2011.

[360] P. Agostinis, K. Berg, K. A. Cengel et al., "Photodynamic therapy of cancer: an update," CA: A Cancer Journal for Clinicians, vol. 61, pp. 250-281, 2011.

[361] B. C. Wilson and M. S. Patterson, "The physics, biophysics and technology of photodynamic therapy," Physics in Medicine and Biology, vol. 53, no. 9, pp. R61-R109, 2008.

[362] M. Triesscheijn, M. Ruevekamp, R. Out et al., "The pharmacokinetic behavior of the photosensitizer mesotetra-hydroxyphenyl-chlorin in mice and men," Cancer Chemotherapy and Pharmacology, vol. 60, no. 1, pp. 113-122, 2007. 
[363] M. J. Bovis, J. H. Woodhams, M. Loizidou, D. Scheglmann, S. G. Bown, and A. J. Macrobert, "Improved in vivo delivery of $\mathrm{m}$-THPC via pegylated liposomes for use in photodynamic therapy," Journal of Controlled Release, vol. 157, pp. 196-205, 2012.

[364] M. García-Díaz, S. Nonell, A. Villanueva et al., "Do folatereceptor targeted liposomal photosensitizers enhance photodynamic therapy selectivity?" Biochimica et Biophysica Acta, vol. 1808, no. 4, pp. 1063-1071, 2011.

[365] H. P. Lassalle, D. Dumas, S. Gräfe, M. A. D’Hallewin, F. Guillemin, and L. Bezdetnaya, "Correlation between in vivo pharmacokinetics, intratumoral distribution and photodynamic efficiency of liposomal mTHPC," Journal of Controlled Release, vol. 134, no. 2, pp. 118-124, 2009.

[366] J. N. Weinstein, R. L. Magin, M. B. Yatrin, and D. S. Zaharko, "Liposomes and local hyperthermia: selective delivery of methotrexate to heated tumors," Science, vol. 204, no. 4389, pp. 188-191, 1979.

[367] K. Kono, T. Ozawa, T. Yoshida et al., "Highly temperaturesensitive liposomes based on a thermosensitive block copolymer for tumor-specific chemotherapy," Biomaterials, vol. 31, no. 27, pp. 7096-7105, 2010.

[368] Y. Wu, Y. Yang, F. C. Zhang, C. Wu, W. L. Lu, and X. G. Mei, "Epirubicin-encapsulated long-circulating thermosensitive liposome improves pharmacokinetics and antitumor therapeutic efficacy in animals," Journal of Liposome Research, vol. 21, pp. 221-228, 2011.

[369] L. Paasonen, T. Sipila, A. Subrizi et al., "Gold-embedded photosensitive liposomes for drug delivery: triggering mechanism and intracellular release," Journal of Controlled Release, vol. 147, pp. 136-143, 2010.

[370] M. Latorre and C. Rinaldi, "Applications of magnetic nanoparticles in medicine: magnetic fluid hyperthermia," Puerto Rico Health Sciences Journal, vol. 28, no. 3, pp. 227-238, 2009.

[371] P. Pradhan, J. Giri, F. Rieken et al., "Targeted temperature sensitive magnetic liposomes for thermo-chemotherapy," Journal of Controlled Release, vol. 142, no. 1, pp. 108-121, 2010.

[372] T. Kikumori, T. Kobayashi, M. Sawaki, and T. Imai, "Anticancer effect of hyperthermia on breast cancer by magnetite nanoparticle-loaded anti-HER2 immunoliposomes," Breast Cancer Research and Treatment, vol. 113, no. 3, pp. 435-441, 2009.

[373] B. Smith, I. Lyakhov, K. Loomis et al., "Hyperthermia-triggered intracellular delivery of anticancer agent to HER2+ cells by HER2-specific affibody (ZHER2-GS-Cys)-conjugated thermosensitive liposomes (HER2+ affisomes)," Journal of Controlled Release, vol. 153, no. 2, pp. 187-194, 2011.

[374] J. W. Hopewell, G. M. Morris, A. Schwint, and J. A. Coderre, "The radiobiological principles of boron neutron capture therapy: a critical review," Applied Radiation and Isotopes, vol. 69, pp. 1756-1759, 2011.

[375] S. Miyata, S. Kawabata, R. Hiramatsu et al., "Computed tomography imaging of transferrin targeting liposomes encapsulating both boron and iodine contrast agents by convection-enhanced delivery to F98 rat glioma for boron neutron capture therapy," Neurosurgery, vol. 68, no. 5, pp. 1380-1387, 2011.

[376] A. Doi, S. Kawabata, K. Iida et al., "tumor-specific targeting of sodium borocaptate (BSH) to malignant glioma by transferrinPEG liposomes: a modality for boron neutron capture therapy," Journal of neuro-oncology, vol. 87, no. 3, pp. 287-294, 2008.

[377] J. H. Ryu, H. Koo, I. C. Sun et al., "tumor-targeting multifunctional nanoparticles for theragnosis: new paradigm for cancer therapy," Advanced Drug Delivery Reviews, vol. 64, no. 13, pp. 1447-1458, 2012.

[378] X. Ma, Y. Zhao, and X. J. Liang, "Theranostic nanoparticles engineered for clinic and pharmaceutics," Accounts of Chemical Research, vol. 44, pp. 1114-1122, 2011.

[379] R. Weissleder and M. J. Pittet, "Imaging in the era of molecular oncology," Nature, vol. 452, no. 7187, pp. 580-589, 2008.

[380] W. T. Al-Jamal and K. Kostarelos, "Liposomes: from a clinically established drug delivery system to a nanoparticle platform for theranostic nanomedicine," Accounts of Chemical Research, vol. 44, pp. 1094-1104, 2011.

[381] C. Heneweer, S. E. Gendy, and O. Penate-Medina, "Liposomes and inorganic nanoparticles for drug delivery and cancer imaging," Therapeutic Delivery, vol. 3, pp. 645-656, 2012.

[382] A. L. Petersen, A. E. Hansen, A. Gabizon, and T. L. Andresen, "Liposome imaging agents in personalized medicine," Advanced Drug Delivery Reviews, vol. 64, pp. 1417-1435, 2012.

[383] G. D. Kenny, N. Kamaly, T. L. Kalber et al., "Novel multifunctional nanoparticle mediates siRNA tumour delivery, visualisation and therapeutic tumour reduction in vivo," Journal of Controlled Release, vol. 149, no. 2, pp. 111-116, 2011.

[384] K. Kono, S. Nakashima, D. Kokuryo et al., "Multi-functional liposomes having temperature-triggered release and magnetic resonance imaging for tumor-specific chemotherapy," Biomaterials, vol. 32, no. 5, pp. 1387-1395, 2011.

[385] A. H. Negussie, P. S. Yarmolenko, A. Partanen et al., "Formulation and characterisation of magnetic resonance imageable thermally sensitive liposomes for use with magnetic resonanceguided high intensity focused ultrasound," International Journal of Hyperthermia, vol. 27, no. 2, pp. 140-155, 2011.

[386] A. Ranjan, G. C. Jacobs, D. L. Woods et al., "Image-guided drug delivery with magnetic resonance guided high intensity focused ultrasound and temperature sensitive liposomes in a rabbit $\mathrm{Vx} 2$ tumor model," Journal of Controlled Release, vol. 158, pp. 487494, 2012.

[387] E. Cittadino, M. Ferraretto, E. Torres et al., "MRI evaluation of the antitumor activity of paramagnetic liposomes loaded with prednisolone phosphate," European Journal of Pharmaceutical Sciences, vol. 45, pp. 436-441, 2012.

[388] S. Li, B. Goins, L. Zhang, and A. Bao, "Novel multifunctional theranostic liposome drug delivery system: construction, characterization, and multimodality MR, near-infrared fluorescent, and nuclear imaging," Bioconjugate Chemistry, vol. 23, no. 6, pp. 1322-1332, 2012.

[389] N. Mitchell, T. L. Kalber, M. S. Cooper et al., "Incorporation of paramagnetic, fluorescent and PET/SPECT contrast agents into liposomes for multimodal imaging," Biomaterials, vol. 34, no. 4, pp. 1179-1192, 2012.

[390] M. De Smet, E. Heijman, S. Langereis, N. M. Hijnen, and H. Grüll, "Magnetic resonance imaging of high intensity focused ultrasound mediated drug delivery from temperature-sensitive liposomes: an in vivo proof-of-concept study," Journal of Controlled Release, vol. 150, no. 1, pp. 102-110, 2011.

[391] M. Mikhaylova, I. Stasinopoulos, Y. Kato, D. Artemov, and Z. M. Bhujwalla, "Imaging of cationic multifunctional liposomemediated delivery of COX-2 siRNA," Cancer Gene Therapy, vol. 16, no. 3, pp. 217-226, 2009.

[392] C. Grange, S. Geninatti-Crich, G. Esposito et al., "Combined delivery and magnetic resonance imaging of neural cell adhesion molecule-targeted doxorubicin-containing liposomes in experimentally induced Kaposi's sarcoma," Cancer Research, vol. 70, no. 6, pp. 2180-2190, 2010. 
[393] L. Deng, X. Ke, Z. He et al., "A MSLN-targeted multifunctional nanoimmunoliposome for MRI and targeting therapy in pancreatic cancer," International Journal of Nanomedicine, vol. 7, pp. 5053-5065, 2012.

[394] J. H. Maeng, D. H. Lee, K. H. Jung et al., "Multifunctional doxorubicin loaded superparamagnetic iron oxide nanoparticles for chemotherapy and magnetic resonance imaging in liver cancer," Biomaterials, vol. 31, no. 18, pp. 4995-5006, 2010.

[395] N. A. Saunders, F. Simpson, E. W. Thompson et al., "Role of intratumoural heterogeneity in cancer drug resistance: molecular and clinical perspectives," EMBO Molecular Medicine, vol. 4, pp. 675-684, 2012.

[396] S. Bhatia, J. V. Frangioni, R. M. Hoffman, A. J. Iafrate, and K. Polyak, "The challenges posed by cancer heterogeneity," Nature Biotechnology, vol. 30, pp. 604-610, 2012. 

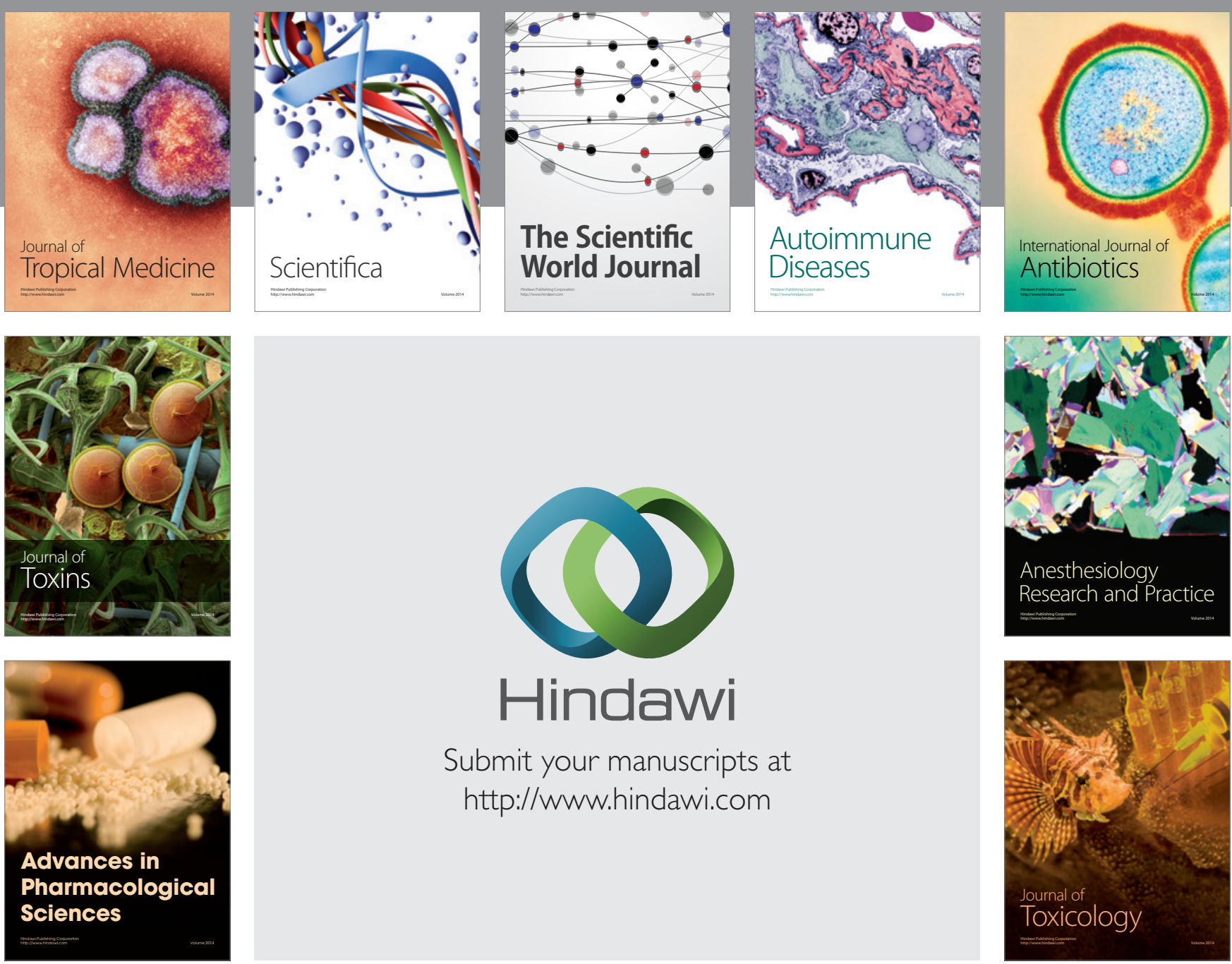

\section{Hindawi}

Submit your manuscripts at

http://www.hindawi.com
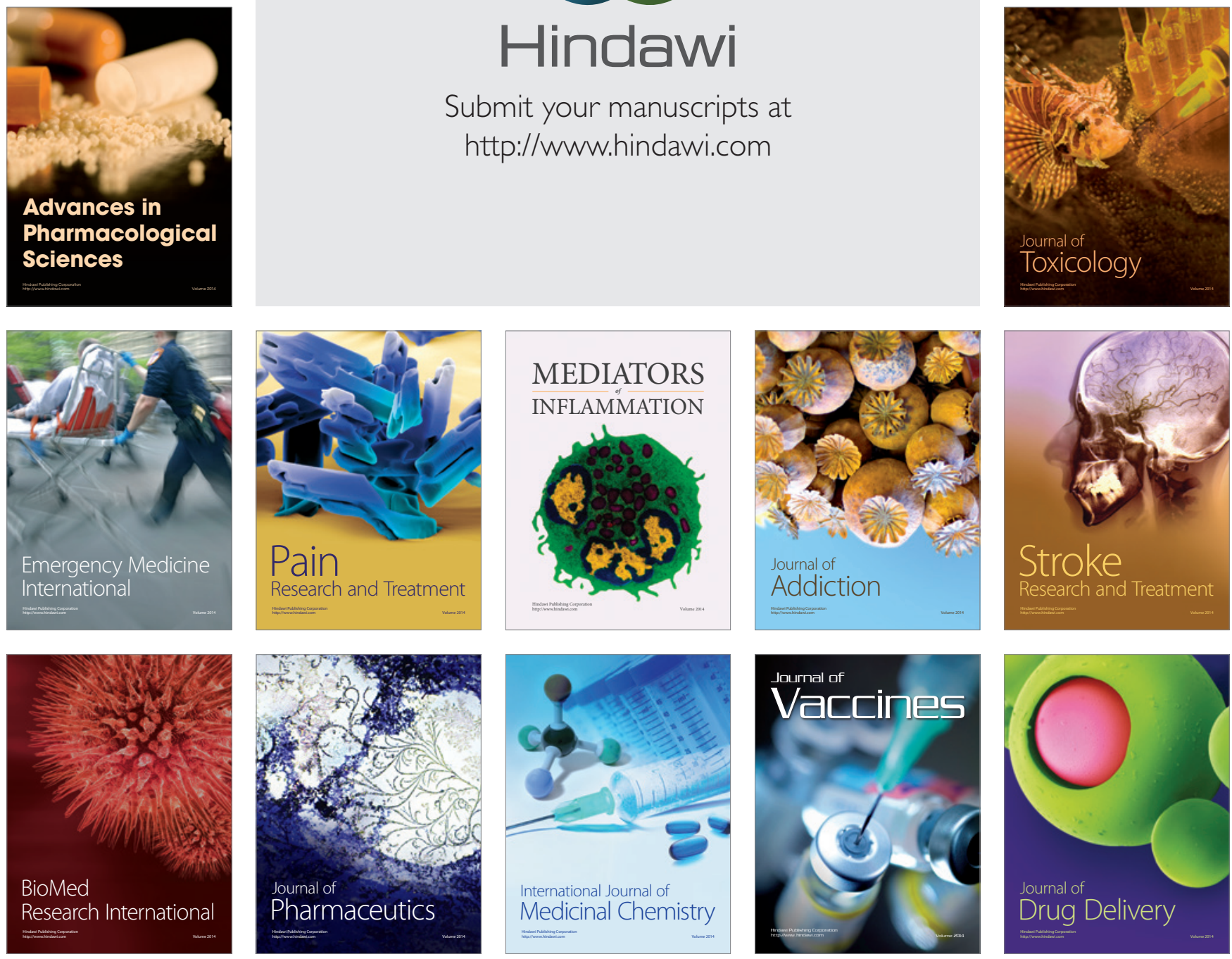